\title{
The Biology and Ecology of the Diamondback moth, Plutella xylostella (L.), in Eastern Ontario Revisited
}

by

\section{Tina Dancau}

A thesis submitted to the Faculty of Graduate and Postdoctoral Affairs in partial fulfillment of the requirements for the degree of

\section{MASTER OF SCIENCE}

in

Biology with Specialization in Bioinformatics

\section{CARLETON UNIVERSITY \\ Ottawa, Ontario, Canada}

(C) Copyright by Tina Dancau, 2018 
"When you become the image of your own imagination, it's the most powerful thing you could ever do."

$-R u P a u l$ 


\begin{abstract}
Diamondback moth, Plutella xylostella Linnaeus (Lepidoptera: Plutellidae) is a globally distributed pest on brassicaceous crops. This study aimed to follow up with aspects of earlier research, mainly to revisit the potential for overwintering of diamondback moth in the Ottawa area, to investigate present day population dynamics using a life-table approach and to use next generation sequencing to describe the diamondback moth microbiome. A review of the literature has reaffirmed that diamondback moth may not be capable of overwintering in Ottawa with populations likely migrant-driven. The population dynamics and parasitoid community appear to be unaltered after 65 years. The microbiome of diamondback moth larvae was dominated by Enterococcaceae, a family of bacteria hypothesized to aid in resistance and detoxification. These findings can provide opportunities for the introduction of new biological control agents and tools for diamondback moth management in the future.
\end{abstract}




\section{Acknowledgements}

First, I would like to honour my study species the diamondback moth; it was a privilege to work in this unique study system and to be a part of many generations of researchers that have investigated its biology. I had limitless material and much inspiration to do my research on, building upon the work from previous researchers and to make my small contribution to the diverse body of knowledge on this particular economically important species.

I would like to thank my supervisors Peter Mason and Naomi Cappuccino for their support and guidance in my projects, as well as funding that kept me out of living in a cardboard box. I would also like to thank Alex Wong, for not only agreeing to be on my committee, but lending his guidance, laboratory space and laboratory equipment for me to learn all about the world of molecular biology and bioinformatics. I thank Risa Sargent for being on my committee and for her inquisitive questions. I would also like to thank my honourary committee member Wen Chen for her tireless efforts and guidance of bioinformatics pipelines and software, and for taking me on as a participant of her lab in the biocluster for my analyses.

I would also like to thank Ana-Maria Farmakis for helping maintain the insect cultures and for being very accommodating if I came short. Andrea Brauner for helping with pheromone traps, HOBOs, photoshoots and lending an ear for my troubles. Jake Miall for stoking the fires of natural history and grounding my ecologically driven questions. Paul Abram for being special guest editor on my work and statistical support. Tim Haye for comments on the life table chapter and initial experimental design. Aleksandra Spasojevic for lending me the Tinytag data loggers for the overwintering experiment. Chris Schmidt for lending me his environmental chambers to produce many well timed life stages. Jessica Hsiung for providing fantastic illustrations. Ross 
Weiss for providing data outputs from the DYMEX bio-climatic and reverse wind trajectory models. I would also like to thank: Nadine Gaskell, Christine Cock, Noah Marion and Stephanie Coghlan for assistance in pheromone trap monitoring, setup and planting of my cabbage plot. Darren Blackburn for assisting in gathering data on moth fecundity. Connie Saunder for her guidance on germinating Brassica weeds and Tracey James for offering me her extra Brassica weeds from the greenhouse even though that project did not come to fruition. Leah Clarke for all her help in teaching me sequencing sample preparation and assisting me in the last leg of it. Huaying Zhang for troubleshooting my data and the bioinformatics pipelines.

I would like to thank the taxonomists at the Canadian National Collection of Insects, Arachnids and Nematodes: Andrew Bennett, José Fernández-Trinia, John Huber and Gary Gibson for identifying my parasitoids. I would also like to thank Henri Goulet and Adam Brunke for beetle identification and Wayne Knee for mite identification. I want to thank Jean-François Landry for letting me use his equipment and for his endless knowledge on diamondback moth and Plutella spp.

I want to thank my roommate and landlord Thomas for binge watching with me, feeding me too many treats and just being a great attentive landlord. My roommate Ruben for his positive energy and reminding me to appreciate the privileges we have here in Canada. I want to thank all the new friends that I have made in Ottawa for their support, stimulating conversation and diverse viewpoints.

I want to thank my parents for their unwavering support all the way from the other side of the country, even though they still don't really understand what my thesis is about. My dear sister Vicki for her support and her company when coincidence brought us together in Ottawa for a short time. Finally, I want to thank Darshan for being no further than a phone call or message away but unfortunately always several cities away. Even from such a distance his unconditional support, understanding and love has helped me through this thesis. 


\section{Table of contents}

Abstract $\quad$ iii

Acknowledgements $\quad$ iv

Table of contents $\quad$ vi

List of Tables $\quad$ ix

List of Figures $\quad$ xi

List of Appendices xiii

Glossary

1 General Introduction $\quad 4$

2 Elusively Overwintering: A review of diamondback moth (Lepidoptera: Plutellidae) cold tolerance and overwintering strategy $\quad 8$

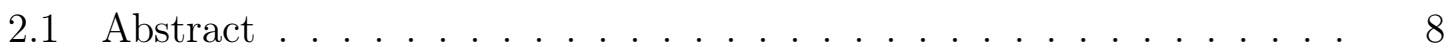

2.2 Introduction . . . . . . . . . . . . . . . . . 9

2.3 Cold tolerance in the diamondback moth . . . . . . . . . . . . . . 11

2.3.1 Cold tolerance by life stage . . . . . . . . . . . . . . . . . . . 11

2.3.2 Cold tolerance strategy . . . . . . . . . . . . . . . . . . 14

2.3.3 Cold tolerance mechanisms . . . . . . . . . . . . . . . . . . 17

2.4 Photoperiod ........................... 18

2.5 Population genetic work on temperate overwintering populations . . . 19

2.6 North American studies on diamondback moth overwintering . . . . . 21

2.6.1 Great Plains . . . . . . . . . . . . . . . . 22

2.6.2 Great Lakes and St. Lawrence Basin . . . . . . . . . . . . . . 23

2.7 Overwintering strategy . . . . . . . . . . . . . . . 25 


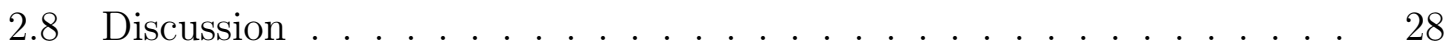

2.9 Future directions $\ldots \ldots \ldots \ldots \ldots$

2.10 Conclusion . . . . . . . . . . . . . . . . . . . . 32

3 Something old, something new: revisiting the diamondback moth $\begin{array}{ll}\text { life table after } 65 \text { years } & 37\end{array}$

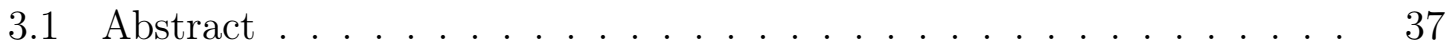

3.2 Introduction . . . . . . . . . . . . . . . . . . . 38

3.3 Materials and Methods . . . . . . . . . . . . . . . . . . . 41

3.3 .1 Field site . . . . . . . . . . . . . . . . . . . 41

3.3 .2 Overwintering potential $\ldots \ldots \ldots \ldots \ldots$

3.3 .3 Abridged life table . . . . . . . . . . . . . . . . . 42

3.3.3.1 Insect rearing . . . . . . . . . . . . . . . . . . . 42

$3.3 .3 .2 \quad \operatorname{Egg} \ldots \ldots \ldots \ldots \ldots \ldots$

3.3.3.3 First instar . . . . . . . . . . . . . . . 43

3.3.3.4 Second to fourth instar . . . . . . . . . . . . . . 43

3.3.3.5 Pupa.................... 44

3.3.3.6 Estimates of diamondback moth fecundity . . . . . . 44

3.3.3.7 Treatments and experimental procedure . . . . . . 44

3.3.3.8 Construction of the life tables and assessment of mortality factors $\ldots \ldots \ldots \ldots \ldots \ldots$

3.3 .4 Static life table . . . . . . . . . . . . . . . 46

3.3.5 Natural enemies . . . . . . . . . . . . . . . . . . 47

3.4 Results . . . . . . . . . . . . . . . . . . . . . . . 48

3.4 .1 Overwintering potential $\ldots \ldots \ldots \ldots$

3.4 .2 Abridged life table . . . . . . . . . . . . . . . . . 49

3.4 .3 Static life table . . . . . . . . . . . . . . . 50

3.4 .4 Natural enemies . . . . . . . . . . . . . . . . . . . . 51 
3.5 Discussion . . . . . . . . . . . . . . .

4 Microbiome analysis of diamondback moth (Lepidotpera: Plutellidae) midgut and associated plants using 16S rRNA amplicon $\begin{array}{ll}\text { sequencing } & 68\end{array}$

4.1 Abstract . . . . . . . . . . . . . . . . . . . 68

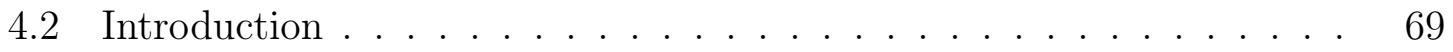

4.3 Materials and Methods . . . . . . . . . . . . . . . . 71

4.3 .1 Insect Rearing . . . . . . . . . . . . . . . . . . . . 71

$4.3 .2 \quad$ Dissection . . . . . . . . . . . . . . . . . . . . . 72

4.3 .3 DNA extraction . . . . . . . . . . . . . . . . 73

4.3 .4 Sequence analysis . . . . . . . . . . . . . . . 75

4.3.4.1 Closed reference V3 and V6 combined reads . . . . 75

4.3.4.2 Open reference V6 reads . . . . . . . . . . . 75

$4.3 .5 \quad$ Data analysis . . . . . . . . . . . . . . 76

4.4 Results . . . . . . . . . . . . . . . . . . . . 77

4.5 Discussion . . . . . . . . . . . . . . . . . . . . . . . . . 79

5 General Conclusion $\quad 91$

5.1 Limitations of research . . . . . . . . . . . . . . . . . . . 93

5.2 Future directions . . . . . . . . . . . . . . . . . 95

$\begin{array}{ll}\text { References } & 98\end{array}$

$\begin{array}{ll}\text { Appendix } & 119\end{array}$ 


\section{List of Tables}

2.1 The longest reported number of days that various life stages of diamondback moth, Plutella xylostella, survived at $5{ }^{\circ} \mathrm{C}, 0{ }^{\circ} \mathrm{C}$, and $-5{ }^{\circ} \mathrm{C}$, including lowest reported supercooling temperature for each life stage and lower lethal temperature. . . . . . . . . . . . . . . . 33

2.2 Comparison of daily average winter air temperatures across different years of the overwintering studies for diamondback moth, Plutella xylostella, conducted by Dosdall (1994) and Dosdall et al. (2001). . . .

2.3 Comparison of daily average winter air temperatures across different overwintering studies for diamondback moth, Plutella xylostella. . . .

3.1 Abridged life table of diamondback moth, Plultella xylostella, on the Central Experimental Farm in Ottawa, Ontario for 2016 on cabbage,

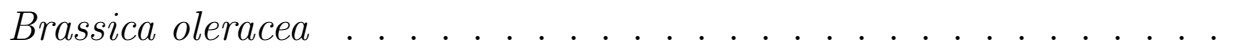

3.2 Abridged life table of diamondback moth, Plultella xylostella, on the Central Experimental Farm in Ottawa, Ontario for 2017 on cabbage, Brassica oleracea . . . . . . . . . . . . . . . .

3.3 Cumulative percent parasitism by parasitoids (Hymenoptera) in the abridged and static life tables on diamondback moth, Plutella $x y$ lostella, in Ottawa, Ontario. Numbers in brackets are number of parasitoid individuals. . . . . . . . . . . . . . . . .

3.4 Predator species composition as total number of individuals in pitfall trap samples collected in a cabbage, Brassica oleracea, plot on the Central Experimental Farm, Ottawa, Ontario during the summer of 2016 (12 traps) and 2017 (8 traps) with data on endemism (Bousquet et al., 2013) and predatory habits (Larochelle and Larivière, 2003) for Carabidae. . . . . . . . . . . . . . . . . . 
4.1 Summary of data in the generation of OTUs from open reference and close reference sequence preparation methods. . . . . . . . . . . . . 83

4.2 Summary of alpha-diversity between leaf and gut samples on different plant types. . . . . . . . . . . . . . . . .

4.3 The eight core OTUs found in all samples and across both open and closed V6 only datasets with rarefied relative abundance normalized using a Hellinger transformation (abundance ranges from 0 to 1 ). . . 


\section{List of Figures}

2.1 Locations of key diamondback moth, Plutella xylostella, overwintering studies in southeastern Canada and the northeastern United States of America. Symbols indicate status of overwintering as reported by respective authors; $\boldsymbol{\Delta}=$ evidence for successful diamondback moth overwintering; $\mathbf{0}$ = little to no evidence of diamondback moth overwintering. Butts (1979) and Smith and Sears (1982): Cambridge Research Station, Cambridge, Ontario $\left(43.4^{\circ} \mathrm{N}, 80.3^{\circ} \mathrm{W}\right)$. Harcourt (1954): Liddell Field Station, Ithaca, New York $\left(42.5^{\circ} \mathrm{N}, 76.4^{\circ} \mathrm{W}\right)$ and Merivale Research Station, Ottawa, Ontario $\left(45.4^{\circ} \mathrm{N}, 75.7^{\circ} \mathrm{W}\right)$. Idris and Grafius (1996): Michigan State University Collins Road Entomology Research Farm, Lansing, Michigan $\left(42.7^{\circ} \mathrm{N}, 84.5^{\circ} \mathrm{W}\right)$. The map was generated in QGIS v 2.18 (Quantum GIS Development Team 2017) using Natural Earth map data set. . . . . . . . . . . . . . .

3.1 Image depicting control cage used in this study consisting of an upside down tomato cage with bent legs, with an insect rearing bag covering it. 63

3.2 Image depicting the oviposition cage used in this study with small access holes on the side of the cage allowing a single leaf of each sample plant to be placed inside the cage for moths to access and oviposit on. Based on a concept by D.R. Gillespie. . . . . . . . . . . . .

3.3 Average temperature and precipitation on the Central Experimental Farm, Ottawa, Ontario during the summer of 2016 and 2017, precipitation data from the National Climate Data and Information Archive (Environment and Climate Change Canada). . . . . . . . . . . .

3.4 Total number of adult male diamondback moth, Plutella xylostella, caught in two pheromone traps set up in a cabbage, Brassica oleracea, plot on the Central Experimental Farm, Ottawa, Ontario. . . . . . . 66 
3.5 Average air temperature, average temperature under the snow and snow depth on the Central Experimental Farm, Ottawa, Ontario during the winter of 2016-2017. Snow cover data provided by the National Climate Data and Information Archive (Environment and Climate Change Canada). . . . . . . . . . . . . . . 67

4.1 Rarefaction curve of all samples after rarefying to a sampling depth of 1054 for closed reference dataset. . . . . . . . . . . . . . 86

4.2 Variability in bacterial community using beta dispersion through BrayCurtis dissimilarity for a) host type; b) environment. . . . . . . . .

4.3 Plot comparing Shannon-Wiener index of OTUs in gut and leaves by plant type using the closed reference dataset. . . . . . . . . . . . . . . 88

4.4 Shannon entropy analysis showing variable regions with high entropy in reads identified as Enterococcus. Highest variation was found in two regions at read positions 8 and 84. Data used was open reference dataset. 89

4.5 Output from Oligotyping analysis showing proportions of four different Enterococcus oligotypes in all samples. Data used for analysis was open reference $16 \mathrm{~S}$ V6 reads. . . . . . . . . . . . . . . . . . . . . . . . 90 


\section{List of Appendices}

Appendix A: Supplementary figures $\ldots \ldots \ldots \ldots \ldots \ldots \ldots \ldots \ldots \ldots \ldots \ldots \ldots$

Appendix B: Parameters for pick_closed_reference_otus.py ........... 124 


\title{
Glossary
}

\author{
Acronyms \\ HSC: Heat Shock Cognate \\ HSP: Heat Shock Protein \\ OTU: Operational Taxonomic Unit \\ PBS: Phosphate Buffer Solution \\ PCR: Polymerase Chain Reaction \\ RH: Relative Humidity
}

\section{Terms}

16S rRNA: Gene for the 30S small ribosomal subunit of prokaryotes. The gene is highly conserved and can be used to discern taxonomic/functional diversity and relationships.

Beta dispersion: The test for homogeneity of multivariate dispersions (Anderson, 2006) is a multivariate analogue to Levene's (1960) test and can be based on any dissimilarity measure of choice. An F-statistic is calculated to compare the average distance of observation units to their group centroid (or spatial median), defined in the space identified by the chosen dissimilarity measure. A P-value is then obtained by permuting appropriate residuals: either least squares residuals (in the case of centroids) or least-absolute deviation residuals (in the case of spatial medians) (Anderson et al., 2006).

Closed reference OTU picking: To obtain OTUs and taxonomy, reads are compared to a reference database. Any reads not identified by the database will be 
discarded.

Degree-days: The total amount of heat required, between the lower and upper thresholds, for an organism to develop from one point to another in its life cycle.

Host: the organism in or on which a microorganism or parasitoid lives.

Hypervariable region: For the $16 \mathrm{~S}$ rRNA gene in bacteria there are nine hypervariable regions (V1-V9) where there is considerable sequence diversity between species to accomplish taxonomic identification. These regions are flanked with conservative sequences that allow for amplification of the target region by universal primers. (Chakravorty et al., 2007)

Metabarcoding: Use of one or more hypervariable regions (barcode) in the $16 \mathrm{~S}$ rRNA gene to interpret trends in microbial biodiversity.

Metagenomics: Use of full length reads or assembly of the whole genome using shotgun sequencing to interpret trends in microbial and functional biodiversity. Microbiome: The combined genetic material of the microorganisms (bacteria) in either the gut or leaf tissues.

Oligotyping: Identifying and utilizing the most discriminating information among reads by focusing on the variable sites revealed by the entropy analysis to identify highly refined taxonomic units (Eren et al., 2013).

Open reference OTU picking: To obtain OTUs and taxonomy, reads are clustered against one another without external reference to obtain a representative set of sequences. The representative sequences are then compared to a reference database. Any representative sequences not identified by the database will be identified as a new OTU.

OTU Table: A matrix with the number of reads per OTU by sample ID with taxonomic identification for the OTUs at the end of the table as determined by the 
Greengenes 16S rRNA gene database.

Pharate: a transition between developmental stages where the insect has already completed development to the following stage but has not emerged from their previous stage. Often in reference before emerging from the egg or pupa. 


\section{Chapter 1}

\section{General Introduction}

As global climate change increases average yearly temperature and incidents of extreme weather events, the population dynamics of pest insects are predicted to change. There are studies that suggest poleward expansion of insects in the face of climate change and the ability to shift ranges away from the natural enemies that control their populations (Parmesan, 2001; Furlong and Zalucki, 2017; Musolin, 2007). This has major implications for agriculture as current management strategies are based on population data from the past. The Central Experimental Farm in Ottawa, Ontario, Canada was the location of a set of studies that took place over two decades starting in 1951 (Harcourt, 1954, 1957, 1960a, 1963, 1986). These studies looked into the biology and population dynamics of the diamondback moth.

Diamondback moth, Plutella xylostella (Linnaeus) (Lepidoptera: Plutellidae) is a globally distributed pest of Brassica spp. (Brassicaceae) and other brassicaceous crops (Furlong et al., 2013). In the Ottawa area, it has four to six generations during the growing season (Harcourt, 1954) and arrives by migration from southerly areas (Dosdall et al., 2001; Hopkinson and Soroka, 2010). It is not known to survive year-

round beyond $\approx 36{ }^{\circ} \mathrm{N}$ (Harcourt, 1957); however, there have been observations of diamondback moth overwintering further North and into Canada (Smith and Sears, 1982; Harcourt, 1954; Talekar and Shelton, 1993). 
The literature on diamondback overwintering is not extensive and is disconnected from physiological and molecular studies on diamondback moth cold tolerance. Much of the historical and current work directly investigating diamondback moth overwintering does not originate from North America (e.g. Kim et al. 2014, 2015; Kimura et al. 1987a,b,c). In addition, there is no consensus on the type of strategy the diamondback uses to pass periods of cold temperatures. Reviewing the literature to provide definitive statements on cold tolerance and overwintering of diamondback moth can provide a platform for the continuation of this important research. With climate change, the boundary for diamondback moth overwintering can expand further North than initially believed. To better understand the implications of climate change the parameters for cold weather survival by this species must be concisely defined. This has implications in agriculture and the management of this pest species in Canada.

If overwintering is possible it can provide early contributions to infestations of economically important crops in Canada. To improve on modern management plans, the major mortality factors that control diamondback moth populations should be revisited. This can be accomplished using a life table study. A life table is a summary of statistics that give a detailed description of the mortality in a population from various factors (Carey, 1993). For the Ottawa area, Harcourt's studies (1954; 1957; $1960 \mathrm{a} ; 1963 ; 1986)$ suggested that rain alongside three species of parasitoids: $D i$ adegma insulare (Cresson) (Hymenoptera: Ichneumonidae), Diadromus subtilicornis (Gravenhorst) (Hymenoptera: Ichneumonidae) and Microplitis plutellae (Muesbeck) (Hymenoptera: Braconidae), were the factors that regulated diamondback moth populations in Ottawa (Harcourt, 1963). Climate change is shifting the weather dynamics of the Ottawa area, potentially altering the mortality factors impacting diamondback moth, including the associated parasitoid community. By describing the contribution of major mortality factors at present day, management plans can target and augment 
these factors to improve control of this pest species.

Diamondback moth is known to be resistant to all major classes of pesticides (Furlong et al., 2013). Insect microbiomes have been hypothesized to facilitate pest resistance (Gressel, 2018). By looking at the association of bacterial communities among plants and in the herbivore, changes in the microbiome associated with diet and environment can be accounted for when conducting microbiome studies looking into changes in the microbiome associated with resistance. There is also the potential for certain taxa to contribute to pest resistance. These can be identified though a microbiome study. Bacteria in the insect microbiome can be a source of naturally occurring mortality, and can be targets for manipulation to be used as a method of biological control. This has implications in ecological studies where potential mortality in the field can be attributed to pathogens and can be a consideration in study design and analysis such as in a life table study. In addition, bacteria associated with this study system in the Ottawa area have yet to described.

The objectives and specific aims of the current study were as follows:

Objective 1: Synthesize the literature for data on overwintering and cold tolerance of diamondback moth and discuss observations of potential overwintering in North America.

Specific aim 1 - 1: Outline the limits for cold temperature survival of diamondback moth at all stages of development through the literature.

Specific aim 1 - 2: Redefine and state the cold tolerance strategy used by the diamondback moth.

Specific aim 1 - 3: Discuss the observations from studies on diamondback moth overwintering in North America using the newly synthesized limits for cold temperature survival.

Objective 2: Describe the mortality factors affecting diamondback moth populations 
in the Ottawa area through a life table study.

Specific aim 2 - 1: Determine if temperatures during the winter season in Ottawa, Ontario are sufficient for diamondback moth overwintering.

Specific aim 2 - 2: Conduct a life table study on diamondback moth in the Ottawa area comparing a contemporary method and the method used by Harcourt (1954). Specific aim 2 - 3: Document the natural enemies of diamondback moth using parasitoid emergence and pitfall trapping.

Specific aim 2 - 4: Compare and contrast the current study with results and observations from Harcourt (1954, 1957, 1960a, 1963, 1986).

Objective 3: Evaluate the effect and contribution of the plant microbiome on late instar diamondback moth larvae midgut bacterial communities.

Specific aim 3 - 1: Using next generation sequencing, compare bacterial community structure and diversity within the midgut of diamondback moth larvae and the leaves of specific plants that the larvae fed on.

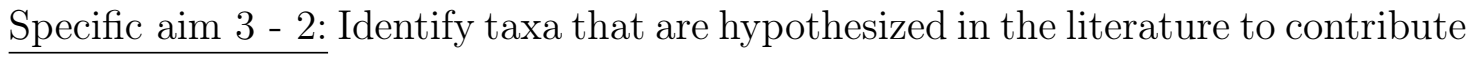
to pesticide resistance or detoxification in the diamondback moth.

By revisiting and looking into new aspects of the biology and population dynamics of the diamondback moth, modern strategies for management and biological control of this species can progress using information gathered in these studies as a new baseline. 


\section{Chapter 2}

\section{Elusively Overwintering: A review of diamondback moth (Lepidoptera: Plutellidae) cold tolerance and overwintering strategy ${ }^{1}$}

\subsection{Abstract}

There is no consensus on the overwintering strategy used by the diamondback moth, Plutella xylostella (Lepidoptera: Plutellidae). As a result, the topic of diamondback moth overwintering in temperate climates remains controversial. However, there is general agreement that the diamondback moth does not overwinter in diapause. This review compiles data on low temperature survival to determine cold tolerance mechanisms and the cold tolerance strategy of the diamondback moth. According to cold tolerance data and observations from key overwintering studies in eastern North America, the diamondback moth likely overwinters in a quiescent state in no specific overwintering stage and is chill susceptible. Observations from key overwintering studies suggest a northern overwintering limit for diamondback moth of approximately $\approx 43^{\circ} \mathrm{N}$ in eastern North America. Climate change is altering winter conditions in

\footnotetext{
${ }^{1}$ Source: Elusively Overwintering: A review of diamondback moth (Lepidoptera: Plutellidae) cold tolerance and overwintering strategy, 150(2), 156-173, The Canadian Entomologist, 2018. Reproduced with the permission of the Minister of Public Works and Government Services, 2018.
} 
temperate climates, making temperate regions susceptible to potential diamondback moth overwintering and recurring outbreaks.

\subsection{Introduction}

Insects are highly successful organisms with a global distribution that is aided by their ability to survive seasonally cold or dry extremes. This is achieved through evolved traits that promote survival in these extremes via dormancy and cold tolerance mechanisms, of which overwintering is a commonly discussed context. There has been extensive work done on the natural history of invasive insect overwintering and cold tolerance (e.g. Ward and Masters 2007; Bale and Hayward 2010; Morey et al. 2016).

Koštál (2006) defined two main subclassifications of dormancy: quiescence and diapause. Quiescence is an immediate response to a change in a limiting factor, such as temperature, above or below a threshold. Once the limiting factor returns to favourable levels there is an equally immediate response for the resumption of normal development. Diapause is a centrally regulated response that alters the developmental programme during a specific phase in the life cycle. A series of physiological events induce a diapause state as well as terminate the diapause state. The response precedes the onset of unfavourable conditions and terminates once favourable conditions are sufficient.

The diamondback moth, Plutella xylostella Linnaeus (Lepidoptera: Plutellidae), is a globally distributed pest of brassicaceous (Brassicaceae) crops, causing economic damage of up to US\$ 5 billion annually (Zalucki et al., 2012; Zhang et al., 2015). In western Canada, diamondback moth is an occasional pest of canola where crop losses associated with outbreak years can be devastating (Dosdall et al., 2011), with losses of up to CAD \$67.0-77.5 million (calculated to 2017 dollars) (Western Committee on Crop Pests, 1995). Diamondback moth is also resistant to all major classes of insecti- 
cides and was one of the first species to develop resistance against Bacillus thuringiensis Berliner (Bacillaceae) in the field (Furlong et al., 2013). In equatorial climates, the diamondback moth reproduces year-round, producing up to 20 generations when it has continuous access to host plants (Dosdall et al., 2011). In temperate climates, the diamondback moth has been documented to produce four to six generations; however, the number of generations can increase due to increases in temperature, availability of host plants, and seasonality (Harcourt, 1954; Harcourt and Cass, 1966). There is general agreement that diamondback moth infestations in northern latitudes often result from massive long-distance dispersal events originating in the more southerly parts of its range (Honda, 1992; Honda et al., 1992; Dosdall et al., 2001; Hopkinson and Soroka, 2010; Wei et al., 2013; Yang et al., 2015). However, there is controversy in the literature about the ability of the diamondback moth to overwinter successfully in climates typical of southern Canada and the northern United States of America (Talekar and Shelton, 1993).

Although the diamondback moth persists year-round in the tropics and milder temperate regions, the highest latitudes for overwintering have been estimated to be 36.0-38.5 ${ }^{\circ} \mathrm{N}$ in Japan (Kimura et al., 1987a; Honda, 1992), 30.5-32.2 ${ }^{\circ} \mathrm{N}$ in China (Li et al., 2016), and 37.0-38.0 ${ }^{\circ} \mathrm{N}$ in South Korea (Kim et al., 2015, 2014). Harcourt (1957) approximated the limit of year-round persistence in North America to be 36 ${ }^{\circ} \mathrm{N}$. This estimate was also demonstrated in the Climex model created by Zalucki et al. (2012). Key overwintering studies (e.g., Marsh 1917; Dosdall et al. 2001) in North America were conducted at higher latitudes, $38-53{ }^{\circ} \mathrm{N}$, with sporadic observations of probable successful overwintering. These observations, beyond the year-round distribution of the diamondback moth, suggest that this species may have the potential to overwinter in southern Canada and the northern United States of America.

In addition to climate, food and habitat availability are among the most important factors limiting insect distributions (Musolin, 2007). Canada is the one of the 
largest producers in the world of canola, Brassica napus Linnaeus and B. rapa Linnaeus (Brassicaceae) (United States Department of Agriculture, Foreign Agricultural Service (FAS), 2017). Increasing demand for canola in the European Union, the United States of America, and China for industrial, biodiesel, and food applications (United States Department of Agriculture, Economic Research Service (ERS), 2017) will ultimately lead to increased acreage. This will result in more land dedicated to growing canola in Canada. An expansion of canola crop acreage will provide a vast resource of suitable host plant material for the diamondback moth in its northernmost range. In parallel, climate change is altering the duration and severity of winters. Gradual increases in mean annual temperatures could result in the range expansion of diamondback moth into more northerly temperate regions, potentially increasing incidence of outbreak years and the possibility for overwintering. To date, research attempting to induce diapause or to determine the diapause stage of the diamondback moth has been unsuccessful. Studies have largely concluded that the diamondback moth does not overwinter in a diapause state, but only speculate as to its probable overwintering strategy.

Our objective here is to review the literature and outline the limits and mechanisms of cold tolerance of the diamondback moth by summarising the available literature. We further interpret the available data to provide a framework describing the overwintering strategy used by the diamondback moth and the potential of this global pest to survive year-round in northern temperate climates by overwintering.

\subsection{Cold tolerance in the diamondback moth}

\subsubsection{Cold tolerance by life stage}

Although numerous studies have addressed cold tolerance and the supercooling capacity of the diamondback moth, a consensus has never been reached with respect to survivorship at colder temperatures. This is because past studies have used a variety 
of methods to test for cold tolerance and overwintering capacity, leading to variable results. The studies reviewed in this section focused on temperature treatments below the lower developmental threshold of the diamondback moth, estimated to be between $7.0^{\circ} \mathrm{C}$ and $7.8{ }^{\circ} \mathrm{C}$ (Umeya and Yamada, 1973; Butts and McEwen, 1981; Liu et al., 2002; Golizadeh et al., 2007).

The earliest study on survivorship of diamondback moth eggs in cold temperatures was done by Hardy (1938), who found that eggs remained viable after 14 days at 0 ${ }^{\circ} \mathrm{C}$. Later studies assessing the number of days until $100 \%$ mortality reported even longer periods of viability of eggs at low temperatures (see Supplementary Material for Dancau et al. 2018). Liu et al. (2002) found that eggs remained viable for up to 55 days at $4{ }^{\circ} \mathrm{C}$ and $6{ }^{\circ} \mathrm{C}$, and Butts (1979) also reported evidence of development after 42 days when eggs were kept at $2{ }^{\circ} \mathrm{C}$. When dissected after complete mortality was reached, there was evidence of development that had occurred within the eggs in the form of pharate (transitional stage preceding emergence) first instars (Liu et al., 2002). Liu et al. (2002) also reported the development time of eggs at warmer temperatures was reduced the longer they were exposed to $4{ }^{\circ} \mathrm{C}$ or $6{ }^{\circ} \mathrm{C}$, providing further evidence for development below the estimated lower developmental threshold. Eggs of diamondback moth survive for about 55 days at temperatures at or slightly above $0{ }^{\circ} \mathrm{C}$ but only for 23 days at temperatures just below $0{ }^{\circ} \mathrm{C}$ (Table 2.1 ).

There is also evidence of diamondback moth larvae continuing to develop at temperatures below the estimated lower developmental threshold (see Supplementary Material for Dancau et al. 2018). On average, each instar took $\approx 28.9$ days at $6{ }^{\circ} \mathrm{C}$ and 46.5 days at $4{ }^{\circ} \mathrm{C}$ to develop into the next instar (Liu et al., 2002). Gu (2009) reported high survivorship in fourth instars beyond 60 days in temperatures alternating between $0{ }^{\circ} \mathrm{C}$ and $5{ }^{\circ} \mathrm{C}$, with a third of the individuals pupating. Consistently within each study, fourth instars appear to survive the longest in cold conditions out of all instars (see Supplementary Material for Dancau et al. 2018). These studies suggest 
that diamondback moth larvae can survive at $0{ }^{\circ} \mathrm{C}$ for almost 80 days and for $\approx 19$ days at sub-zero temperatures (Table 2.1).

Historically, the hypothesised overwintering stage of diamondback moth was thought to have been the pupal stage (Kanervo, 1936; Hardy, 1938; Razumov, 1970). Under the assumption that the diamondback moth overwintered in diapause, investigations on pupal overwintering were led by Harcourt (1954) and Butts (1979). Outdoors at $\approx 0{ }^{\circ} \mathrm{C}$, pupae survived for 80 days or more (Kimura and Fujimura, 1988) (see Supplementary Material for Dancau et al. 2018). These authors reported that adults emerging from pupae that had survived for 30 days at $0{ }^{\circ} \mathrm{C}$ were relatively healthy and could fly; however, adults emerging from pupae that had survived for 40 days died soon after emerging. They also noted that mortality of pharate adults increased, with fewer capable of eclosing, as their study continued. Liu et al. (2002) showed that pre-pupae continued to develop into pupae at $4{ }^{\circ} \mathrm{C}$ (12 days) and $6{ }^{\circ} \mathrm{C}$ (9.8 days), which are temperatures below the estimated lower developmental threshold. Pupae survived for about 80 days at $0{ }^{\circ} \mathrm{C}$ and $\approx 19$ days at $-5{ }^{\circ} \mathrm{C}$ (Table 2.1 ).

The adult stage has also been proposed to be the overwintering stage of the diamondback moth with both historical and contemporary support (Marsh, 1917; Frost, 1949; Harcourt, 1954; Smith and Sears, 1982; Saito, 1994b). In conditions alternating between $0{ }^{\circ} \mathrm{C}$ and $5^{\circ} \mathrm{C}, \mathrm{Gu}$ (2009) found that adults survived $\geq 60$ days, with mating observed (see Supplementary Material for Dancau et al. 2018). Adults have also been observed to oviposit at $5{ }^{\circ} \mathrm{C}$ (Ohtomo and Chiba, 2001). Adults that had survived exposures at $-5{ }^{\circ} \mathrm{C}$ produced viable eggs after being placed in warmer conditions (Saito, 1994b; Gu, 2009). Kimura and Fujimura (1988) reported that in field conditions under snow cover, approximated to be $0{ }^{\circ} \mathrm{C}, 50 \%$ of the adults survived $\geq 70$ days with viable eggs. In laboratory conditions, Honda (1992) found that adults can survive 60 days or more at $0{ }^{\circ} \mathrm{C}$; however, eggs were no longer viable in adults that survived past 50 days. Adults survived $\geq 70$ days at $0{ }^{\circ} \mathrm{C}$ and for at least 20 
days at $-5{ }^{\circ} \mathrm{C}$ (Table 2.1).

\subsubsection{Cold tolerance strategy}

Cold-tolerant insects can be broadly divided into freeze-tolerant and freeze-avoidant species. Park and Kim (2014) concluded that the diamondback was a freeze-avoidant species based on this dichotomous concept of cold tolerance. However, this division has been widely criticised (Sinclair, 1999; Lee, 2010). Currently, there are three recognised categories of insect cold-tolerance: freeze-tolerant, freeze-avoidant, and chill-susceptible (Lee, 2010). Broadly, the categorisations correspond to susceptibility to different types of cold injury - freezing injury, cold shock injury, and cumulative chill injury (Nedvěd, 2000; Lee, 2010). To narrow down the cold-tolerance strategy of diamondback moth the supercooling point, lower lethal temperature, and rapid cold hardening must also be discussed.

Cold tolerance strategy can be inferred by using the supercooling point and lower lethal temperature (Sinclair et al., 2015). Supercooling is the process whereby insects can avoid ice formation in their tissues, and thus survive being cooled to subzero temperatures by concentrating solutes (e.g., ions, amino acids, proteins) in their hemolymph (Lee, 2010). The point at which ice spontaneously forms in their tissues is known as the supercooling point or freezing point of the organism (Lee, 2010). The lower lethal temperature is the temperature at which mortality occurs as a result of cold-shock injury during brief exposures to sub-zero temperatures (Nedvěd, 2000; Lee, 2010).

Three studies (Kimura and Fujimura, 1988; Kaneko, 1995; Park and Kim, 2014) examined supercooling in the diamondback moth. The lowest supercooling point values reported for each stage are shown in Table 2.1; however, there was variation depending on treatment and study, with supercooling points ranging from $-10.1{ }^{\circ} \mathrm{C}$ to $-23.2{ }^{\circ} \mathrm{C}$ (see Supplementary Material for Dancau et al. 2018). The lower lethal 
temperature was found to be $-20{ }^{\circ} \mathrm{C}$ for two-hour exposures (Nguyen et al., 2014) using ecologically relevant cooling and thawing rates of $0.25{ }^{\circ} \mathrm{C} /$ minute (Lee, 2010; Sinclair et al., 2015). Generally, discrimination of cold tolerance strategy using supercooling point and lethal temperature where $50 \%$ mortality occurs $\left(\mathrm{LT}_{50}\right)$ involves the relative difference between the two measurements (Bale, 1996; Sinclair, 1999; Nedvěd, 2000). However, this method becomes imprecise when the differences between the supercooling point and lower lethal temperature are small (Sinclair et al., 2015). For diamondback moth the measures of supercooling point from the literature are highly variable, as a result the supercooling point is the same or lower than the $\mathrm{LT}_{50}$. This makes it difficult to discern the exact cold tolerance strategy using this method; however, freeze tolerance can be excluded as a potential strategy as the lower lethal temperature is not markedly lower than supercooling point in this species. Instead, the diamondback moth is likely freeze avoidant or chill susceptible.

Cold shock injury and cumulative chill injury are additional measures used to narrow down cold tolerance strategy (Bale, 1996; Nedvěd, 2000). Accumulated chilling injury occurs during extended periods of exposure (days to weeks) to temperatures just below or above $0{ }^{\circ} \mathrm{C}$ and cold shock injury occurs after a brief exposure to cold temperatures. Both often result in mortality or decreased biological function if the insect is susceptible (Lee, 2010).

Rapid cold hardening is an induced response that protects insects from nonfreezing injuries such as chilling injury or cold shock injury (Denlinger and Lee, 2010). Although rapid cold hardening is a plastic trait documented in many insect groups (Denlinger and Lee, 2010), chill injury and prolonged exposure to extreme temperatures can nevertheless result in mortality, even for insects with the capability to be supercooled (Chown and Sinclair, 2010). To induce a rapid cold hardening response in diamondback moth, exposure at $4{ }^{\circ} \mathrm{C}$ need to be in excess of five hours (Park and Kim, 2014). After induction of rapid cold hardening, fourth instar diamond- 
back moths can still experience fatal temperature exposures as warm as $-10{ }^{\circ} \mathrm{C}$ (Park and Kim, 2014) despite having a supercooling point reported at $-10{ }^{\circ} \mathrm{C}$ or lower (see Hayakawa et al. 1988; Kaneko 1995, Supplementary Material for Park and Kim 2014). Nguyen et al. (2014) also reported that at temperatures below $-10{ }^{\circ} \mathrm{C}$ mortality of adult diamondback moth increased at all exposure times (10-minute intervals) up to two hours with decreasing survivorship approaching the lowest reported supercooling point temperatures, indicating cold shock injury.

As noted in section 2.1, exposure to sub-zero temperatures near $0{ }^{\circ} \mathrm{C}$ results in mortality after less than one month of exposure and exposure at $0{ }^{\circ} \mathrm{C}$ and $5{ }^{\circ} \mathrm{C}$ ultimately results in mortality occurring before completion of a winter season. In addition, studies have reported reduction in fecundity of adult moths (Kimura and Fujimura, 1988) and reduced eclosion rates from pupae (Honda, 1992) for individuals surviving long exposures at $0{ }^{\circ} \mathrm{C}$; these are indicators of accumulating chill injury. Chill injury and cold-shock injury result in mortality over short periods of time thus; the diamondback moth is likely chill susceptible and therefore susceptible to all three types of cold injury. With a chill susceptible strategy, supercooling point is not an ecologically relevant indicator for cold temperature survival in the diamondback moth. Instead, the lower lethal temperature may be a more informative measure of low temperature survival (Sinclair et al., 2015). However, the exposure time used in Nguyen et al. (2014) to determine lower lethal temperature was very brief $(\leq$ two hours). Data on survivorship under longer exposure times would be more ecologically relevant.

Diamondback moth larvae can continue to develop and feed at temperatures below the estimated lower development threshold, potentially incurring chill injury (Kimura et al., 1987c; Saito, 1994b; Liu et al., 2002). Kimura et al. (1987c) removed second instars from snow cover at $0{ }^{\circ} \mathrm{C}$ and placed them at $20{ }^{\circ} \mathrm{C}$ for a day before being returned to snow cover developed to fourth instar and survived beyond 80 days. 
This suggests that diamondback moth can opportunistically use warm periods when temperatures are fluctuating to potentially recover from cold shock or chill injury to prolong survival (Koštál et al., 2007; Colinet et al., 2015). This ability only applies to species that are freeze avoidant or chill susceptible (Colinet et al., 2015). Additional testing is needed to confirm the cold tolerance strategy of the diamondback moth.

\subsubsection{Cold tolerance mechanisms}

Cryoprotectant synthesis in insects involves converting glycogen to polyols or sugars (Storey and Storey, 2012). Glycerol, composed of two polyols, is one of the main cryoprotective agents used by insects to increase cold hardiness (Leather et al., 1993). Glycerol decreases the supercooling point in freeze-avoidant species and prevents the formation of intracellular ice in freeze-tolerant species (Storey and Storey, 2012). Glycerol was determined to be the main cryoprotective agent in the diamondback moth, using a glycerol kinase and glycerol-3-phosphate biosynthesis pathway (Park and Kim, 2014). Fourth instar diamondback moths that were induced with rapid cold hardening had significantly increased glycerol concentrations in hemolymph as well as increased survival at sub-zero temperatures than individuals without rapid cold hardening. Injections of glycerol also significantly increased the survivorship of fourth instars at sub-zero temperatures without prior rapid cold hardening, resulting in a rapid-cold-hardening-like response (Park and Kim, 2014).

Heat shock proteins are molecular chaperones that protect cells from harmful agents to help an organism maintain homeostasis under stress (Kregel, 2002; Sørensen et al., 2003; King and MacRae, 2015). Many insect families exhibit increased expression of heat shock proteins during their overwintering and diapause stages and there appears to be a relationship between heat shock protein expression and thermotolerance in insects (Denlinger, 2002; Rinehart et al., 2007; Choi et al., 2014; Wang et al., 2017). Studies conducted on heat shock protein expression in diamondback moth 
have focused on heat shock treatments with HSP70 and HSC70 found to be highly expressed in adult and larval stages (Sonoda et al., 2006; Sonoda and Tsumuki, 2008; Bahar et al., 2013b). A few studies have been conducted on diamondback moth heat shock proteins and their expression related to cold temperature exposures. Chen and Zhang (2015) found that expression of 12 small heat shock proteins increased when fourth instars underwent a cold shock treatment, with HSP22.1 being the most prominently expressed. Comparison of basal expression of heat shock proteins among developmental stages revealed that the majority of heat shock proteins were highly expressed in the pupal and adult stages Chen and Zhang (2015). The expression of these protective and restorative chaperones during different stages of development could play a role in how diamondback moth prepares for, and recovers from, cold stress and overwintering. Additional cold tolerance mechanisms have yet to be studied in the diamondback moth.

\subsection{Photoperiod}

Changes in photoperiod can trigger physiological changes in insects to prepare, through dormancy or migration, for upcoming unfavourable conditions (Hodkova and Hodek, 2004; Saunders, 2009). Studies of photoperiod control of insect dormancy have been conducted on insects from many families and have revealed induction of rapid cold hardening and diapause in some species (Jungreis, 1978; Hodkova and Hodek, 2004; Koštál, 2006). As the growing season progresses and daylength shortens, diamondback moth females become less fecund, consistent with preparation for reproductive diapause and migration (Harcourt and Cass, 1966). In a minimally replicated experiment ( $n=2$ replicates), Harcourt and Cass (1966) showed that fecundity was reduced with shorter light regimes; the mean number of eggs laid per female in the 12-hour treatment was half the number laid in the 16-hour treatment. Atwal (1955) and Shirai (1993) found that larval development was slower under shorter (9:15 hours, 
8:16-hour light:dark photoperiods, respectively) photoperiods compared with longer (15:9, 16:8-hour photoperiods, respectively). Atwal (1955) noted female moths that had developed slowly from winter simulations could not oviposit, but were full of eggs when dissected. In a more recent study comparing life-history parameters under five different photoperiods ranging from 8 to 16 hour light, Campos (2008) found no effect of photoperiod on survival, development time, weight, adult size, or adult fecundity in Brazilian populations of diamondback moth. He argued that because the seasonal effects on development time and fecundity observed in the field appear to accumulate over successive generations, photoperiod is likely affecting these parameters only indirectly. Seasonal changes in temperature, habitat, and host plants are the more plausible explanations for decreased fecundity and increased development time (Atwal, 1955; Campos, 2008). Although studies in the past have demonstrated extended development time and decreased fecundity as a result of photoperiod, Campos (2008) proposed that indirect effects of photoperiod is the likeliest explanation for these observations. In addition, there is the potential for the effects to be population dependent; the effects of photoperiod should be revisited in the context of temperate and tropical populations as well as, overwintering.

\subsection{Population genetic work on temperate overwintering pop- ulations}

Molecular genetics can reveal variation within and among populations that explains traits that have been favoured by selection. Mild winters could favor adaptations

for overwintering and cold tolerance in this species. Kim et al. (2014, 2015) found that winter conditions in South Korea in 2013-2014 were more than suitable for the overwintering survival of the diamondback moth, with average winter temperatures from $0.7^{\circ} \mathrm{C}$ to $1.6^{\circ} \mathrm{C}$ and an average of only 45 days below or at $0{ }^{\circ} \mathrm{C}$ at the most northern sample sites. In contrast, conditions in North American studies where dia- 
mondback overwintering was reported were much colder, with average temperatures from November to March at $0.0{ }^{\circ} \mathrm{C}$ (Harcourt, 1954) in Ithaca, New York, United States of America and $-1.6{ }^{\circ} \mathrm{C}$ (Idris and Grafius, 1996) in Lansing, Michigan, United States of America, with 57 and 76 days at or below $0{ }^{\circ} \mathrm{C}$, respectively.

Consensus data from three markers using a random amplified polymorphic DNA analysis demonstrated distinctive clustering by sampling region in South Korea of individuals from the overwintering generation (Kim et al., 2014). This molecular evidence demonstrated that populations of diamondback moth faced a genetic bottleneck before winter, resulting in genetically distinct regional groups. The genetic distinction between groups became diluted during the following spring and summer, likely due to mixing with migrant populations (Kim et al., 2015).

In contrast, Kim et al. (2000) analysed COI haplotypes in diamondback moth in South Korea and found no differentiation among populations, as well as high gene flow likely due to migration and dispersal. Endersby et al. (2006) found no genetic differentiation among populations sampled in Australia and New Zealand, indicating high genetic homogeneity. Juric et al. (2017) analysed COI haplotypes in diamondback moth worldwide, and found that samples from China, South Korea, and India were grouped together, with no apparent differentiation among African, Asian, and European samples. Furthermore, these authors found that differentiation among populations of diamondback moth was detected only over large distances, mainly among populations from Africa/Asia/Europe, Australia/New Zealand, and North America (Endersby et al., 2006; Juric et al., 2017). This lack of genetic differentiation at smaller scales suggests a species characterised by high levels of gene flow through migration, rather than one in which founder effects are common (Endersby et al., 2006).

In the South Korean populations studied by Kim et al. (2015), there were also significantly different levels of resistance to insecticides when comparing regional groups 
with a laboratory control. The detectable genetic variability in the overwintering population in South Korea indicates strong selection associated with both seasonal variation and localised pesticide resistance. This resistance could potentially spread via high gene flow, and persist in the population if insecticide use remains a constant selection pressure (Talekar and Shelton, 1993; Endersby et al., 2006; Kim et al., 2015). The persistence of pesticide resistance into the next growing season is an ultimate consequence to successful overwintering of diamondback moth. This can have strong implications on early season pest management and crop protection.

\subsection{North American studies on diamondback moth overwin- tering}

Cold tolerance literature on the diamondback moth can aid in placing several key North American studies into a modern context (Fig. 2.1). In this section, we review these studies and discuss observations of overwintering using weather data. Snow cover would provide the best information about the probability for diamondback moth overwintering; however, historically weather stations have not collected these data routinely or reliably, if at all. Therefore, for comparing and discussing past overwintering studies, the only data available and consistent across sites are daily air temperature values, with the exception of Dosdall et al. (2001) where gaps in recording from 1993 to 1995 were supplemented with data from a nearby station. Daily average air temperatures were gathered from government weather stations as close as possible to the study sites (see Supplementary Material for Dancau et al. 2018). Temperatures from October to May were used, as this is the period of time when diamondback is typically reported to no longer be in flight and potentially overwintering (Harcourt, 1957). The following sections have key studies roughly divided by climatic region and ecozone. Calculations of accumulated degree days were made with an assumed lower development threshold of $7.3{ }^{\circ} \mathrm{C}$ (Butts and McEwen, 1981) to estimate potential 
diamondback moth development in spring assuming successful overwintering. Oneway analysis of variance tests were used to analyse daily winter temperatures across study years and sites (Tables 2.2 and 2.3); all analyses were done in JMP 13 (SAS Institute 2017).

\subsubsection{Great Plains}

Marsh (1917) at Rocky Ford, Colorado, United States of America (38.0 N, 103.7 $\left.{ }^{\circ} \mathrm{W}\right)$ was the first to study overwintering of the diamondback moth in North America. Marsh (1917) noted adults surviving the winter in field debris. Average winter temperature for Rocky Ford from 1914 to 1916 was $3.5 \pm 5.0{ }^{\circ} \mathrm{C}$ (November to May). In May, Marsh (1917) collected adult moths that he believed had emerged from overwintering. The average temperature in the preceding months (March-April) was 8.4 $\pm 4.1^{\circ} \mathrm{C}$. Therefore, it is possible that overwintered moths emerged as early as March rather than May. Average temperature in May $\left(16.0 \pm 1.5^{\circ} \mathrm{C}\right)$ was warm enough for moths to resume active flight (Goodwin and Danthanarayana, 1984), as well as mating (Ohtomo and Chiba, 2001) and oviposition (Gu, 2009). The moths Marsh (1917) observed in the field could also have been migrants, as Colorado is close to the southern

parts of the United States of America where diamondback moth persists year-round $\left(36^{\circ} \mathrm{N}\right)$. Dosdall (1994) was the first to report apparent diamondback moth overwintering in western Canada, when he collected 13 adult moths from emergence traps in late June to early July at Vegreville, Alberta $\left(53.5^{\circ} \mathrm{N}, 112.1^{\circ} \mathrm{W}\right)$ after the winter of 1991-1992. Follow-up studies over six years at sites in Vegreville, Alberta and Saskatoon, Saskatchewan, Canada $\left(52.1^{\circ} \mathrm{N}, 106.6^{\circ} \mathrm{W}\right)$ found no further evidence of overwintering (Dosdall et al., 2001). Average winter temperatures decreased over the period from 1991-1992 to 1997-1998, although the winter of 1991-1992 was one of the warmer winters during this period (Table 2.2). One treatment in 1997-1998 provided additional insulation via a styrofoam cover; however, there was no evidence that pop- 
ulations overwintered that year (Dosdall et al., 2001). It is possible the explanations provided in Dosdall (1994) for successful overwintering in 1991-1992, such as timing of first snowfall and life stage of the cohort in the field, were important determining factors for diamondback overwintering in Alberta. Winter conditions experienced during 1991-1992 appear to be beyond the physiological tolerance of the diamondback moth (see Cold tolerance by life stage). Average winter air temperatures for all years in the studies by Dosdall (1994) and Dosdall et al. (2001) were significantly colder on average $\left(\mathrm{F}_{(13,2957)}=39.1, P<0.0001\right.$, data not shown $)$ than temperatures associated with observations of diamondback overwintering in the northeastern United States of America (Table 2.3). Thus, the purported successful diamondback moth overwintering in Alberta and Saskatchewan in the above studies would have represented an extremely rare event.

\subsubsection{Great Lakes and St. Lawrence Basin}

A cage study in Ithaca, New York, United States of America $\left(42.5^{\circ} \mathrm{N}, 76.4^{\circ} \mathrm{W}\right)$ in 1953-1954, where diamondback moth was provided with plant material for shelter, claimed that adults survived the winter in outdoor conditions (Harcourt, 1954). However, there was very little detail provided concerning the cage setup and observation. Talekar and Shelton (1993) studied pupal overwintering in upstate New York in the winter of 1990-1991 and found no evidence for overwintering. Average air temperature for the winter of $1990-1991$ in Ithaca, New York was $3.1 \pm 7.5^{\circ} \mathrm{C}$ with 77 days at or below $0{ }^{\circ} \mathrm{C}$ and two days where minimum temperatures were at or below the lower lethal temperature, similar to that of the winter of 1953-1954 (Table 2.3). Talekar and Shelton (1993) also monitored adult activity using pheromone traps and reported no adult catches in upstate New York. However, there were adults caught in traps located on Long Island, New York during the same winter, where the average winter air temperature was $6.8 \pm 6.4^{\circ} \mathrm{C}$ with 25 days at or below $0{ }^{\circ} \mathrm{C}$, with no daily minima 
approaching the lower lethal temperature during the winter.

In Ottawa, Ontario, Canada $\left(45.4^{\circ} \mathrm{N}, 75.7^{\circ} \mathrm{W}\right)$, Harcourt (1954) found no evidence of pupae overwintering during the winter of 1951-1952 or 1952-1953. Other studies have demonstrated that pupae survived up to 80 days at $0{ }^{\circ} \mathrm{C}$ (e.g., Kimura and Fujimura 1988), although successful eclosion of adults from pupae exposed beyond 80 days was unlikely (Kimura and Fujimura, 1988). Therefore, the conditions during the Harcourt (1954) study were unsuitable for pupal survival with 122 and 95 days at or below $0{ }^{\circ} \mathrm{C}$ during that two-year study. Based on air temperature alone there may have been potential for larvae or adults to survive the winter of 1952-1953 in Ottawa; however, Harcourt (1954) did not include observations of those stages in his original study.

At Cambridge, Ontario $\left(43.4^{\circ} \mathrm{N}, 80.3^{\circ} \mathrm{W}\right)$, Butts (1979) placed 250 diamondback moth pupae into an overwintering cage. Inadvertently, $40 \%$ of the pupae emerged as adults before the winter, some of which subsequently oviposited, thus the experiment also included adult moths and eggs. The following spring there was no evidence for successful overwintering of any stage, likely due to the number of days $\leq 0{ }^{\circ} \mathrm{C}(123$ days). However, Butts (1979) reported that $6.2 \%$ of pupae kept at $2 \pm 1{ }^{\circ} \mathrm{C}$ were viable after six months, with adult moths successfully eclosing. This high survivorship has never been replicated in studies since (see Supplementary Material for Dancau et al. 2018). Smith and Sears (1982), working at the same site, used more individuals in different life stages, and removed the cage after the first snowfall and replaced it in early spring. Removal of the cage may have allowed snow to accumulate and insulate the individuals placed in the field. Successful overwintering of one individual out of 5000 was reported. Due to this low survivorship, coupled with the previous results from Butts (1979), Smith and Sears (1982) hypothesised that Cambridge, Ontario was near the northern limit for overwintering of the diamondback moth. Snow cover in 1977-1978 was 126 days, whereas in 1980-1981 it was 82 days. Average air 
temperature during the study by Smith and Sears (1982) was significantly colder than in other studies where diamondback moth overwintering was reported (Table 2.3). Despite significantly colder average air temperatures, the accumulated degree days and number of days at or below $0{ }^{\circ} \mathrm{C}$ were similar to the conditions in studies where diamondback moth overwintering was observed (Table 2.3). With only 82 days of snow cover and rapidly warming spring temperatures, the potential for diamondback moth to have overwintered in Cambridge in the study by Smith and Sears (1982) is physiologically plausible.

The study of Idris and Grafius (1996) in Lansing, Michigan $\left(42.7^{\circ} \mathrm{N}, 84.5^{\circ} \mathrm{W}\right)$, provides a very compelling case for diamondback moth overwintering. They found fourth instars in early May, although there was no evidence for survival of any other stage of diamondback moth. These authors suggested that the number of accumulated degree days leading up to the discovery of fourth instars was insufficient for development from egg to fourth instar if the observed larvae were the F1 generation from overwintered adults (Table 2.3). They also noted that the accumulated degree days were sufficient for pupation if fourth instars had overwintered. Poor food quality, in the form of overwintered plant material, may have delayed further development of fourth instars. Saito (1994b) noted risk of starvation increases at $0{ }^{\circ} \mathrm{C}$ because frozen plant material is inaccessible for larval feeding. The circumstances in the study by Idris and Grafius (1996) could be an extreme case of overwintering or may involve the influence of other variables to explain the observed larval survival.

\subsection{Overwintering strategy}

The consensus in the literature is that the diamondback moth does not overwinter in diapause (Hardy, 1938; Frost, 1949; Atwal, 1955; Harcourt and Cass, 1966; Butts, 1979; Smith and Sears, 1982; Kimura et al., 1987a; Saito, 1994b; Campos, 2008; Kim et al., 2015); instead it likely survives unfavourable conditions in a state of 
quiescence (Honda et al., 1992; Campos, 2008). This is demonstrated by: (1) the slowing of development in response to decreasing temperature with no indication of arrested development (Atwal, 1955; Liu et al., 2002); (2) the ability to become active immediately when placed back in favourable conditions despite long durations at 0 ${ }^{\circ} \mathrm{C}$ (Kimura et al., 1987c); and 3) evidence of continual feeding at temperatures near $0{ }^{\circ} \mathrm{C}$ (Kimura et al., 1987c; Saito, 1994b; Liu et al., 2002; Gu, 2009).

The diamondback moth is likely capable of overwintering in temperate climates via plastic responses under particular abiotic conditions. Park and Kim (2014) demonstrated decreasing supercooling points after the induction of rapid cold hardening. In addition, generations leading into the winter season had slightly lower supercooling points (Hayakawa et al., 1988; Kaneko, 1995) this could represent an acute response associated with rapid cold hardening (Sinclair and Roberts, 2005). However, the ecological relevance of the supercooling point remains debatable in the diamondback moth. Honda (1992) was the first to incorporate acclimation in the cold tolerance study design; however, a constant temperature treatment was not used for comparison. $\mathrm{Gu}(2009)$ included a fluctuating temperature regime from $0{ }^{\circ} \mathrm{C}$ to $5{ }^{\circ} \mathrm{C}$ to assess survival. This resulted in asynchronous development of individuals in a cohort, where some developed into the next life stage while others did not. Unfortunately, these individuals were not subjected to colder conditions to assess potential effects of acclimation compared with individuals at constant temperatures. There is currently no study or suite of studies that have explored the set of experiments suggested by Sinclair et al. (2015) to detect phenotypic plasticity at low temperatures. This includes treatments involving: induction of rapid cold hardening, acclimation, low temperature development with a short photoperiod, and low temperature development with decreasing temperature and photoperiod. However, the induction of rapid cold hardening and the associated changes in low temperature survivorship (Park and Kim, 2014), changes in supercooling points (Hayakawa et al., 1988; Kaneko, 1995), 
and asynchronous development at cold temperatures (Atwal, 1955; Butts, 1979; Gu, 2009) can represent some evidence for plastic responses to cold. This could result in survival by a portion of the population capable of passing short durations of extreme temperatures until the return of more favourable conditions.

The observed overwintering stages of the diamondback moth include late instars (Idris and Grafius, 1996), pupae (Kanervo, 1936; Hardy, 1938; Razumov, 1970), and adults (Marsh, 1917; Harcourt, 1954; Frost, 1949; Smith and Sears, 1982). Our review suggests that all the above observations likely involve overwintering in quiescence, with the adult stage being the most capable of tolerating temperate winters. It is conceivable that the diamondback moth can pass the entire duration of a short and mild winter season in any of the three stages. The duration of cold conditions appears to be an important factor, with stages of the insect generally experiencing increased mortality only after about 40 days (Kimura and Fujimura, 1988) but with the potential for some survivorship beyond 80 days in conditions near $0{ }^{\circ} \mathrm{C}$ (see Cold tolerance by life stage). In summary, favourable conditions for diamondback moth overwintering include the following: (1) the moth should be in a later developmental stage (fourth instar, pupa, adult) before the first snowfall and seek shelter in crop debris (Marsh, 1917; Dosdall, 1994) or manufactured structures, such as greenhouses (Razumov, 1970; Kimura et al., 1987b; Saito, 1994a; Kim et al., 2014); (2) the winter would average $0{ }^{\circ} \mathrm{C}$ with occasional dips into sub-zero temperatures or have consistent snow cover; and (3) unfavourable conditions would not last longer than 50-80 days (Kimura and Fujimura, 1988; Saito, 1994b).

Survivorship among different life stages of the diamondback moth in cold temperatures appears to vary (Table 2.1). However, with the lack of standardisation between different cold tolerance studies, it is difficult to say if the variation seen reflects the true physiology of the species or the variable physiology of geographically (and thus genetically) distinct populations. In addition, a few authors have discussed how they 
evaluated mortality for each life stage. The literature does, however, support the longstanding view that the adult stage of the diamondback moth is the most cold tolerant and the most likely stage to overwinter successfully (Kimura and Fujimura, 1988; Honda, 1992; Honda et al., 1992; Saito, 1994b).

\subsection{Discussion}

Availability of crop or wild brassica plants early in the spring may play a role in the overwintering success of the diamondback moth. Yellow rocket, Barbarea vulgaris Aiton (Brassicaceae), is a native North American species that grows and flowers early in the spring (April-May) that often provides the first evidence of diamondback moth early in the season (Harcourt, 1957; Idris and Grafius, 1996). Canola is a commercial oilseed Brassica, and is a major crop attacked by the diamondback moth (Dosdall, 1994). Fully commercial varieties of canola were released in the 1970s (Slinkard and Knott, 1995) and production in Ontario only began in 1983 (Kulaserkera, 2014). Overwintering studies before the 1980s focused on cruciferous vegetables. Since then, canola has been planted at a large scale in Canada at 9306500 ha, with 18200 ha in the province of Ontario in 2017 (Statistics Canada, 2017), making canola a CAD $\$ 26.7$ billion industry in Canada (Canola Council of Canada, 2016). The significant change in the crop landscape with the introduction of canola in Ontario and the rest of Canada may provide a major annual food source for the diamondback moth, increasing the magnitude of selective pressure on traits that improve overwintering capacity. However, in the United States of America, canola is not grown at the same scale, with only 874525 ha planted in 2017 (United States Department of Agriculture, National Agricultural Statistics Service (NASS), 2017). Canola can represent a large food source for migrating populations of diamondback moth providing numerous opportunities for adaptation to Canadian winters. One such event may have resulted

in the Dosdall (1994) observation of diamondback overwintering in Alberta. Further 
study is required to examine the life history of the diamondback moth in Ontario and western Canada due to the significant change in agricultural landscapes.

Observations of diamondback overwintering in north temperate North America have been sporadic and tend to be associated with milder average temperatures and rapidly warming spring temperatures. By considering the results of overwintering studies conducted from 1953 to 1993 between $42.41^{\circ} \mathrm{N}$ and $45.38^{\circ} \mathrm{N}$, the overwintering limit for diamondback moth in eastern North America is $\approx 43{ }^{\circ} \mathrm{N}$. However, the northern limit of diamondback moth in more central regions could exist at much higher latitudes due to a continental climate. In addition, climate change has likely affected the seasonality of these climatic regions that may result in the limit being further north at present day. This could lead to earlier incidences of diamondback moth infestation with the potential for pesticide-resistant populations establishing from previous years.

Despite the potential for diamondback moth to overwinter in southeastern regions of Canada, northern migration in the spring from southern climates is still the major contributing factor of diamondback moth populations in Canada, as demonstrated by Dosdall et al. (2001), Hopkinson and Soroka (2010), and to a certain extent by Smith and Sears (1982). Air trajectory models can accurately predict incoming populations of diamondback moth, with several studies demonstrating that the diamondback moth can travel distances up to $3000 \mathrm{~km}$ (Chu, 1986; Talekar and Shelton, 1993; Chapman et al., 2002; Coulson et al., 2002). Unfortunately, extensive regional scale molecular genetic work on the diamondback moth has been conducted only in Asia and Australia (Endersby et al., 2006; Wei et al., 2013; Kim et al., 2015; Yang et al., 2015) and has yet to be done on a similar scale in North America. Studies that have examined variation and gene flow among populations between continents or countries use North American samples from select regions (Capriol and Tabashnik, 1992; Chang et al., 1997; Roux et al., 2007; Juric et al., 2017). Unfortunately, samples were derived 
from one population representing each country or continent and may not provide the best representation of the variation found in diamondback moth populations in North America. Refining molecular genetic techniques and sampling to differentiate diamondback moth populations in a meaningful way is critical. Molecular tools could resolve the original source populations of migrants from southern regions of North America, which is essential to future management of this pest species. In addition, the ability to discriminate between regional and migrant populations in the field can aid in determining whether populations have overwintered.

\subsection{Future directions}

In future studies, recording parameters such as duration of snow cover, temperature under the snow, and extreme temperature events would provide better indicators of diamondback moth overwintering potential. Although these types of data are not available from the past studies and across all study sites, there appears to be a detectable trend when observing air temperature and the associated parameters calculated from it such as degree days and the number of days minimum temperatures reach the lower lethal temperature. Management strategies in the future should include the duration and temperature of winters as part of their pest monitoring programmes.

For overwintering experiments, the most important factor determining successful overwintering and initiation of the subsequent spring generation is the viability of the insect. This is usually reported as successful hatching, eclosion and, more critically, the ability of adult females to lay eggs that are themselves viable. Future cold tolerance studies should be cautious in how they report physiological survivorship and should distinguish between cold-period durations allowing viability to be maintained and durations in which viability is no longer possible. In addition, winter conditions can permit brassicaceous plant material to be suitable feeding material for larvae; 
however, early spring carbohydrate sources for overwintering adults in the field are more of a challenge, although early flowering volunteer canola may provide such a source. Measures of survivorship in the laboratory and field must consider energy provisions available to adults in the wild to be applicable to real-world scenarios.

Physiological changes and phenotypic responses to seasonal cues in the diamondback moth must also be explored via investigations on the direct effects of photoperiod, dehydration/desiccation, low temperature energetics/metabolism, low temperature oxygen consumption, location of intracellular ice formation, upper and lower limits of cold injury, identification of antifreeze proteins, role of ice-nucleating bacteria, and more in-depth assessments of developmental plasticity of generations leading into winter. In addition, there is no consensus on the lower developmental threshold for the diamondback moth. The lower developmental threshold was extrapolated from data taken at higher temperatures (Umeya and Yamada, 1973; Butts and McEwen, 1981; Golizadeh et al., 2007) resulting in different values between studies. However, Butts (1979) and Liu et al. (2002) have shown development continues to occur below these estimated thresholds indicating the reported values are likely inaccurate. Future work should reassess the lower developmental threshold using a physiological approach directly at these lower temperatures. The expression of additional heat shock proteins during and after cold temperature exposures and including the induction of rapid cold hardening in the diamondback moth should also be examined. This would aid in differentiating heat shock proteins that are involved in a thermotolerance role, which is critical to determining cold temperature survival and subsequent ability to recover from potential chill injury. Equally important is the comparison of responses to potential overwintering cues between tropical and temperate populations of diamondback moth. Gene flow and potential for insecticide resistance to proliferate within suspected overwintering populations and migrant populations must also be examined. 
Bioclimatic models can be useful to predict the world distribution, year-round persistence and migration potential of the diamondback moth. These models rely heavily on the parameters listed above and would benefit from additional assessment of these parameters at low temperatures to improve predictive power. A model projecting potential overwintering ranges using cold tolerance data has yet to be developed. Diamondback moth overwintering limits in higher latitudes have been mainly anecdotal. The aid of an overwintering model can predict areas of potential risk and persistence of overwintered populations, and could further inform timing of outbreaks and management action in at-risk areas.

\subsection{Conclusion}

With climate change, it is urgent that we obtain better knowledge on the overwintering ability of the diamondback moth. Climate change has been implicated as the primary driver of poleward range expansion in butterflies (Parmesan, 2001) and Heteropteran species (Musolin, 2007). A barrier that insects must overcome in the context of range expansion due to climate change is the asynchrony in timing of seasonal development and overwintering (Musolin, 2007; Bale and Hayward, 2010). As presented in this review, the diamondback moth is multivoltine, with the number of annual generations determined by food availability and the length of the growing season. It is potentially chill susceptible with the ability for rapid cold hardening to increase cold tolerance. The diamondback moth likely overwinters in quiescence in no specific stage, with the adult stage being the most capable of surviving short and mild winter seasons. With the aid of new genetic tools, and rigorous temperature data and tracking models, the set of parameters necessary for diamondback moth overwintering may not remain elusive for much longer. 
Table 2.1: The longest reported number of days that various life stages of diamondback moth, Plutella xylostella, survived at $5{ }^{\circ} \mathrm{C}, 0{ }^{\circ} \mathrm{C}$, and $-5{ }^{\circ} \mathrm{C}$, including lowest reported supercooling temperature for each life stage and lower lethal temperature.

\begin{tabular}{lcccc}
\hline & Egg & Larvae & Pupae & Adult \\
\hline Cold temperature survival & & & & \\
$5{ }^{\circ} \mathrm{C}$ & $\leq 55(1)$ & $\leq 40(4)$ & $\leq 56(6)$ & $\leq 66(3)$ \\
$0{ }^{\circ} \mathrm{C}$ & $\leq 50(2)$ & $\leq 80(5)$ & $\geq 80(5)$ & $\geq 70(5)$ \\
$-5{ }^{\circ} \mathrm{C}$ & $\leq 23(3)$ & $\geq 19(7)$ & $\geq 19(7)$ & $\geq 20(4)$ \\
Supercooling Point & & & & \\
& $-15.8{ }^{\circ} \mathrm{C}(8)$ & $-20.6{ }^{\circ} \mathrm{C}(9)$ & $-23.2{ }^{\circ} \mathrm{C}(10)$ & $-22.4{ }^{\circ} \mathrm{C}(10)$ \\
Lower Lethal Temperature & & & & \\
& $\mathrm{NA}$ & $\mathrm{NA}$ & $\mathrm{NA}$ & $-20{ }^{\circ} \mathrm{C}(11)$ \\
\hline
\end{tabular}

References: (1) Liu et al. (2002); (2) Honda (1992); (3) Saito (1994b); (4) Gu (2009); (5) Kimura and Fujimura (1988); (6) Smith and Sears (1982); (7) Kim et al. (2014); (8) Supplementary material for Park and Kim (2014); (9) Hayakawa et al. (1988); (10) Kaneko (1995); (11) Nguyen et al. (2014). 


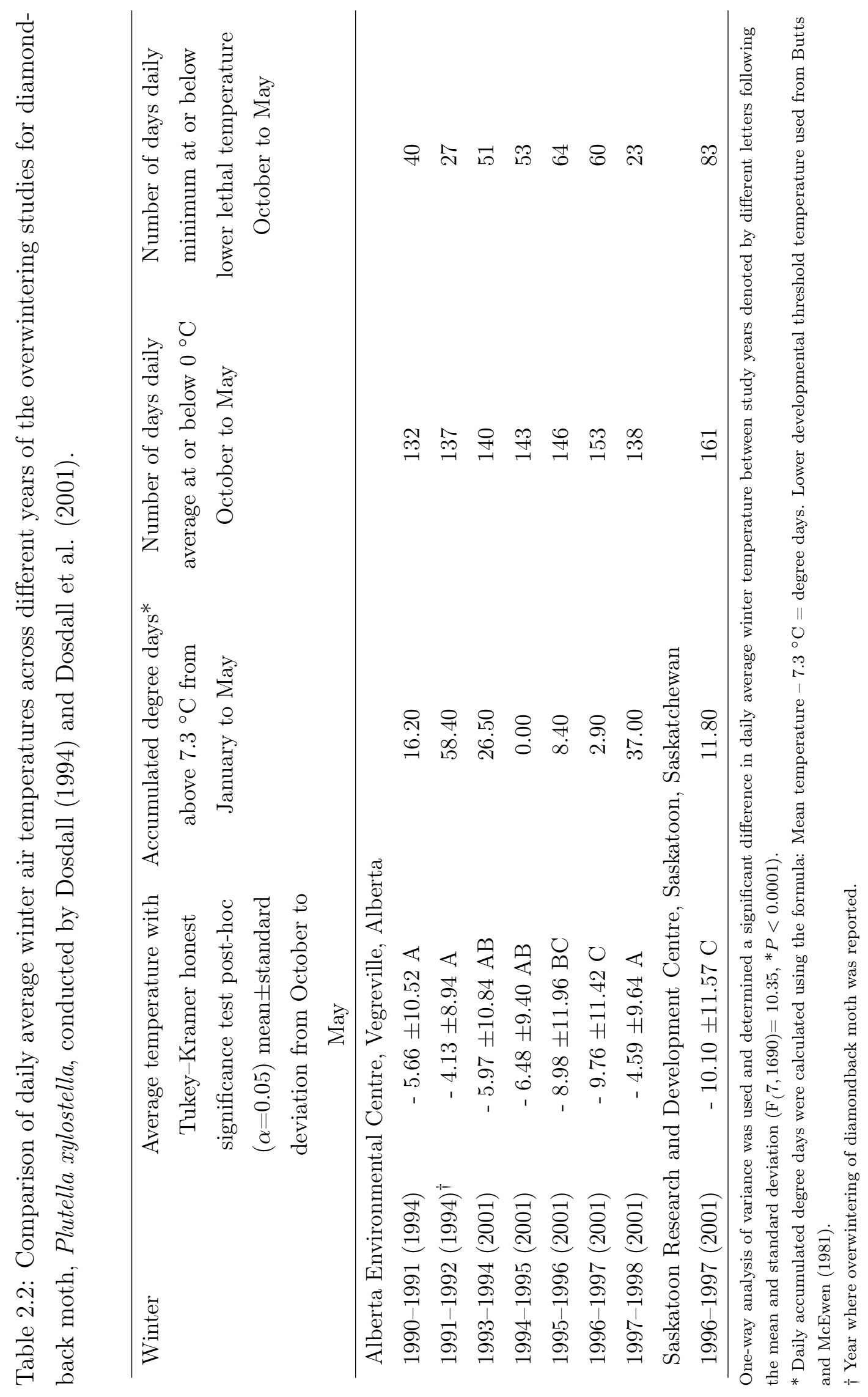




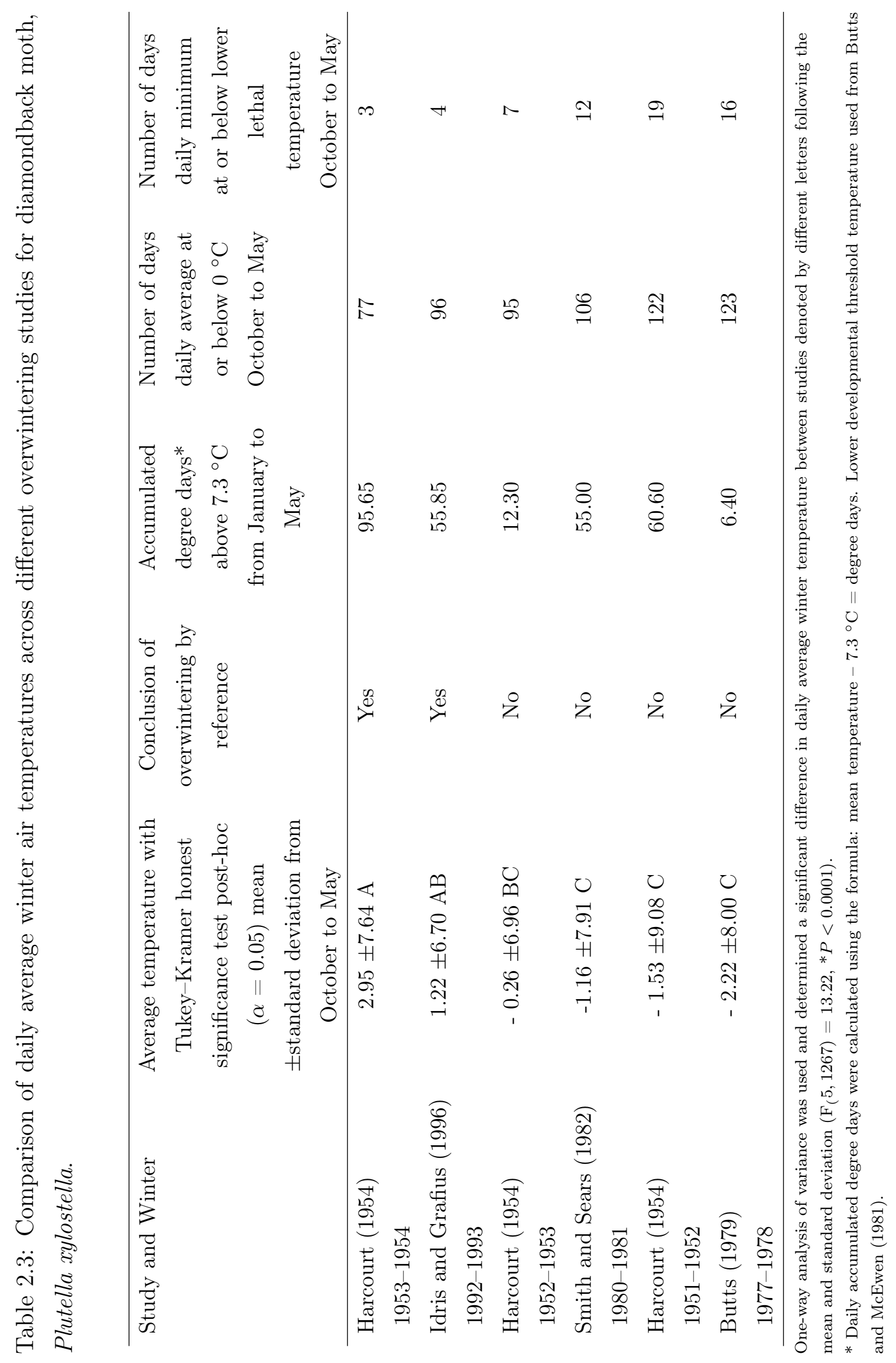




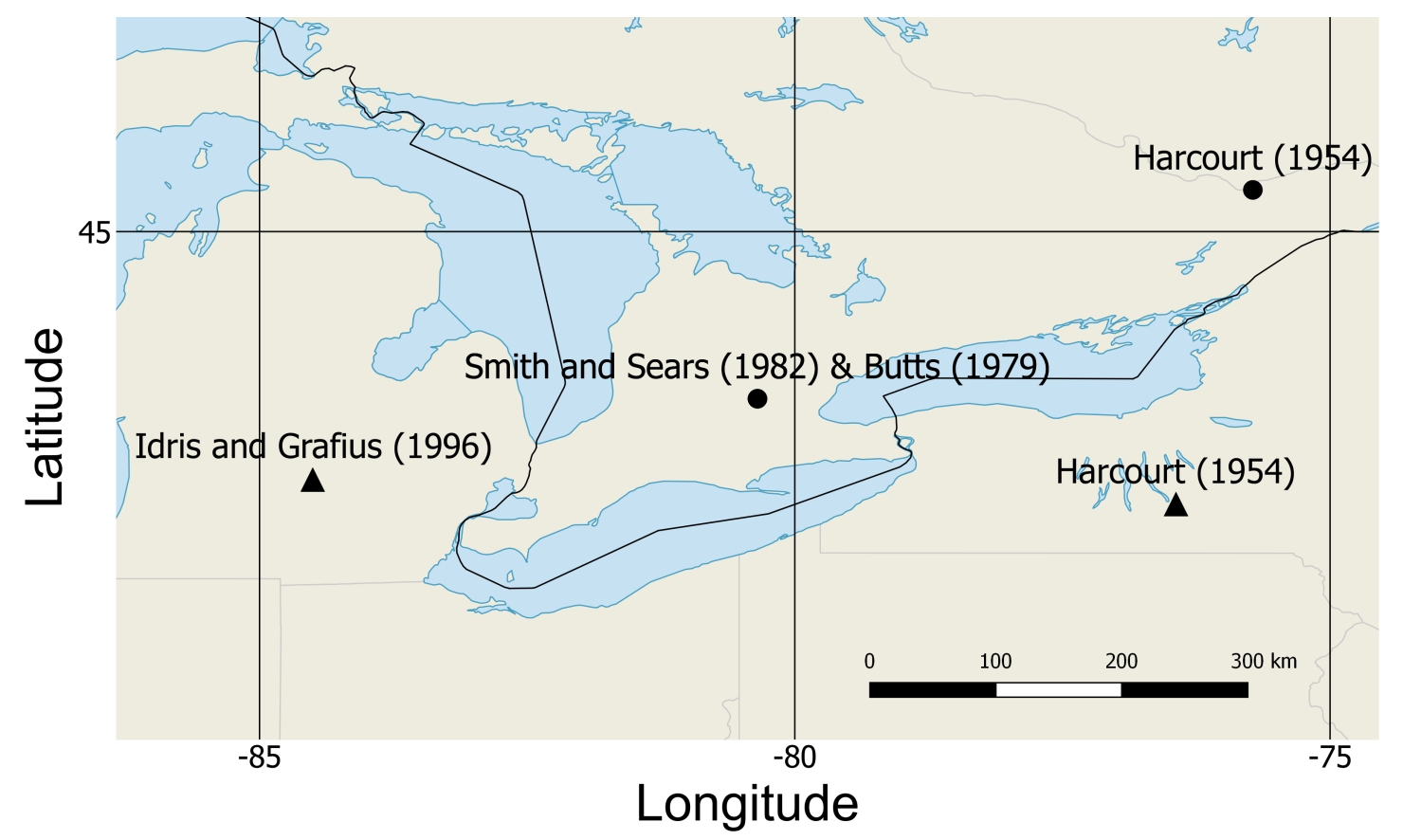

Figure 2.1: Locations of key diamondback moth, Plutella xylostella, overwintering studies in southeastern Canada and the northeastern United States of America. Symbols indicate status of overwintering as reported by respective authors; $\boldsymbol{\Lambda}=$ evidence for successful diamondback moth overwintering; $\mathbf{0}$ = little to no evidence of diamondback moth overwintering. Butts (1979) and Smith and Sears (1982): Cambridge Research Station, Cambridge, Ontario $\left(43.4^{\circ} \mathrm{N}, 80.3^{\circ} \mathrm{W}\right)$. Harcourt (1954): Liddell Field Station, Ithaca, New York $\left(42.5^{\circ} \mathrm{N}, 76.4^{\circ} \mathrm{W}\right)$ and Merivale Research Station, Ottawa, Ontario $\left(45.4^{\circ} \mathrm{N}, 75.7^{\circ} \mathrm{W}\right)$. Idris and Grafius (1996): Michigan State University Collins Road Entomology Research Farm, Lansing, Michigan $\left(42.7^{\circ} \mathrm{N}, 84.5\right.$ ${ }^{\circ} \mathrm{W}$ ). The map was generated in QGIS v 2.18 (Quantum GIS Development Team 2017) using Natural Earth map data set. 


\section{Chapter 3}

\section{Something old, something new: revisiting the diamondback moth life table after 65 years}

\subsection{Abstract}

Nearly 65 years ago, D.G. Harcourt developed the first comprehensive life table of the diamondback moth, Plutella xylostella, on the Central Experimental Farm (CEF) in Ottawa, Ontario, Canada. This work is continually cited when authors discuss the life history of the diamondback moth and its parasitoids in Canada. Since Harcourt's study, the techniques used in life tables and their analysis have changed. We also know a great deal more about the ecology and biology of the diamondback moth. Furthermore, since the original life table study, climate change, urbanization and crop diversity may have altered the population dynamics of both the diamondback moth and its natural enemy community. To follow up on Harcourt's work, we developed a contemporary life table for the diamondback moth. We used two approaches to build life tables to describe mortality factors in the field and the natural enemies attacking diamondback moth in Ottawa. After 65 years, the primary parasitoids attacking diamondback moth remain the same. Total mortality and parasitism levels also remain similar. Notably, parasitoid composition between the two life table techniques differed. Overall, diamondback moth population dynamics remained similar after 65 years. 


\subsection{Introduction}

The diamondback moth Plutella xylostella (Linnaeus) (Lepidoptera: Plutellidae) is a global pest of Brassica spp. (Brassicaceae) crops. In North America, the first report of diamondback moth was in 1854 (Harcourt, 1954). Diamondback moth has since become a major pest in Western Canada mainly attacking canola, Brassica napus (Linnaeus) and B. rapa (Linnaeus) (Brassicaceae), commercial oilseed crops developed in the 1970s (Slinkard and Knott, 1995). Canola is a large part of the Canadian economy, contributing an estimated $\$ 26.7$ billion dollars annually (Canola Council of Canada, 2016). The main growing regions are the prairie provinces, where $98 \%$ of Canada's canola is grown (Statistics Canada, 2017). In Eastern Canada, diamondback moth is an occasional pest of brassicaceous vegetable crops, although canola acreage is increasing in these areas. The vulnerability to large outbreaks on this relatively new crop type in Canada provides renewed interest in revisiting the biology of the diamondback moth.

A factor that may influence the significance of diamondback moth in the future is climate change, which has the potential to increase the frequency and severity of diamondback moth outbreaks (Dosdall et al., 2006). In the Ottawa area, diamondback moth is likely a seasonal migrant with no evidence of overwintering to date (Harcourt, 1954, 1963; Dancau et al., 2018). It arrives in early spring, and has overlapping generations based on host plant availability and seasonal temperatures. There are approximately 4-6 generations in Ottawa (Harcourt, 1954; Harcourt and Cass, 1966).

From 1951 to 1970, extensive research was conducted into the biology and population dynamics of diamondback moth on the Central Experimental Farm (CEF) in Ottawa, Ontario, Canada (Harcourt, 1954, 1957, 1960b,a, 1963, 1986). Outcomes of this research have been widely cited in publications on the dynamics and management of diamondback moth (e.g., Sarfraz et al. 2005; Nedorezov et al. 2008; Dosdall and Mason 2010). However, to inform contemporary decision making on control ini- 
tiatives, such as the potential release of exotic biological control agents, data from past studies may not represent the population dynamics of this species in the modern world.

The global average temperature has been increasing steadily since the time of Harcourt's study in the 1950's (Hansen et al., 2010; Rahmstorf et al., 2017). Increasing average temperatures and extreme seasonality have been predicted to cause poleward expansion and changes in the ranges of pests and their natural enemies (Hance et al., 2007; Macfadyen et al., 2018; Olfert et al., 2016). Changes in efficacy of biological control agents may occur due to phenological mismatches (Meineke et al., 2014; Wu et al., 2016). For example, diamondback moth was found to tolerate higher temperatures than the larval parasitoids Diadegma insulare (Cresson) (Hymenoptera: Ichneumonidae) (Bahar et al., 2012) and Cotesia vestalis (Haliday) (Hymenoptera: Braconidae) (Machekano et al., 2017) in laboratory experiments. In addition, increases in average temperature can potentially cause a shift in host-parasitoid interactions for diamondback moth resulting in reduced biological control by the larval parasitoid Diadegma semiclausum (Hellén) (Hymenoptera: Ichneumonidae) by the year 2070 (Furlong and Zalucki, 2017).

Between 1954 and 1958, after Harcourt's original study, the urban sprawl in the Ottawa area began expanding into the western and southern borders of the CEF which had previously been farmland (MacOdrum Library Aerial Photographs, 1958; University of Toronto Map and Data Library, 1954). Increasing urbanization in the areas surrounding the CEF could have influenced the persistence of natural enemies through habitat fragmentation, urban heat-island effects and increased pollution (McIntyre, 2000; Gagné and Fahrig, 2010). Additional stresses caused by urbanization on host plants have the potential to benefit herbivorous pests (Dale and Frank, 2014; Gibb and Hochuli, 2002) or disrupt trophic interactions (Christie et al., 2010; Fenoglio et al., 2013; Nelson and Forbes, 2014). 
Because these changes in temperature, land use and crop type over the past 65 years have potentially altered diamondback moth population dynamics, our goal was to gather new baseline data on diamondback moth and its natural enemies to inform future control strategies. We did this using a life table approach, with two different methods of building life tables. A life table of diamondback moth is indispensable in integrated pest management, since it describes population-level impacts of mortality factors in the field, with emphasis on mortality caused by parasitoids.

Our objective was to describe these population-level impacts and to describe the present day parasitoid complex in the Ottawa area by generating contemporary life tables. Life tables are rarely revisited, with the exception of those involving human epidemiology or occupational safety (e.g. Jaddoe et al. 2010; Roscoe 1997; Ruder et al. 2006). They are also rarely revisited in conservation biology, due to the difficulty of obtaining new data in the field. Follow-up on life tables of threatened species is often undertaken using population modelling approaches (e.g. Cortés 2002; Heppell 1998; Wisdom et al. 2000). A contemporary life table study on the CEF represents a unique opportunity where a historical ecological study with extensive monitoring is revisited at the same site at present day.

The data we obtained were qualitatively compared to those in various publications by Harcourt $(1954,1957,1960 a, 1963,1986)$ to interpret changes that may have occurred over 65 years. As well, comparison of new and old life table techniques can be made. The study objectives were: 1) to interpret temperature data to assess overwintering potential of diamondback moth in the Ottawa area; 2) describe the population dynamics of the diamondback moth through a static life table method and an abridged life table; and 3) describe the natural enemy community associated with diamondback moth. 


\subsection{Materials and Methods}

\subsubsection{Field site}

The life table study was conducted on the CEF ( $\left.45^{\circ} 23^{\prime \prime} \mathrm{N}, 75^{\circ} 43^{\prime \prime} \mathrm{W}\right)$ from 2016 2017. The experimental plot was $10 \mathrm{~m}$ x $10 \mathrm{~m}$ in size and was tilled prior to planting. Cabbage seedlings, Brassica oleracea (Linnaeus) var. Adaptor (Brassicaceae) were planted in May of each year, with plants spaced every $0.5 \mathrm{~m}$ in rows $1 \mathrm{~m}$ apart (Harcourt, 1954) to accommodate 200 plants. For the life table, 20 spots were randomly selected and left unplanted to contain experimental plants within the plot. A buffer zone, consisting of 44 plants were planted one meter from the plot edge and one meter apart. Plants were watered accordingly based on seasonal temperatures and rainfall. No chemical intervention was used, all plot maintenance was done manually. The crop surrounding the experimental plot was barley (Hordeum vulgare (Linnaeus) (Poaceae)) in 2016 and soybean (Glycine max (Linnaeus) (Fabaceae)) in 2017. Experimental plots of canola, as well as volunteer canola plants, were present nearby.

\subsubsection{Overwintering potential}

To determine the potential for diamondback overwintering in the cabbage plot over the winter of 2016-2017, temperature above ground was taken with an air temperature and humidity logger (Onset HOBO U23) located $1.5 \mathrm{~m}$ above the ground surface contained in a solar radiation shield. Ground level temperature was recorded using a soil probe (Tinytag TGP-4017) buried one centimeter below ground, with the sensor at surface level. Snow depth data were retrieved from the National Climate Data and Information Archive (Environment and Climate Change Canada (ECCC)) from the weather station located on the CEF (Ottawa CDA RCS, World Meteorological Organization Identifier: 71063). 


\subsubsection{Abridged life table}

An abridged life table is a modern technique for describing mortality factors experienced by organisms in the field. This approach integrates a mark-recapture technique to control numbers of individuals entering a particular life stage and narrows down the occurrence of mortality by stage over a complete cohort life table (Carey, 1993, 2001). Field mortality data were applied to a synthetic cohort by year with a starting population of 1000 eggs (Carey, 1993).

Four discrete life stages were exposed in 2016: egg (E), first larval instar (L1), second to fourth larval instar combined (L2/L3/L4), and pupa (P). In 2017 five discrete life stages were exposed by separating the fourth larval instar (L4) as a discrete stage and combining the second and third larval instars into one stage. Insects were exposed on 3-6 week old plants (5-8 true leaves) for easier handling and host acceptance (Moreira et al., 2016). To ensure sufficient numbers for analysis, data were pooled over multiple runs consisting of two runs (July-August) in 2016 and four runs (May-August) in 2017.

The multiple abiotic and biotic mortality factors involved at each stage of the diamondback moth life cycle can be analyzed using a multiple decrement life table, where individuals can die from multiple mutually exclusive mortality factors (Carey, 1993). Pooling data for a multivoltine species can limit the ability to discern seasonality of mortality factors and potential density-dependent effects. However, our approach was to explain the contribution of each mortality factor using the data available as a general overview of the population dynamics of the diamondback moth in the Ottawa area.

3.3.3.1 Insect rearing The insects used for the abridged life table were sourced from a laboratory colony maintained at the CEF. The colony was founded in 2000 from a local wild population. To maintain genetic diversity, adults caught in the field 
were introduced into the rearing population annually. Insects were reared on canola until May, 2016 when the host plant was changed to cabbage prior to commencing the life table study to align with the methods of Harcourt (1954). Insects were reared at $22 \pm 1{ }^{\circ} \mathrm{C}$ degrees at $60 \% \mathrm{RH}$, with $16 \mathrm{~h}$ light. Adult moths were sustained with a $10 \%$ honey-sucrose solution.

3.3.3.2 Egg An oviposition cage was created using a tall insect rearing cage (BugDorm-4F3074, Megaview Science Co. Ltd.) modified with additional sleeved entry holes (Figure 3.2). One individual leaf from each experimental plant was placed through the entry hole to the inside of the cage and the sleeve was tied off. Adult moths were introduced into the cage along with sucrose and left overnight for oviposition. The following day the leaves were removed through the sleeve. The eggs were counted using a microscope light source and magnifying visors. The average number per plant was $288 \pm 28.14$ eggs (mean $\pm \mathrm{SE})(N=60)$.

3.3.3.3 First instar Plants were exposed to adult moths using the same oviposition cages as for the egg stage (3.3.3.2). Eggs were left in the laboratory at ambient temperature and relative humidity until hatching. First larval instars were counted using a microscope light source and magnifying visors. Unhatched eggs were removed with a paintbrush. The average number per plant was $75 \pm 8.0$ larvae $(N=60)$.

3.3.3.4 Second to fourth instar In 2016, 20 plants were each infested with 30 second instar larvae before being transferred to the field plot, where they were left until they had reached fourth instar. In 2017, 20 plants with 30 second instars were left in the plots until they had reached third instar. A second set of 20 plants each infested with 20 fourth instars was transferred to the plot and left until the larvae had transformed into pre-pupae. 
3.3.3.5 Pupa Plants were artificially infested with 20 late fourth instars and left in a laboratory setting at ambient temperature and relative humidity overnight until pupation. Larvae that did not pupate were removed from the plants prior to counting. Average number per plant was $17 \pm 0.52$ pupae $(N=60)$.

3.3.3.6 Estimates of diamondback moth fecundity Pupae from one cohort of the laboratory colony were kept individually in small petri plates until adult emergence. The adult moths were sexed and the females were placed singly in a container with two males, sucrose and a clean cabbage leaf disk and kept in laboratory conditions $\left(22 \pm 1{ }^{\circ} \mathrm{C}\right.$ degrees at $60 \% \mathrm{RH}, 16 \mathrm{~h}$ light). Leaf discs were changed daily until the female was no longer fecund or had died. Eggs oviposited on the leaf discs were counted to calculate average fecundity for the females in the laboratory population and used in the subsequent life table analyses.

3.3.3.7 Treatments and experimental procedure Plants were randomly assigned to one of two treatments, control (caged) or full exposure (uncaged). Cages were constructed using a $45.72 \mathrm{~cm}$ diameter tomato cage fitted with an insect rearing bag (DC3148, Megaview Science Co. Ltd.) similar to the total exclusion cage used by Furlong et al. (2004b) (Figure 3.1). Plants in the control treatment were placed into the cages using a zipper on the side of the bag, with the sleeve end securely tied off. Plants were placed in randomly assigned unplanted experimental locations in the plot regardless of treatment. The experimental plants were partially buried up to the pot rim in a shallow hole. Plants were left in the field until insect individuals were transitioning into the next life stage. This exposure period was determined using temperature data from the air temperature logger in the experimental plot and a modified degree day model for the diamondback moth (Butts and McEwen, 1981). Plants were processed in the lab where all remaining individuals were counted and moved into rearing containers to assess parasitism levels and additional mortality. 


\subsubsection{Construction of the life tables and assessment of mortality factors}

Due to the change in number of discrete life stages exposed, data from 2016 and 2017 were analyzed separately. All life tables began with a hypothetical cohort of 1000 eggs. The values for specific mortality factors were calculated indirectly from field data. In most life table studies, a large number of individuals are killed by unknown mortality factors or simply disappear. Rainfall is a notable source of mortality for late-instars (Harcourt, 1954). In 2016, we attempted to measure mortality due to rainfall by adding a rain shelter treatment consisting of a $62 \mathrm{~cm} \mathrm{x} 62 \mathrm{~cm}$ transparent corrugated plastic sheet on wooden stakes; however, this treatment failed to reveal differences in mortality compared to treatments with no shelters (median percent recovery, shelter exposed: $43.75, \mathrm{IQR}=65.76$, exposed: $60, \mathrm{IQR}=62.14, N=$ 160, $P<0.33$, Mann-Whitney-Wilcoxon rank sum test). Data from the rain shelter treatment were excluded from further analyses and the treatment was discontinued in 2017. Therefore, mortality by rain is included in abioitic and unknown mortality (temperature, rain, wind, exposure, non-emergence, pathogens and mortality that cannot be accounted for between the control and exposed treatments) in the life table.

To avoid underestimating the impact of parasitism, we used a correction calculation which accounts for a combination of potential non-reproductive parasitoid induced mortality and density-dependence between the number of individuals exposed and recovered (Abbott 1925; Bellows and Fisher 1999, Haye et al. unpublished) (Equation 1):

$$
\left(\text { Parasitism }=\left(\left(N_{\text {Parasitoid }} / N_{\text {Moth }+ \text { Parasitoid }}\right) N_{\text {Recovered }}\right) / N_{\text {Total }} * 100 \%\right)
$$

where $\mathrm{N}$ equals the number of individuals. The predation mortality factor was calculated by subtracting background mortality experienced in the control samples from mortality attributed to individuals that were not recovered in the exposed treatments.

The abiotic and unknown mortality factor was calculated by adding the background 
mortality experienced in the control treatments to mortality of individuals that died after being recovered from the field in the exposed treatments and subtracting the difference between the corrected parasitism rate and the directly calculated parasitism rate. Infertility was a term given to eggs recovered from the exposed treatment that appeared viable upon recovery but did not hatch. This was calculated directly as a percent of all individuals that were exposed. Total mortality of each stage was a summation of the percent mortality from these factors combined.

Mortality factors were then expressed as apparent mortality, killing power $(k$ values) and generational mortality as defined in Bellows et al. (1992). Apparent mortality by stage $\left(q_{s}\right)$ is the proportion of individuals entering the stage $\left(l_{x}\right)$ that die in the same stage $\left(d_{s}\right)$ calculated as $q_{s}=d_{s} / l_{x}$. Apparent mortality by factor $\left(q_{x}\right)$ is the proportion of individuals from the beginning of the stage $\left(l_{x}\right)$ that die by each mortality factor $\left(d_{x}\right)$ calculated as $q_{x}=d_{x} / l_{x}$. Killing power $\left(k_{x}\right)$ is an index of mortality independent from numbers in a population $\left(m_{x}=1-\left(\left(1-q_{s}\right)^{\left(q_{x} / q_{s}\right)}\right)\right.$ calculated as $k_{x}=-\log \left(1-m_{x}\right)$. The $k$-value of each factor is shown as a proportion of generational mortality $\left(K_{G}\right)$. Population dynamics of the diamondback moth were reported using the net reproductive rate $\left(R_{0}\right)$ as an indicator of whether a population is growing $\left(R_{0}>1\right)$ or declining $\left(R_{0}<1\right)$ (Van Driesche et al., 2008) calculated by dividing potential F1 progeny at the end of the generation by the number of individuals at the beginning of the generation. Potential F1 progeny was calculated using a 1:1 sex ratio (Harcourt, 1957) and the estimation of female fecundity was obtained from the laboratory colony (Section 3.3.3.6).

\subsubsection{Static life table}

A static life table was the method employed by (Harcourt, 1954) where destructive sampling was used as a cross-sectional examination of different cohorts and stages of development at a single time point in the field. This method was used in the current 
study to facilitate comparisons with Harcourt (1954). Destructive sampling was conducted on mature cabbage plants that were planted inside the plot and separate from the abridged life table. Sampling was done in July and late August of both years to examine natural infestation rates of diamondback moth and to evaluate parasitism in a crop setting. For each sampling period $\approx 70$ plants were randomly harvested and destructively processed. Sampled plants were replaced in the plot by replanting with cabbage seedlings grown in the greenhouse. Number of individuals in each life stage was recorded for each plant sample. The various stages of diamondback moth recovered from these samples were kept in rearing containers and maintained in laboratory conditions $\left(22 \pm 1{ }^{\circ} \mathrm{C}\right.$ degrees at $60 \% \mathrm{RH}, 16 \mathrm{~h}$ light $)$ to assess parasitism levels. To confirm the presence of natural populations inside the plot, two delta traps (Cooper Mill Ltd.) were set up on the north and south side of the plot. Direction was determined by placing the openings of the traps to face plots of canola and other Brassica. Traps were lined with a sticky card, and a diamondback moth pheromone lure (Cooper Mill Ltd.) was suspended in the center of the trap. The liner was changed weekly and the lure changed every two weeks. Traps were established on 11 May, 2016 and 5 April, 2017 and taken down at first snowfall: 23 November, 2016 and 19 November, 2017, respectively.

\subsubsection{Natural enemies}

Parasitoids that emerged from field-collected diamondback moth individuals placed in rearing were immediately aspirated and stored in $70 \%$ ethanol. Expert identification of parasitoids was provided by taxonomists at the Canadian National Collection of Insects, Arachnids and Nematodes in Ottawa, Ontario, Canada.

Pitfall traps were set up to gauge the ground predators inside the experimental plot, which may identify species responsible for predation mortality. Pitfall traps consisted of buried plastic cups $(12 \mathrm{~cm}$ height, $9.5 \mathrm{~cm}$ diameter top, $6 \mathrm{~cm}$ diameter 
bottom) buried in the soil with the rim at ground level. Each trap was filled with $150 \mathrm{~mL}$ of ethylene glycol and protected with a wooden cover raised $\approx 10 \mathrm{~cm}$ off the ground by nails. In 2016, there was a total of 12 pitfall traps set up in three groups of four in a square formation at 4, 8 and 10 meters from the center of the plot. In 2017, a total of 8 pitfall traps were set up in the experimental plot in a square formation at 4 and 8 meters from the center of the plot. The traps were set out twice throughout the season in both years (July and August), exposed for one week in 2016 and for two weeks during 2017. The traps were collected and their contents stored in $95 \%$ ethanol. Specimens were identified with numbers of each species recorded (Table 3.4).

\subsection{Results}

During the study, average summer temperature in 2016 was $16.5 \pm 8.0^{\circ} \mathrm{C}$ and in 2017 was $15.7 \pm 6.0{ }^{\circ} \mathrm{C}$. Total precipitation was $277 \mathrm{~mm}$ in 2016 and $573 \mathrm{~mm}$ in 2017 (ECCC) (Figure 3.3). The Canadian Drought Monitor program (Agriculture

and Agri-Food Canada) had Ottawa under severe drought conditions in 2016 (Figure A2). In contrast, no drought warnings were issued for the summer of 2017, which was instead characterized by wide-spread flooding as a result of spring melt and overall high precipitation.

\subsubsection{Overwintering potential}

Winter temperature data were summarized similar to those in Chapter 2. There were 141 days of snow cover where average daily temperature under the snow from 26 November, 2016 to 1 April, 2017 was $0.01 \pm 1.03{ }^{\circ} \mathrm{C}$. The average daily air temperature from October 2016 to May 2017 was $-0.22 \pm 8.23{ }^{\circ} \mathrm{C}$ with 101 days where the average temperature was at or below $0{ }^{\circ} \mathrm{C}$ and 4 days where the daily minimum was at or below the lower lethal temperature for diamondback moth adults $\left(-20{ }^{\circ} \mathrm{C}\right)($ Nguyen et al., 2014) (Figure 3.5). 


\subsubsection{Abridged life table}

The mean average lifetime fecundity of female diamondback moth from the laboratory colony was $255 \pm 25$ eggs $(N=9)$. This was used as the potential fecundity for female moths in constructing the abridged life tables for each study year.

Recovery of diamondback moth was significantly different between fully exposed and caged plant treatments (Kruskal-Wallis $H=118.4,1$ d.f., $P<0.0001$ ). Mortality at the egg stage was high and mainly due to abiotic and unknown factors in both years, $69.8 \%$ (2016) and $42.9 \%$ (2017) (shown as apparent mortality in Tables 3.1 and 3.2). No egg parastioids were recovered in either year; parasitism noted at the egg stage was likely due to a small portion of individuals developing past the first instar before recovery from the field that were attacked by larval parasitoids.

Major mortality factors for first instars differed between years, with abiotic and unknown factors accounting for $36.6 \%$ of mortality in 2016 and predation accounting for $36.2 \%$ in 2017 (shown as apparent mortality in Table 3.1 and 3.2). Overall mortality for first intars differed, being higher in 2016 (88.6 \%) compared to 2017 $(63.7 \%)$.

In 2016, the major mortality factors for second to fourth instars were abiotic and unknown factors at $54.6 \%$ (Table 3.1) with parasitism by D. insulare being low at $2.9 \%$. In 2017, the major mortality factor for second to third instars was predation at $43.8 \%$ (Table 3.2). Parasitism for the second to third instars was 15.8 $\%$ with parasitoid composition at $79.1 \%$ D. insulare and $18.6 \%$ Microplitis plutellae (Muesbeck) (Hymenoptera: Braconidae). Predation (70.2\%) was the major mortality factor of fourth instars. Parasitism for fourth instars was $8.1 \%$, of which $69.2 \%$ was from D. insulare and $15.3 \%$ from M. plutellae.

For the pupal stage, predation was the major mortality factor in both years at 42.9 $\%$ (2016) and $45.8 \%$ (2017) (Table 3.1 and 3.2). Parasitism of pupae by Diadromus subtilicornis (Gravenhorst) (Hymenoptera: Ichneumonidae) was $10.4 \%$ in 2016, and 
$8.0 \%$ in 2017.

Total mortality for the abridged life tables was $99.96 \%$ in 2016, and $99.97 \%$ in 2017 (Table 3.1 and 3.2). The net reproductive rates $\left(R_{0}\right)$ of 0.054 (2016) and 0.042 (2017) indicate declining populations in both years. In 2016, mortality in the second to fourth instar stage was the largest contributor to generational mortality $(28.1 \%)$, whereas, mortality at the fourth instar stage was the largest contributor to generational mortality in $2017(27.9 \%)$. Combined parasitism of all stages contributed to $11.1 \%$ (2016) and $13.7 \%$ (2017) of generational mortality. Parasitoid species composition was also very similar between years with the dominant species being $\approx 76 \%$ D. insulare followed by $\approx 17 \%$ M. plutellae.

\subsubsection{Static life table}

In 2016, adult moths were already present in the field when the pheromone traps were set up on 11 May and were no longer caught in traps after 4 November. In 2017 traps were setup much earlier, starting on 5 April. One moth was caught during the first week of trapping. Overall, a total of 148 moths (2016) and 247 moths (2017) were caught in the traps. Notably, in 2017, there was a sharp peak in trap catches for the week of 15 May-24 May, where 61 moths were caught (Figure 3.4). Using the pheromone trap data, temperature data and a degree day development model with a developmental threshold of $7.3{ }^{\circ} \mathrm{C}$ and 293 degree day accumulation for completion of a generation (Butts and McEwen, 1981), we estimated there were 4 and 3 generations of diamondback moth in 2016 and 2017, respectively. These findings were validated using the bio-climatic model (DYMEX ${ }^{\circledR}$ ) presented in Dosdall et al. (2006) running 2016 and 2017 seasonal weather data from the National Climate Archive (ECCC) (Figure A3).

For the static life table, a total of 677 diamondback moth individuals were collected in 2016 and only 57 individuals were collected in 2017. Since there were so few 
individuals collected in 2017 the larval stages were pooled into early (L1 \& L2) and late instar (L3 \& L4) stages. The most abundant life stages collected in 2016 were the late instar stages at $45.0 \%$ followed by the pupal stage at $34.7 \%$. In 2017 , the most abundant stage collected was the pupal stage at $54.4 \%$ followed by the late instar stages at $22.8 \%$.

Natural densities of life stages found in the static life table for 2016 were 0.1 egg per plant, 4.26 larvae per plant and 2.3 pupae per plant. For July 2017, there were 0.37 larvae per plant and 0.44 pupae per plant with no eggs recovered. No life stages were recovered in August 2017. The densities of exposed life stages used in the abridged life table could potentially impose density-dependent effects on observed mortality rates, since the number of individuals used in the abridged life tables were much higher than the numbers collected in the static life tables.

In 2017, cumulative percent parasitism was $25.7 \%$ due to the parasitoids $D$. insulare and M. plutellae. Interestingly, in 2016 the corrected parasitism rate was $58.2 \%$ with higher parasitoid species diversity, including hyperparasitoids (Table 3.3) although $D$. insulare and D. subtilicornis were still the most abundant species.

\subsubsection{Natural enemies}

Over the two years of this study ten parasitoid species were associated with diamondback moth in the Ottawa area. Taxonomic names of the parasitoids in Harcourt (1954, 1960a) have been updated to the current valid names. Voucher specimens for this study have been deposited at the Canadian National Collection of Insects, Arachnids and Nematodes in Ottawa, Ontario, Canada.

Parasitoids that were found in common between this study and the studies by Harcourt $(1954,1960$ a) were the larval parasitoids D. insulare and M. plutellae, the pupal parasitoid D. subtilicornis, the larval-pupal parasitoid Oomyzus sokolowskii (Kurdjumov) (Hymenoptera: Eulophidae) and the facultative hyperparasitoid Conura alb- 
ifrons (Walsh) (Hymenoptera: Chalcididae).

Parasitoids reported by Harcourt (1954, 1960a) but not found in this study were Dibrachys microgastri (Bouché) (Hymenoptera: Pteromalidae), Pteromalus phycidis (Ashmead) (Hymenoptera: Pteromalidae), Trichomalopsis viridescens (Walsh) (Hymenoptera: Pteromalidae), Gelis tenellus (Say) (Hymenoptera: Ichneumonidae) and Campoletis sp. (Hymenoptera: Ichneumonidae). These species are mostly generalists. These identifications may no longer be valid based on current species concepts; for example, the genera Gelis and Pteromalus cannot be reliably identified to species at present.

Parasitoids found in this study that were not previously reported on diamondback moth in the Ottawa area were Cotesia spp., Diolcogaster claritibia (Papp) (Hymenoptera: Braconidae), Gelis sp. and Trichomalopsis dubia (Ashmead) (Hymenoptera: Pteromalidae). The Gelis sp. individuals found in this study were wingless females and cannot be identified to species. However, wingless females indicate that these individuals are not G. tenellus (Bennet, personal communication) previously reported by Harcourt $(1954,1960 a)$, which are known to have winged females. Trichomalopsis dubia is a generalist facultative hyperparasitoid; this study is the first to report a host association with diamondback moth or any of its known parasitoids. There were also two distinct Cotesia species recovered. Both require additional resources for expert identification; one is likely Cotesia rubecula (Marshall) (Hymenoptera: Braconidae) and the other is currently unknown.

Pitfall trapping determined that Coleoptera (primarily Carabidae) were the most abundant ground predators in the experimental plot. Other predators were from the orders Opiliones, Araneae, Hymenoptera, Trombidiformes, and Hemiptera, listed from most to least abundant (Table 3.4). The most abundant species of beetles were the native Harpalus pensylvanicus (DeGeer) (Coleoptera: Carabidae) and the adventive Pterostichus melanarius (Illiger) (Coleoptera: Carabidae). The most abundant 
arachnids in the traps were Opiliones. Harcourt (1960a) had previously reported finding predatory mites belonging to the families Erythraeidae and Anystidae. Our study identified mites from the families Anystidae and Parasitidae, which are also predatory.

\subsection{Discussion}

With the passage of several decades since Harcourt's life table studies on diamondback moth (Harcourt, 1954, 1957, 1960b,a, 1963, 1986) there has been considerable urban expansion (University of Toronto Map and Data Library, 1954; MacOdrum Library Aerial Photographs, 1958), changing global climate (Hansen et al., 2010; Rahmstorf et al., 2017) and the introduction of new crop types (Slinkard and Knott, 1995). Despite this, the mortality factors and demography of this important pest of Brassica appear to have remained consistent.

In the summers of 2016 and 2017, predation accounted for a large proportion of generational mortality. The dominant parasitoid attacking diamondback moth was still the larval parasitoid D. insulare. The larval parasitoid M. plutellae and the pupal parasitoid D. subtilicornis were also present, with smaller contributions to total mortality. The total mortality was found to be $99.96 \%$ in 2016 and $99.97 \%$ in 2017. This was similar to that which Harcourt reported in his studies (Harcourt, 1963, 1986). Immigration from southern climates (Dosdall et al., 2001; Hopkinson and Soroka, 2010; Smith and Sears, 1982; Harcourt, 1986) was likely the driver initiating populations in the experimental plot due to winter conditions that were too harsh for diamondback moth overwintering.

Overwintering of diamondback moth during this study was unlikely due to the physiological tolerance of moths under the snow and the extended winter conditions experienced in the Ottawa area during 2016-2017. Furthermore, it is unlikely any stage of diamondback moth could survive 141 days at $0{ }^{\circ} \mathrm{C}$ (Chapter 2). Figure 
3.5 shows that near the beginning of March 2017, spring freeze-thaw cycles likely caused average temperatures under the snow to dip below $0{ }^{\circ} \mathrm{C}$ for the duration of March (average temperature $-1.08 \pm 1.08{ }^{\circ} \mathrm{C}$ ). Sub-zero temperatures following a long period at $0{ }^{\circ} \mathrm{C}$ would be lethal to all stages of diamondback moth. Therefore, the conditions at present day, for the winter of 2016-2017, still support the hypothesis of diamondback moth being incapable of overwintering in the Ottawa area (Harcourt, 1954).

In both years, diamondback moth adults were detected in the field earlier in the spring and later in the fall than reported by Harcourt (1957), where moths typically arrived in May and were no longer detected by October (Figure 3.4). The first pheromone trap catch in the current study occurred during the week of 5 April to 12 April, 2017. Temperatures during the week were below the developmental threshold for diamondback moth $\left(7.3-7.5^{\circ} \mathrm{C}\right)$, which is too cold for flight (Goodwin and Danthanarayana, 1984), with the exception of 10 April, 2017, where the average temperature rose to $14.8^{\circ} \mathrm{C}$, which was warm enough for flight (Goodwin and Danthanarayana, 1984; Shirai, 1993). This is an extremely early record for diamondback moth trap catches in the Ottawa area. This early catch is only rivaled by Smith and Sears (1982) with a catch date of 9 April, 1981 in Cambridge, Ontario located $\approx 430 \mathrm{~km}$ southwest of Ottawa.

Using the early catch date in 2017 and temperature data from the National Climate Data and Information Archive (ECCC), a reverse wind trajectory was generated using the model in Dosdall et al. (2006). The model validated an arrival date of 1011 April, 2017, where the back trajectories at 2500 and 1500 meter above ground traversed the states of Texas, New Mexico and Arizona (United States of America) (Figure A1). These regions are historically believed to be the source of immigrant populations of diamondback moth into Canada (Dosdall et al., 2001; Hopkinson and Soroka, 2010; Dosdall et al., 2006; Harcourt, 1957). Furthermore, the spike in males 
caught in our traps in May 2017 (Figure 3.4) was also likely to be due to immigration, since the number of degree days that had accumulated prior to that date (151.1) was below 293, the minimum number of degree days for development of a complete diamondback moth generation (Butts and McEwen, 1981).

Following the immigration of moths from more southerly parts of the range, we estimate that diamondback moth produced 4 generations in 2016 and 3 in 2017. The pheromone trap counts show peaks that are separated by a degree day accumulation sufficient to allow for the production of a new generation in the field. However, it is not possible to determine the proportion of males in the traps that were locally produced as opposed to immigrants. The low net reproductive rates from the life tables $\left(R_{0}<1\right)$ suggest that the system is immigration-driven. However, there may have been variation in $R_{0}$ over the course of the season that we could not detect with our single composite life table for each year; such variation could have allowed for population growth to occur in situ for some of the generations.

By including a cage treatment that excluded predators while allowing rain to reach the plants, we were able to assess the importance of predation as a mortality factor for diamondback moth. Harcourt (1963) noted that larvae occasionally fell prey to birds, syrphid flies, mites and spiders; however, he disregarded predation as an important source of mortality and did not include it as a factor in his life table analyses. Undoubtedly, the rain mortality factor in his life tables, which was a mortality factor at the larval stage, included some predation (Harcourt, 1963, 1986). Rain and predation may act in concert; when rain knocks larvae off the plants they become available to ground-dwelling predators (Mauduit, 2012). In the present study, predation accounted for $33.26 \%$ and $59.62 \%$ of generational mortality in 2016 and 2017 , respectively, although these figures might be inflated somewhat due to wandering of late-instar larvae, especially in 2017 when mortality of fourth instars was evaluated separately. Pitfall trapping allowed us to identify 10 species of carabid beetles that 
were present in the plots, as well as arachnids, hemipterans and hymenopterans (Table 3.4). The taxonomic groups of predators abundant in our cabbage plot were similar to those observed in Alberta canola fields (Mauduit, 2012), and in cabbage (Furlong et al., 2004b) and broccoli (Hosseini et al., 2006) plots in Australia.

Harcourt constructed his static life tables based on destructive sampling of all diamondback moth life stages on mature cabbage plants throughout the season. In the present study, in addition to this static life table approach, we also constructed an abridged life table, by inoculating cabbage plants in the lab with known numbers of a given life stage and placing these plants in the field for the duration of that life stage. Comparison of the two methods revealed important differences. The abridged life tables identified three dominant parasitoid species in both years: D. insulare, D. subtilicornis and M. plutellae. These parasitoids were the dominant species in Harcourt's $(1954 ; 1960 a)$ studies and are also the main species found on diamondback moth in the provinces of Prince Edward Island (Noronha and Bahar, 2018), Alberta and Saskatchewan (Braun et al., 2004; Dosdall et al., 2011; Bahar et al., 2013a). Sampling for the abridged life table detected only one individual of one other species in 2017, D. claritibia, a larval parasitoid. The static life table, on the other hand, revealed more parasitoid diversity; in addition to the three main parasitoids, D. claritibia and five other larval and pupal parasitoids were present in these samples (Table 3.3), but only in 2016, when diamondback moth was more abundant in the field. Four of the additional species were hyperparasitoids, which may require diamondback moth larvae or pupae that contain primary parasitoids at a specific stage of development. The static life table technique, in which the diamondback moth hosts are exposed for a longer period, may have facilitated the detection of hyperparasitoids and rarer species in the system. Other possibilities include parasitoids being more sensitive to herbivore-induced plant responses produced by younger plants (Mao et al., 2017) or cues produced by cumulative attack of hosts and non-hosts (Bukovinszky et al., 
2012). Crop plants were occasionally infested with Pieris rapae (Linnaeus) (Lepidoptera: Pieridae) and Trichoplusia ni (Hübner) (Lepidoptera: Noctuidae) in the static life table (data not shown) and that of Harcourt (1954). The study by Putnam (1978) showed $M$. plutellae is the only confirmed parasitoid capable of overwintering in Canada. However, parasitoids have also been implicated to migrate along with their adult host (Furlong et al., 2013; Dosdall and Mason, 2010). Since the diamondback moths examined in each life table are from different sources we cannot discount the possibility that colony-reared diamondback moth may not be as attractive to parasitoids as diamondback moth from the field due to potential genetic or behavioural differences.

Although the current study makes comparisons of historical and modern data, the data for this study were collected over two years. This is a relatively small data set compared to the data in the studies by Harcourt (1957, 1954, 1963, 1986, 1960a,b), which span nearly two decades. Population dynamics often fluctuate and the conclusions drawn from our study may not represent the comprehensive dynamics involved in the population at present day. Differing dynamics can be a result of experimental host plant choice, climatically different field seasons between the two years, and seasonally extreme weather patterns that could be a result of climate change. Additional follow up would be beneficial in reinforcing the conclusions in this study.

Comparing the two different methods of conducting life table studies, we found that the abridged life table showed more consistent results between years and in parasitoid composition, whereas the static life table was more capable of detecting hyperparasitoids. Regardless of technique, both life tables showed decreasing or inconsistent populations compared to pheromone trap data. Despite changes in global climate, local urbanization, and crop type, the parasitoid species attacking diamondback moth in Ottawa remains unchanged with D. insulare, D. subtilicornis and $M$. 
plutellae being the main species associated with diamondback moth. Our findings may indicate that the three major parasitoid species attacking diamondback moth are potentially robust to changes over the decades. This will require further examination. Both life table approaches showed high total mortality and would require additional study to tease apart the source components. This study provides insight into a system that appears to remain unaltered after 65 years. These findings could aid management initiatives moving forward for introductions of new exotic biological control agents for diamondback moth in Canada. 


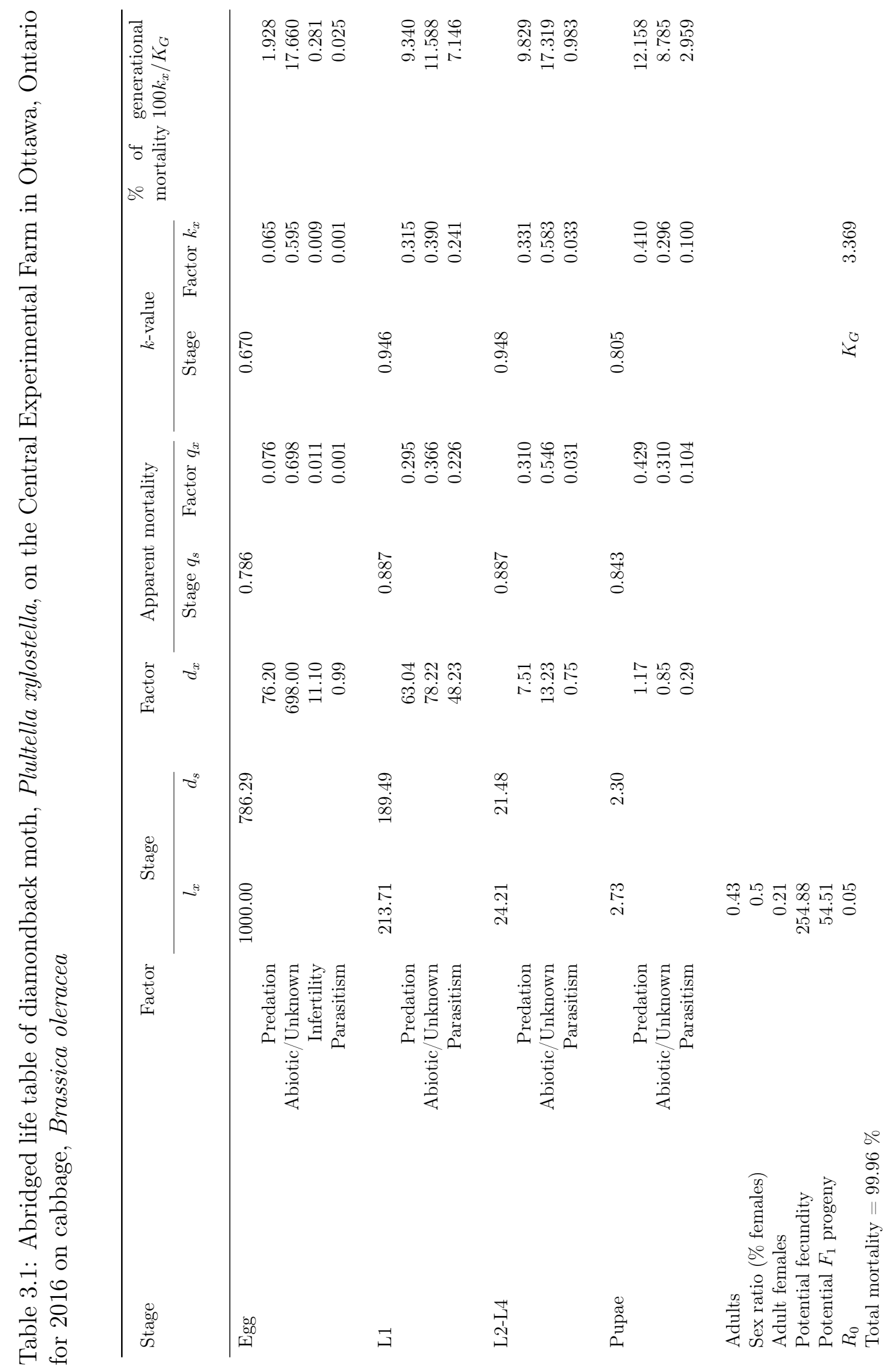




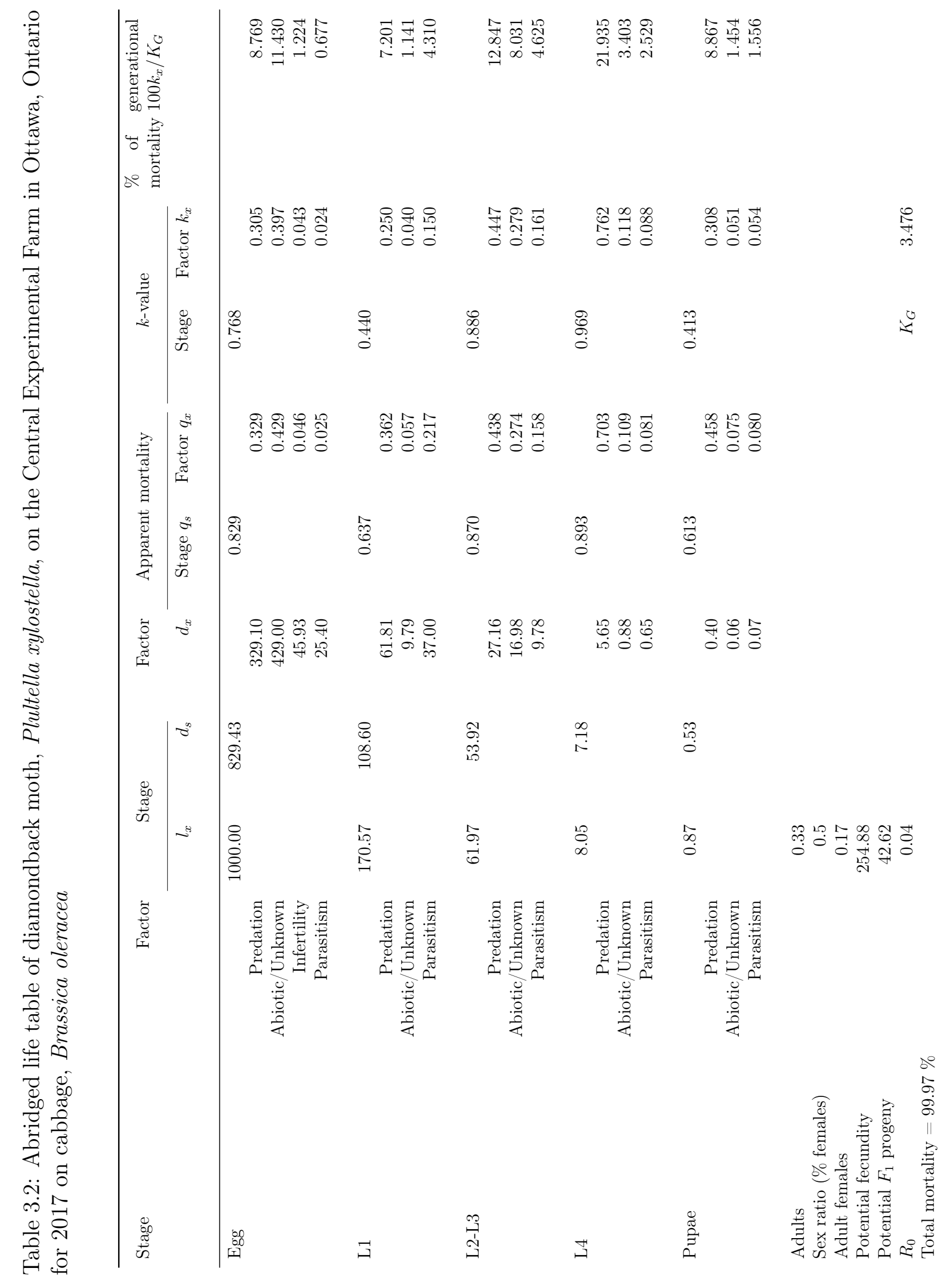


Table 3.3: Cumulative percent parasitism by parasitoids (Hymenoptera) in the abridged and static life tables on diamondback moth, Plutella xylostella, in Ottawa, Ontario. Numbers in brackets are number of parasitoid individuals.

\begin{tabular}{|c|c|c|c|c|c|}
\hline \multirow[t]{2}{*}{ Parasitoid } & \multirow[t]{2}{*}{ Stage } & \multicolumn{2}{|c|}{ Abridged Life table } & \multicolumn{2}{|c|}{ Static Life table } \\
\hline & & 2016 & 2017 & 2016 & 2017 \\
\hline \multicolumn{6}{|l|}{ Braconidae } \\
\hline Microplitis plutellae (Muesbeck) & Larval & $6.1(39)$ & $9.3(109)$ & $2.2(11)$ & $2.6(1)$ \\
\hline Cotesia spp. & Larval & - & - & $4.0(20)$ & - \\
\hline Diolcogaster claritibia (Papp) & Larval & - & $0.2(1)$ & $0.2(1)$ & - \\
\hline \multicolumn{6}{|l|}{ Ichneumonidae } \\
\hline Diadegma insulare (Cresson) & Larval & $19.3(162)$ & $36.8(495)$ & $33.9(168)$ & $23.1(9)$ \\
\hline Diadromus subtilicornis (Gravenhorst) & Pupal & $10.6(12)$ & $9.8(44)$ & $9.7(48)$ & - \\
\hline Gelis sp. & Hyperparasitoid & - & - & $0.2(1)$ & - \\
\hline \multicolumn{6}{|l|}{ Chalcidoidea } \\
\hline Oomyzus sokolwoskii (Kurdjumov) & Larval-Pupal & - & - & $0.5\left(27^{1}\right)$ & - \\
\hline Pteromalus sp. & Hyperparasitoid & - & - & $1.0(5)$ & - \\
\hline Trichomalopsis dubia (Ashmead) & Pupal/Hyperparasitoid & - & - & $1.2(6)$ & - \\
\hline Conura albifrons (Walsh) & Hyperparasitoid & - & - & $5.3(26)$ & - \\
\hline Total Cumulative Percent Parasitism & & 36.0 & 56.1 & 58.2 & 25.7 \\
\hline
\end{tabular}


Table 3.4: Predator species composition as total number of individuals in pitfall trap samples collected in a cabbage, Brassica oleracea, plot on the Central Experimental Farm, Ottawa, Ontario during the summer of 2016 (12 traps) and 2017 (8 traps) with data on endemism (Bousquet et al., 2013) and predatory habits (Larochelle and Larivière, 2003) for Carabidae.

\begin{tabular}{|c|c|c|c|c|c|c|c|}
\hline & \multirow[t]{2}{*}{ Endemic } & \multirow[t]{2}{*}{ Habits } & \multicolumn{2}{|c|}{2016} & \multicolumn{2}{|c|}{2017} & \multirow{2}{*}{$\begin{array}{c}\text { Total } \\
\text { individuals }\end{array}$} \\
\hline & & & July & August & July & August & \\
\hline \multicolumn{8}{|l|}{ Coleoptera: Carabidae } \\
\hline Harpalus pensylvanicus (DeGeer) & Yes & Ground Dweller & 77 & 230 & 590 & 1708 & 2605 \\
\hline Pterostichus melanarius (Illiger) & No & Ground Dweller & 73 & 52 & 73 & 477 & 675 \\
\hline Harpalus affinis (Schrank) & No & Ground Dweller & 1 & 3 & 3 & 51 & 58 \\
\hline Poecilus chalcites (Say) & Yes & Ground Dweller & 10 & 3 & 5 & 5 & 23 \\
\hline Anisodactylus sp. & Yes & Ground Dweller & 1 & 0 & 1 & 5 & 7 \\
\hline Harpalus herbivagus (Say) & Yes & Ground Dweller & 3 & 1 & 1 & 1 & 6 \\
\hline Agonum placidum (Say) & Yes & Ground Dweller & 1 & 3 & 0 & 0 & 4 \\
\hline Amara sp. & Yes & Ground Dweller & 0 & 1 & 1 & 0 & 2 \\
\hline Clivina fossor (Linnaeus) & No & Climber & 1 & 0 & 0 & 1 & 2 \\
\hline Poecilus lucublandus (Say) & Yes & Ground Dweller & 0 & 1 & 0 & 0 & 1 \\
\hline \multicolumn{8}{|l|}{ Coleoptera: Staphylinidae } \\
\hline Aleochara curtula (Goesze) & & Ground Dweller & 0 & 0 & 1 & 8 & 9 \\
\hline Dinarea angustula (Thomson) & & Ground Dweller & 0 & 0 & 0 & 2 & 2 \\
\hline Philonthus varians (Paykull) & & Ground Dweller & 0 & 0 & 0 & 1 & 1 \\
\hline \multicolumn{8}{|l|}{ Insecta } \\
\hline \multicolumn{8}{|l|}{ Hymenoptera } \\
\hline Formicidae & & Climber & 11 & 13 & 5 & 16 & 45 \\
\hline Vespidae & & Aerial & 0 & 1 & 0 & 1 & 2 \\
\hline \multicolumn{8}{|l|}{ Hemiptera } \\
\hline Orius sp. & & Climber & 1 & 0 & 0 & 6 & 7 \\
\hline \multicolumn{8}{|l|}{ Arachnida } \\
\hline Opiliones & & Climber & 19 & 28 & 23 & 32 & 102 \\
\hline Araneae & & Climber & 8 & 13 & 7 & 40 & 68 \\
\hline Trombidiformes & & Climber & 0 & 20 & 12 & 1 & 33 \\
\hline
\end{tabular}




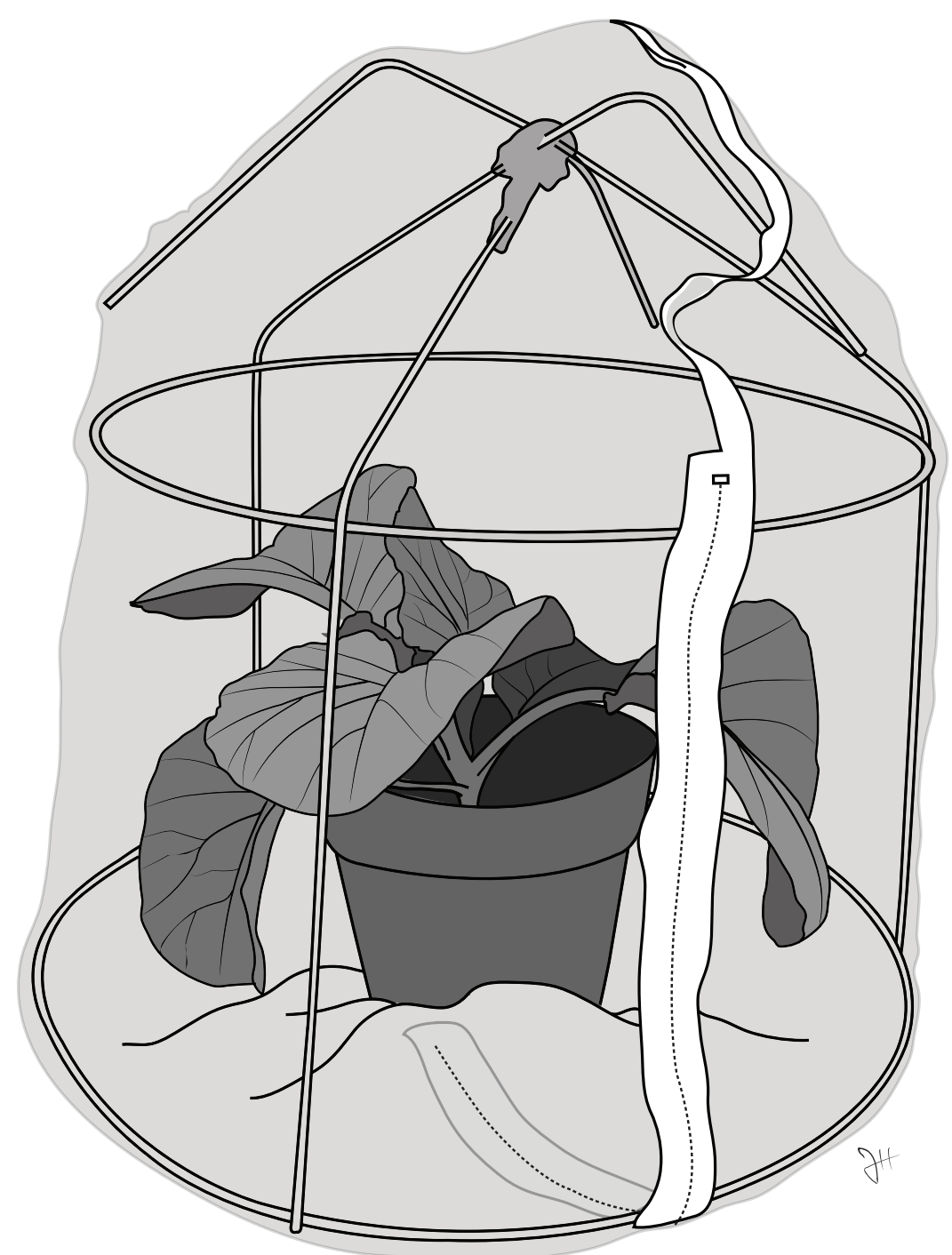

Figure 3.1: Image depicting control cage used in this study consisting of an upside down tomato cage with bent legs, with an insect rearing bag covering it. 


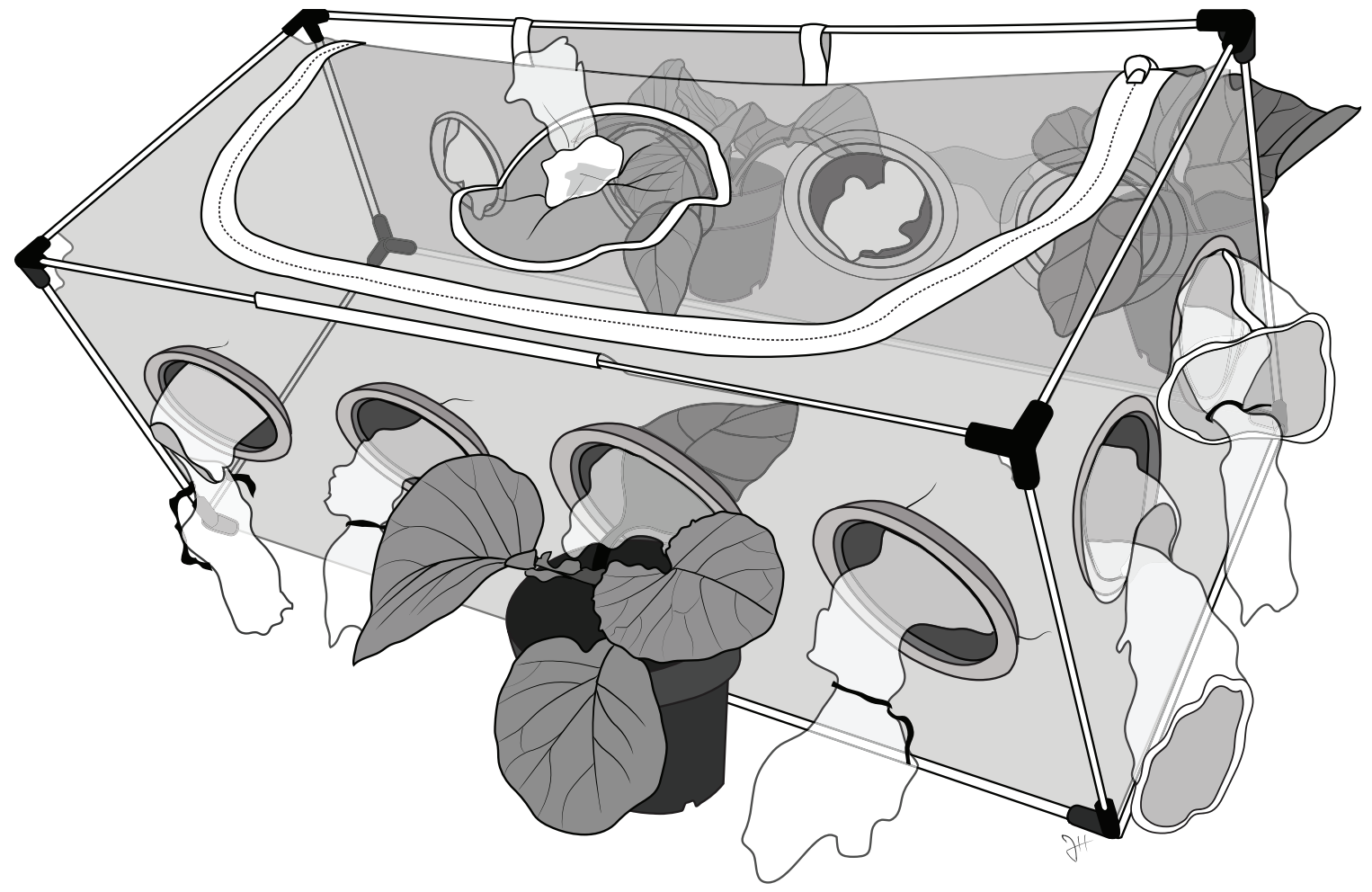

Figure 3.2: Image depicting the oviposition cage used in this study with small access holes on the side of the cage allowing a single leaf of each sample plant to be placed inside the cage for moths to access and oviposit on. Based on a concept by D.R. Gillespie. 


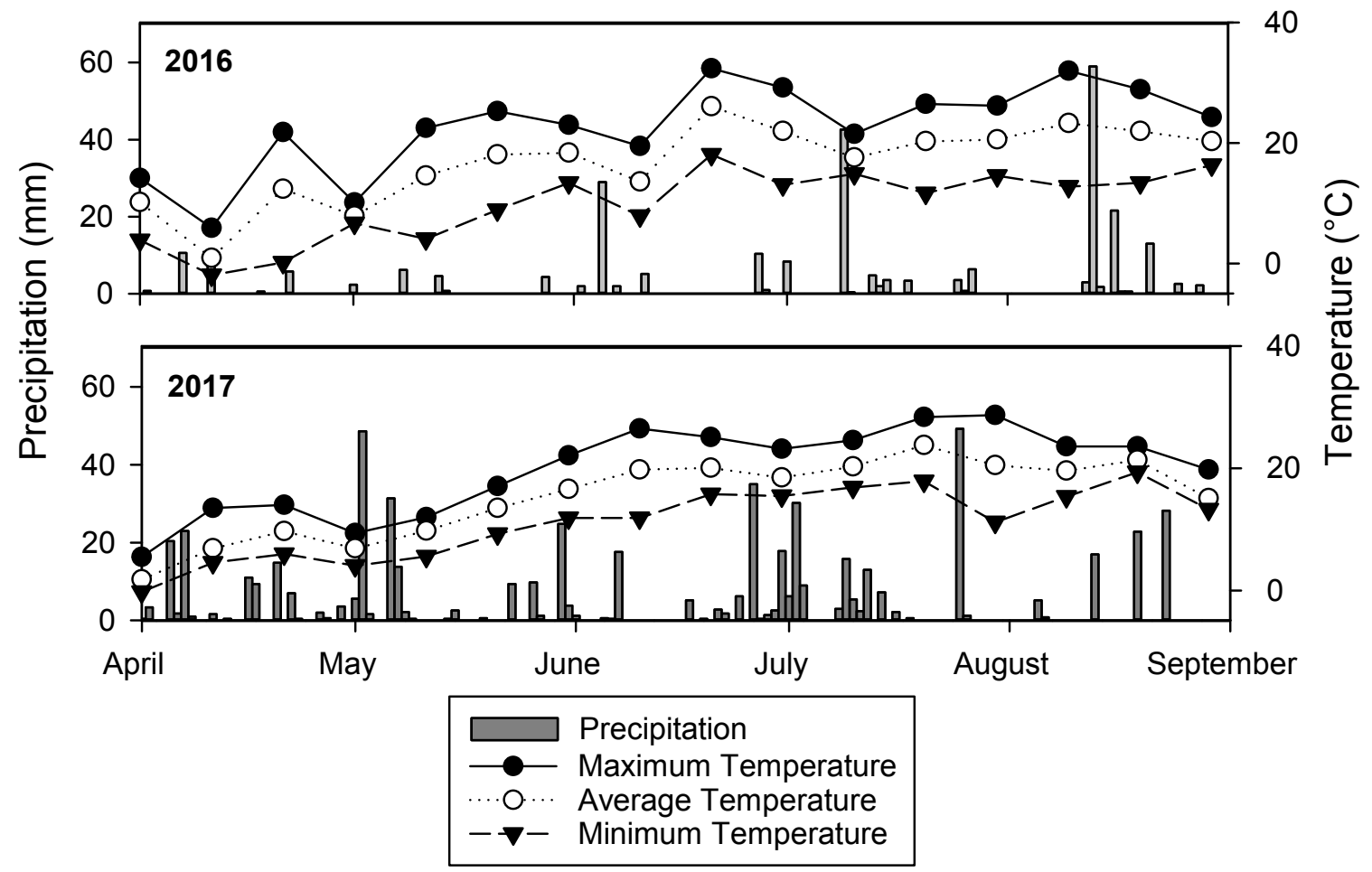

Figure 3.3: Average temperature and precipitation on the Central Experimental Farm, Ottawa, Ontario during the summer of 2016 and 2017, precipitation data from the National Climate Data and Information Archive (Environment and Climate Change Canada). 


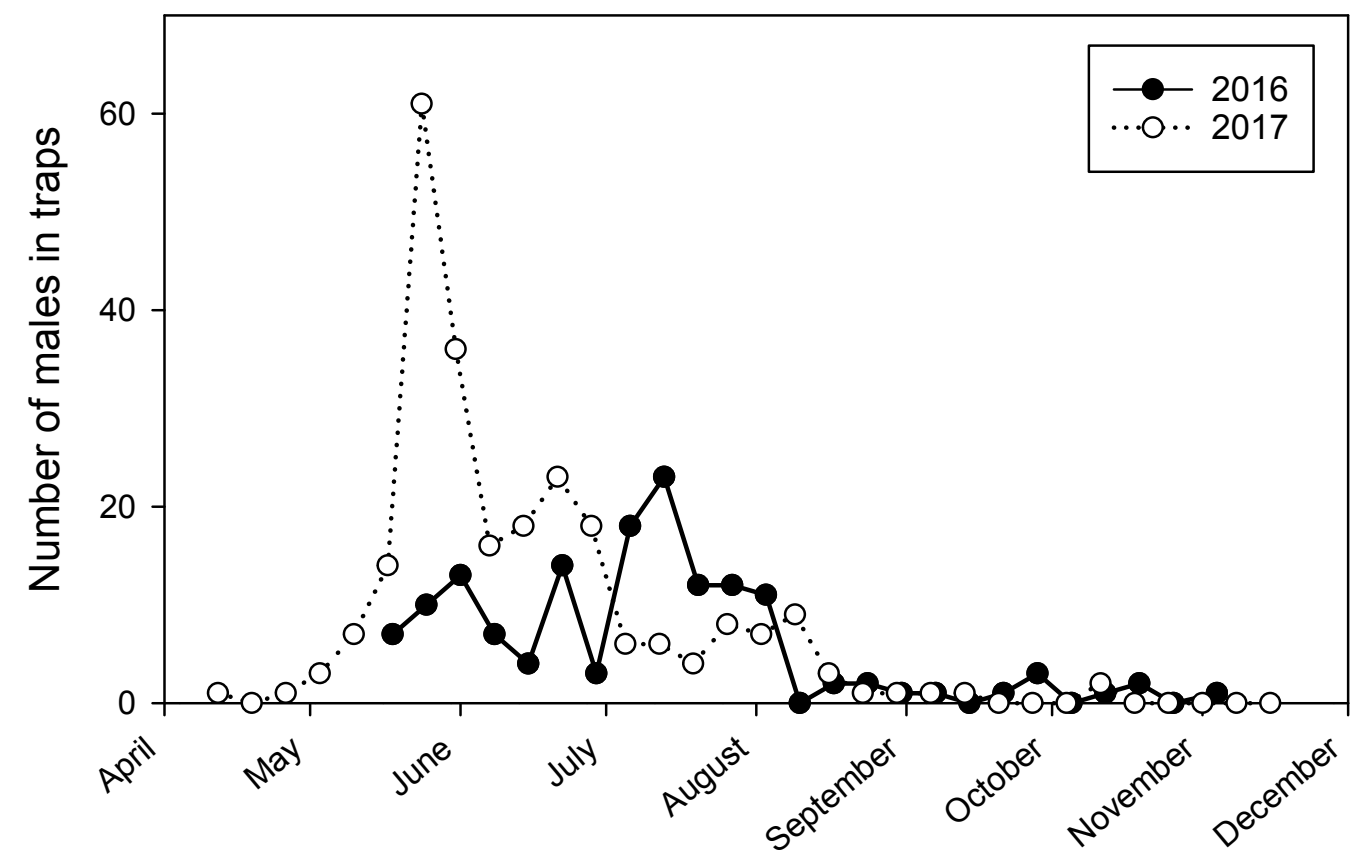

Figure 3.4: Total number of adult male diamondback moth, Plutella xylostella, caught in two pheromone traps set up in a cabbage, Brassica oleracea, plot on the Central Experimental Farm, Ottawa, Ontario. 

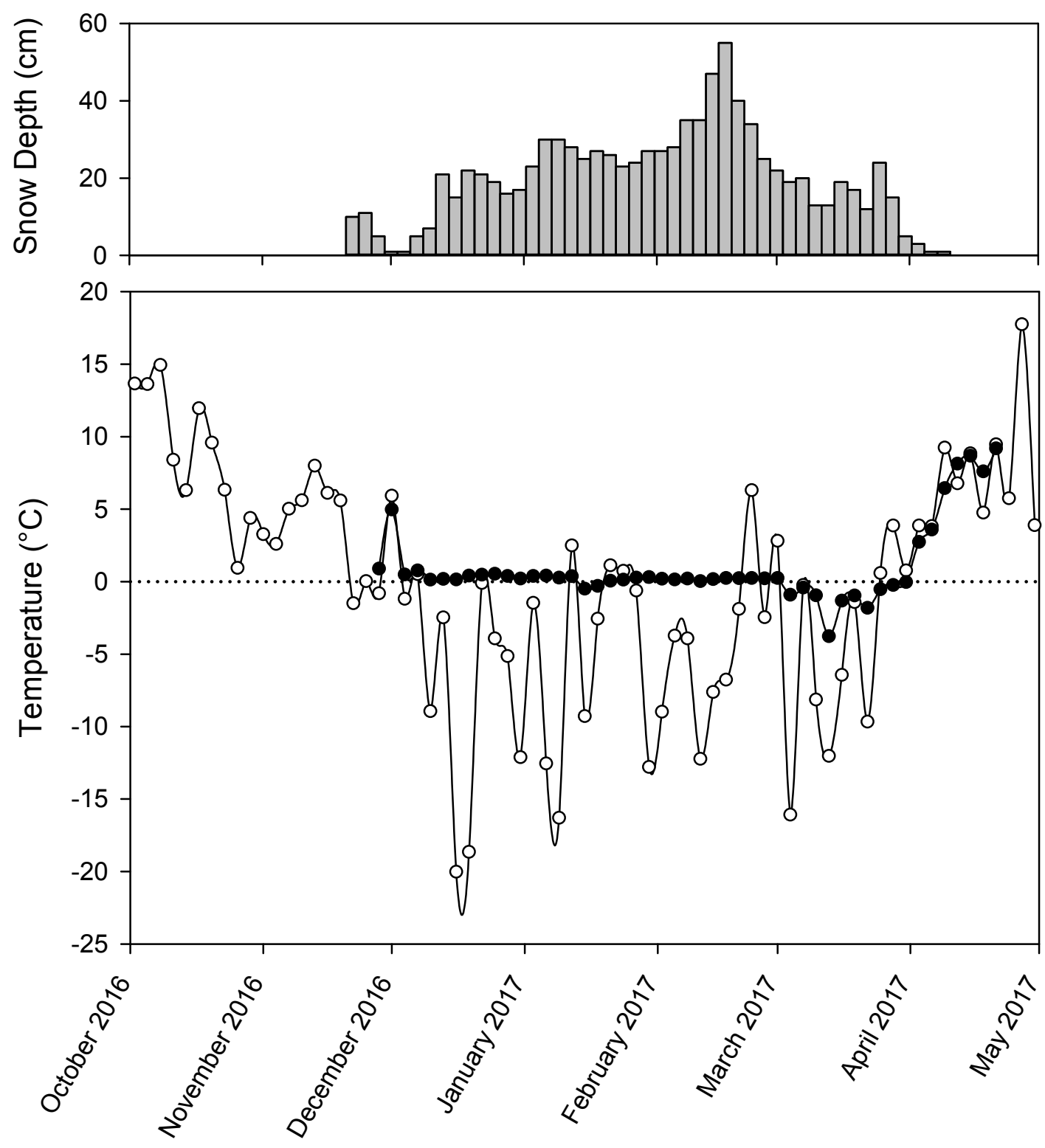

\section{Snow depth $(\mathrm{cm})$}

Figure 3.5: Average air temperature, average temperature under the snow and snow depth on the Central Experimental Farm, Ottawa, Ontario during the winter of 20162017. Snow cover data provided by the National Climate Data and Information Archive (Environment and Climate Change Canada). 


\section{Chapter 4}

\section{Microbiome analysis of diamondback moth (Lepidotpera: Plutellidae) midgut and associated plants using 16S rRNA amplicon sequencing}

\subsection{Abstract}

Various studies have investigated the diversity and composition of the microbiome of diamondback moth, Plutella xylostella, and have characterized the effects of the microbiome in facilitating pesticide resistance and improving immune responses. However, few studies have investigated the microbiome of this pest's diet in the field. This study explores the microbiome of canola leaves in the field, canola and cabbage leaves in the lab and the associated microbiome found in midguts of late instar diamondback moth larvae. Using 16S rRNA sequencing, a total of 1070 OTUs were identified. The midgut microbiota was consistent between diets with $99.3 \%$ identified as belonging to the family Enterococcaceae, with no differences in community composition of the genus Enterococcus between samples. The host in which the microbiome was found (leaf or midgut) was the factor that best described changes in microbiome composition. The core community in all leaf and gut samples was composed of eight OTUs assigned to the families Enterobacteriaceae, Enterococcaceae and Comamonadaceae. We hypothesize that the midgut microbiota of diamondback moth larvae highly favours Enterococcaceae and speculate that it may have a protective role for 
this pest.

\subsection{Introduction}

Herbivorous insects rely on microorganisms to aid in digesting plant material, detoxification and nutrient supplementation (Hammer et al., 2017; Chaturvedi et al., 2017). Modes of a microbiome can span from being transient, pathogenic or beneficial to an insect host (Hammer et al., 2017). Studies have noted that gut microbiomes have measurable physiological benefits to insect herbivores (Xia et al., 2017, 2013; Paniagua Voirol et al., 2018; Rempoulakis et al., 2017; Ruokolainen et al., 2016). Some examples include facilitating the breakdown of secondary plant metabolites (CejaNavarro et al., 2015; Pizzolante et al., 2017; Berasategui et al., 2017), aiding in insect growth (Rempoulakis et al., 2017; Ruokolainen et al., 2016), insecticide resistance (Kikuchi et al., 2012; Cheng et al., 2017), increased immunity (Ganley et al., 2018; Zhang et al., 2016) and even the ability to break down abiotic material, such as mixed plastics (Brandon et al., 2018).

Diamondback moth, Plutella xylostella L. (Lepidoptera: Plutellidae) is a global pest of Brassicaceous crops causing damage up to US\$ 5 billion annually (Zalucki et al., 2012). It was the first species to develop resistance to Bt (Bacillus thuringiensis) and is field resistant to all major classes of insecticides (Furlong et al., 2013). Despite the ability of the diamondback moth to consume various species of Brassicaceae, in the lab, its feeding behaviour can be best described as monophagous (Mereghetti et al., 2017).

There has always been speculation that the microbiome of diamondback moth aids in conferring insecticide resistance in this pest (Xia et al., 2013; Ramya et al., 2016; Indiragandhi et al., 2007), which is a targeted interest for agricultural pest management. Xia et al. (2013) found differences in gut microbiota in the diamondback

moth between pesticide resistant and susceptible populations in China. Follow up 
studies by Xia et al. $(2017,2018)$ described the functional group of major bacterial species in the diamondback moth midgut. These species were involved with the degradation of plant material and detoxification of plant chemicals and are thought to potentially contribute to pesticide resistance. When inoculated with bacterial cultures of Enterobacteriaceae, Serratia sp. and Enterococcus sp., diamondback larvae had increased pesticide resistance and induced expression of immune response compounds (Xia et al., 2018).

Lin et al. (2015) described the gut microbiome of the diamondback moth when fed cabbage, artificial diet and five different antibiotics. Under concentrations of antibiotics that were safe for the larvae, the majority of bacteria were removed from larval midguts. However, certain bacteria could never be fully removed in antibiotic treatments.

Studies often do not take proper control measures to disentangle the origin of the bacterial community in microbiome studies (Paniagua Voirol et al., 2018). Studies on the diamondback moth microbiome have been typically carried out in laboratory settings where the larvae may only consume one type of plant during their development. Studies using specimens from the field often do not mention the plant the larvae were feeding on. Generalizing the changes in microbial diversity and abundance when we lack information on how diet and environment can influence the microbiome can leave a gap in the interpretation of the results.

The microbiome found in diamondback moth larvae could be heavily dependent on diet. By altering properties of the diet it might be possible to manipulate pesticide resistance. The microbiome of the diet and the resulting microbiome found in the larvae must first be characterized.

Our objective was to examine and describe differences in bacterial communities in the larval midgut of the diamondback moth between diet (plant species), environment (field versus lab reared) and host (gut versus leaf). We also describe the leaf 
microbiome and the insect gut microbiome and characterize them taxonomically to draw conclusions on the nature of the relationships between diet, environment and host.

\subsection{Materials and Methods}

\subsubsection{Insect Rearing}

To describe the microbiome of diamondback moth larvae on canola Brassica napus (Linnaeus) and B. rapa (Linnaeus) (Brassicaceae) in the field, canola plants were artificially infested with diamondback moth eggs at the Central Experimental Farm (CEF), Ottawa, Ontario, Canada $\left(45^{\circ} 23^{\prime \prime N}, 75^{\circ} 43^{\prime \prime} \mathrm{W}\right)$. Three to four volunteer canola plants growing in a filler soybean Glycine max, (Linnaeus) (Fabaceae) crop were fitted with insect rearing bags (DC3170 MegaView Science Co., Ltd.) to confine the insects on the plants. Eggs were obtained by allowing laboratory-reared diamondback moth females to oviposit on canola leaves taken from other canola plants growing in the soybean field. Approximately 500 eggs on three separate leaf discs were pinned to the plants inside each rearing bag. The plants were infested with the eggs on 18 August, 2017 and the resulting larvae were collected on 4 September, 2017 when they had reached fourth instar. Leaf material from inside the rearing bag, as well as adjacent plants in the plot were collected for sequencing.

In the lab diamondback moth were reared on either greenhouse grown cabbage, Brassica oleracea var. Adaptor (Linneaus) (Brassicaceae), or greenhouse grown canola plants. The two greenhouse plant species were housed in separate environmental chambers (Conviron Adaptis CMP6010) running the same environmental conditions $\left(30{ }^{\circ} \mathrm{C}, 65 \% \mathrm{RH}\right.$ on a $10 \mathrm{~h}: 14 \mathrm{~h} \mathrm{~L}: \mathrm{D}$ cycle). Eggs were obtained by allowing laboratoryreared females to oviposit on either greenhouse grown cabbage or greenhouse grown canola leaves on 26 October, 2017. The leaves were cut into smaller leaf discs and pinned on the plants in the cages. The resulting larvae were allowed to feed on 
the plants until they had reached fourth instar, at which time they were collected for dissection on 3 November, 2017 for Canola and 4 November, 2017 for Cabbage. Leaf material from inside the cages were also collected from the rearing plants for sequencing.

\subsubsection{Dissection}

Larvae of either sex were surface sterilized with $95 \%$ ethanol for 30 seconds to one minute and then moved to sterile 1x Phosphate Buffer Solution (PBS) (pH 7.4) for an additional 30 seconds to one minute (Hammer et al., 2015; Micchelli, 2014). A wax dissection plate was made from a small petri dish lined with modelling wax. The wax lined petri plate was sterilized with $20 \%$ bleach for 10 minutes prior to dissections. The dish was then rinsed with sterile 1x PBS solution. A small drop of 1x PBS was placed into the center of the dish, along with the surface sterilized larva. Two \#3 sized insect pins rinsed with $70 \%$ ethanol were used to pin down the head and anus of the larva with the ventral side facing up. The larva was dissected under a simple stereo microscope with two pairs of fine forceps (Dumont \#5 Forceps) sterilized in $20 \%$ bleach solution between dissections. Forceps were used to grasp onto the first pair of true legs or to the insect cuticle near the legs and then pulled away on both sides shearing the insect integument. This was repeated until the integument was sheared down the length of the larval body. The midgut was then pinched off near the head and before the hindgut and pulled out of the body cavity using the forceps. The malpighian tubules and the silk glands were removed if found attached. Midgut extracts were pooled, three midguts per sample to eliminate individual variability. This was determined to be the optimum number for detection using PCR.

Leaf material was sampled by cutting leaf discs using a $4 \mathrm{~mm}$ diameter cork borer (Humboldt Mfg. Co.) sterilized in $20 \%$ bleach solution. Leaf discs were retrieved using sterile forceps and placed in sterile 1x PBS solution. Leaf extracts were pooled 
samples of three leaf discs per sample. Midgut and leaf disc samples were kept intact in a 1:4 mixture of sterile $1 \mathrm{x}$ PBS and $50 \%$ glycerol and stored at $-20^{\circ} \mathrm{C}$ until further analysis. Pins and the wax dissection plate were rinsed with $70 \%$ ethanol between specimens and the forceps were kept in $20 \%$ bleach between dissections.

\subsubsection{DNA extraction}

All plant and larval midgut samples were centrifuged for one minute at 13,000 rpm. The glycerol and PBS supernatant was disposed. Samples were provided with $200 \mu \mathrm{L}$ fresh sterile 1x PBS and homogenized using a sterile micropestle (Eppendorf AG). Samples were then centrifuged for 12 minutes at 12,000 rpm until a pellet formed. The pellet was then used for DNA extraction using One-4-All Genomic DNA kit (Bio Basic Inc.) using the protocol for gram-positive bacteria. Additional steps included the addition of $20 \mu \mathrm{L}$ of Proteinase $\mathrm{K}$ and RNAse A, following the manufacturer's protocol. All samples were validated for PCR product prior to sequencing using 1.0 $\%$ agarose gel electrophoresis, resulting in a total of 39 midguts in 13 samples, and 51 leaf discs in 17 samples $(N=30)$.

Two hypervariable regions of the 16S rRNA gene were used for better detection of the bacterial community in a phytophagous insect. The universal primer (V3-V4) can also detect chloroplast 16S rRNA due to strong homology with bacterial $16 \mathrm{~S}$ rRNA (Hanshew et al., 2013). Although sequences can be filtered downstream, amplification of chloroplast $16 \mathrm{~S}$ rRNA could potentially reduce the detection of rarer bacterial taxa. A second primer pair, for the V6 region, was also used because it does not amplify chloroplast 16S rRNA and has specificity for the detection of microbiomes in plants (Lebeis, 2017). The V6 primer chosen was previously used in another microbiome study on diamondback moth (Xia et al., 2013). Thus, each sample was divided in half for each of the two primers resulting in a total of 60 samples for sequencing.

PCR was carried out in a total volume of $10 \mu \mathrm{L}$ : NEBNext Ultra II Q5 ${ }^{\circledR}$ Master 
Mix (New England Biolabs Inc.) $5.0 \mu \mathrm{L}$, DNA template $1.0 \mu \mathrm{L}$, forward primer $2.0 \mu \mathrm{L}$ and reverse primer $2.0 \mu \mathrm{L}$. Amplification targeted the V3-V4 and V6 hypervariable regions of the 16S rRNA gene (Hanshew et al., 2013; Klindworth et al., 2013).

Universal primers for the V6 region, V6F: 5'-TCGTC GGCAG CGTCA GATGT GTATA AGAGA CAGCA ACGCG ARGAA CCTTA CC -3', V6R: 5'- GTCTC GTGGG CTCGG AGATG TGTAT AAGAG ACACG ACAGC CATGC ASCAC CT -3' (Xia et al., 2013). After initial denaturation at $95{ }^{\circ} \mathrm{C}$ for $5 \mathrm{~min}$, amplification was performed using 30 cycles of $30 \mathrm{sec}$ at $95{ }^{\circ} \mathrm{C}, 20 \mathrm{sec}$ at $58{ }^{\circ} \mathrm{C}, 6$ sec at $72{ }^{\circ} \mathrm{C}$, followed by a final extension at $72{ }^{\circ} \mathrm{C}$ for $7 \mathrm{~min}$ (Xia et al., 2013).

Universal primers for the V3-V4 regions, 16S-F = 5' - TCGTC GGCAG CGTCA GATGT GTATA AGAGA CAGCC TACGG GNGGC WGCAG - 3', 16S-R = 5' GTCTC GTGGG CTCGG AGATG TGTAT AAGAG ACAGG ACTAC HVGGG TATCT AATCC - 3' (Klindworth et al., 2013). After initial denaturation at $95{ }^{\circ} \mathrm{C}$ for $3 \mathrm{~min}$, amplification was performed using 25 cycles of $30 \mathrm{sec}$ at $95{ }^{\circ} \mathrm{C}, 30 \mathrm{sec}$ at $55{ }^{\circ} \mathrm{C}, 30 \mathrm{sec}$ at $72{ }^{\circ} \mathrm{C}$, followed by a final extension at $72{ }^{\circ} \mathrm{C}$ for $5 \mathrm{~min}$ (Klindworth et al., 2013).

Samples were prepared for sequencing according to the Illumina MiSeq platform system instructions (Illumina Inc.) (Amplicon et al., 2013). Samples were validated after the first PCR clean-up by gel electrophoresis using randomly chosen samples. The quantity and quality of the extracted DNA was determined by PicoGreen quantitation (Thermo Fisher Scientific Ltd.) and normalized for sample loading prior to sequencing.

All reagents used, including glycerol, lysis buffer, PBS and the PBS-glycerol supernatant, were tested for contamination using the two primers. Any contamination in the reagents was below the level of detection using gel electrophoresis. 


\subsubsection{Sequence analysis}

4.3.4.1 Closed reference V3 and V6 combined reads Paired-end reads from 16S rRNA amplicons were trimmed and merged separately using FLASH (v1.2.11) (Magoč and Salzberg, 2011) (options V3:-m 100 -M 500, V6:-m 50 -M 150). Quality checking was done by fastqc (Andrews, 2010) looking for acceptable quality scores and read length. Sequences were concatenated into a single FASTA file. To compare nonoverlapping amplicons, OTUs were selected using the pick_closed_reference_otus.py command in Qiime (v1.7) (Caporaso et al., 2010) clustered against Greengenes (v13.5) reference database (DeSantis et al., 2006) (See Appendix B for parameters). Closed reference OTU picking determines OTUs using a predefined taxonomy map, therefore the use of FLASH was to assemble the longest and most complete contigs for OTU picking since there is no de novo picking step (Caporaso et al., 2010). OTUs with fewer than one observation were filtered out. Additional filtering removed OTUs originating from mitochondria and chloroplasts.

4.3.4.2 Open reference V6 reads Paired-end reads from 16S rRNA amplicons were quality filtered using Trimmomatic (v0.32) (Bolger et al., 2014) (options LEADING:25 TRAILING:25 SLIDINGWINDOW:25:25 MINLEN:50 AVGQUAL:25).

Reads were then merged using fastq-join (Aronesty, 2011) with a minimum overlap of $50 \mathrm{bp}$. All filtered and overlapped sequences were then clustered into OTUs at 97 \% sequence similarity using the clustering method by cd-hit (Li and Godzik, 2006) through the pick_otus.py command in Qiime. Sequences were de-replicated using the command pick_rep_set.py in Qiime followed by two rounds of referenced-based chimera filtering using uchime (Edgar et al., 2011) (ChimeraSlayer gold.fa database). Representative OTUs were then aligned to the Greengenes reference database using the command pick_open_reference_otus.py in Qiime (option -s 1). Open reference OTU picking uses a de novo picking step and representative sample picking to as- 
sign taxonomy. This picking method can allow for the discovery of new and rare OTUs (Caporaso et al., 2010). Rare OTUs that were observed fewer than two times (Singletons) were filtered out. Additional filtering removed OTUs originating from mitochondria and chloroplasts.

We used oligotyping analysis to explore differences in the community of the genus Enterococcus using the oligotyping pipeline (v2.1) (Eren et al., 2013). Oligotyping utilizes entropy analysis to reveal variable sites to identify highly refined taxonomic units. For oligotyping we used the quality-controlled open reference V6 reads. The reads for each Enterococcus OTU were filtered from the raw FASTA file using the q2oligo.py script (https://github.com/jfmeadow/q2oligo) and the filter_fasta.py command in Qiime. To make partial alignment reads of equal length they were first padded (o-pad-with-gaps) and then trimmed to an equal length (o-smart-trim) of 98 bp. Oligotyping was performed using the identified high entropy positions (options $-c 2-M 5000)$.

\subsubsection{Data analysis}

Reads in the closed reference combined dataset were filtered for singletons. The community was then rarefied using the vegan package (v2.5-1) in $R$ (v3.4) (Oksanen et al., 2018; R Core Team, 2017). Rarefaction curves to determine species richness were generated using the BiodiversityR package (v2.9-2) (Kindt and Coe, 2005). Alpha-diversity was assessed between factors (diet, environment and host) using the Shannon-Wiener diversity index, which accounts for species abundance and evenness, through the OTU.diversity command in the RAM package (v1.2.1.3) (Chen et al., 2016).

To assess beta-diversity the relative abundance was transformed through beta dispersion to detect the average dissimilarity between variables using Bray-Curtis dissimilarity index. Pairwise differences in dispersion were tested using betadisper and 
permutest in the vegan package. If there was homogeneous dispersion, the comparison was further tested for significance using an Analysis of Similarities (ANOSIM).

\subsection{Results}

The taxonomic composition of the closed reference and open reference methods are summarized in Table 4.1, after removing chloroplasts, mitochondria and samples with low numbers of reads. For the open reference method there was a similar number of OTUs with a Greengene ID compared to the closed reference method (Table 4.1). However, there were an additional 3026 new reference OTUs in the open reference method making it the larger dataset. This is not surprising since there is a de novo picking step in pick_open_reference_otus.py. Detection of major families between the two methods were similar, where over $99 \%$ of reads from the gut were idenified as Enterococcaceae. Detection of Enterobacteriaceae in the leaves did differ between the two methods with the open reference dataset detecting higher percent abundance (Table 4.1).

Rarefaction curves were used to detect the species richness in all samples. This determines if coverage of the bacterial community in each sample was sufficient. Rarefaction curves before rarefying showed that most of the samples had reached a plateau; however, some samples had not reached a plateau meaning that coverage of the bacterial community for those samples was insufficient (Figure A4). Median number of OTUs per sample was $91(\mathrm{IQR}=69)$ with a median sampling depth of 56259 reads $(\mathrm{IQR}=117$ 039). Samples were rarefied so the sum of OTUs in each sample was equal to the sample with the lowest number of reads (1054 reads). The resulting rarefaction curves showed that most samples had reached a plateau after rarefying (Figure 4.1).

The alpha-diversity of the bacterial community in the closed reference combined dataset, measured by the Shannon-Wiener index, was significantly higher in the leaf 
samples compared to gut samples (Table 4.2). There was no significant difference in alpha-diversity between diet type within the gut and leaf samples (Figure 4.3). There was also much higher species richness in the leaf samples compared to gut samples (Figure 4.2). Alpha-diversity in field samples were also found to be significantly higher than lab samples (Median Shannon-Wiener index, field: 2.10, IQR = 2.06, lab: 0.75, $\mathrm{IQR}=1.0, N=60, P=0.013$, Mann-Whitney-Wilcoxon rank sum test).

To determine variability in the bacterial community through beta-diversity, we used beta dispersions to compare between different factors. This involves detecting the average dissimilarity of samples to their group centroid in multivariate space using Bray-Curtis dissimilarity measure (Anderson et al., 2006; Anderson, 2006; Levene, 1960). For sample type, the microbiome on leaves had higher community variability than the gut microbiome (permutest, $F=102.67, P<0.01$ ) (Figure 4.2a). Samples from the field also had higher community variability than samples from the lab (permutest, $F=10.07, P<0.01$ ) (Figure $4.2 \mathrm{~b}$ ).

There was no significant difference in the alpha-diversity between the hypervariable regions within the closed reference dataset. However, there was a significant difference in beta-diversity for both the bacterial community and community composition (ANOSIM $R=0.961, P=0.001$ ). This may be due to the sensitivities of each region to the detection of different taxa since there was consistent detection of certain taxa by hypervariable region.

Comparison of the two sequence processing methods using only the V6 reads, the differences in the bacterial community (Greengene ID) was larger within the open and closed reference datasets than between the datasets (ANOSIM: $R=0.33, P<0.001$ ). Between the two methods, there were eight core OTUs identified in all samples in both datasets (Table 4.3).

Since the genus Enterococcus was over $90 \%$ composition of the midgut microbiome, we further described the community by detecting more subtle variation within 
the OTUs. To look into community composition of Enterococcus, we performed oligotyping on the open reference V6 reads. The total set for oligotyping included 2534316 Enterococcus reads from all 30 samples with an average of 179332 reads for gut samples and 11826 reads for leaf samples. Shannon entropy analysis found two variable sites with high entropy at read positions 8 and 84 (Figure 4.4). Oligotyping revealed 14 oligotypes for Enterococcus; however, after a minimum substantive abundance of 5000 reads, only four oligotypes remained. The four oligotypes represented $99.92 \%$ of all reads with a purity score of 1.00 (Figure 4.5). Percent representation of each of the four oligotypes was consistent across all samples (mean $\pm \mathrm{SD}, \mathrm{GC} 44.5$ $\pm 2.9 \%$, AC $28.5 \pm 1.7 \%$, GG $15.3 \pm 2.4 \%$, AG $11.4 \pm 1.4 \%)$.

\subsection{Discussion}

The microbiome of the diamondback moth midgut is mainly characterized by the bacterial family Enterococcaceae, at over $98 \%$ relative abundance and the genus Enterococcus, at over $90 \%$ relative abundance. There was no effect of diet (plant species) on gut microbiome (Figure 4.3); this was predicted since many other studies have detected consistent microbiomes within a species (e.g. Robinson et al. 2010; Wong et al. 2015). We also detected families that have been previously identified in microbiome studies on diamondback moth and other Lepidoptera (e.g. Enterobacteriaceae, Lactobacillaceae, Vibrionaceae, Pseudomonadaceae, Xanthomonadaceae) (Chaturvedi et al., 2017; Hammer et al., 2017; Xia et al., 2013, 2017). We detected significant differences between lab and field samples, with field samples having higher alpha and beta diversity. However, the most markedly different bacterial community structures came from significant differences between the hosts (gut and leaf samples).

There was no significant difference in the bacterial community structure of the midgut between plant treatments. The family Enterocccaceae had the highest relative abundance with $99.6 \%$ in larvae fed with greenhouse grown plants and $98.5 \%$ in 
larvae fed field canola. The next most abundant families were Comamonadaceae at $0.19 \%, 0.17 \%$ and $0.48 \%$, Enterobacteriaceae at $0.07 \%, 0.09 \%$ and $0.34 \%$, and Xanthomonadaceae at $0.07 \%, 0.07 \%$ and $0.33 \%$, for larvae that fed on greenhouse cabbage, greenhouse canola and field canola, respectively.

We also detected a significant difference in the bacterial community in the leaves between plant treatments. For both greenhouse cabbage and canola the most abundant family was Enterococcaceae at $89.9 \%$ and $47.0 \%$, respectively. For field canola the major families with highest relative abundance were Xanthomonadaceae (37.8 \%), Pseudomonadaceae (14.4\%), and Enterobacteriaceae (11.2\%). Enterococcaceae comprised of $5.3 \%$ of reads in field canola leaves; however, in the midguts of larvae that fed in the field, Enterococcaceae was the most abundant family at $98.5 \%$ of reads. It appears that the midgut of the late instar larvae was potentially an environment that was not suitable to the majority of bacterial families resulting in Enterococcaceae proliferating. There was no detectable difference in alpha diversity in midgut samples regardless of which plant treatment the larvae fed on.

Oligotyping analysis identified 4 oligotypes for Enterococcus. The oligotypes were generally consistent in proportional abundance in all samples. There were no notable differences of oligotypes between samples. This can indicate that the Enterococcus community on the leaves represents the community that can be found in the larval midgut of diamondback moth, with the midgut being a preferential environment for this genus. In addition, since there were no notable differences between field and lab plants, the proportion of Enterococcus populations appears to be consistent across environments.

The disproportionate amount of Enterococcaceae found in the midgut samples of the field larvae on canola is quite striking compared to the amount of Enterococcaceae detected in the leaves in the field (Figure A5). One possible explanation for this could be contamination from anthropogenic sources (Staudacher et al., 2016; Van 
Der Horst et al., 2013). The study by Staudacher et al. (2016) suggested the presence of Enterococcus in only lab associated samples was likely due to contamination as a result of handling. However, the canola plants used in the field were volunteer, thus were not planted or maintained. The only routes of contamination would occur from the insect bag covering the plant or carried over on the egg surface after oviposition. The control samples from untouched adjacent plants were not significantly different from samples of leaves within the rearing bags (Shannon Wiener index, $P=0.33$, Mann-Whitney-Wilcoxon rank sum test). Contamination from anthropogenic sources of Enterococcus is possible but unlikely. Environmental stresses such as antibiotics or anoxia of the larval midgut can also lead to the dominance of Enterococcus sp. (Lin et al., 2015; Berman et al., 2018).

Other studies revealed more than $97 \%$ of midgut bacteria in diamondback moth were from the orders Enterobacteriales, Vibrionales and Lactobacillales (Lin et al., 2015; Xia et al., 2013, 2017). However, in the current study Enterococcaceae (Lactobacillales) represented $99.3 \%$ of the reads for midgut bacteria alone, followed by Carnobacteriaceae (Lactobacillales) at $0.27 \%$ and Enterobacteriaceae (Enterobacteriales) at $0.15 \%$ of the abundance. The family Carnobacteriaceae contains a potential gut symbiont of diamondback moth Carnobacterium sp. (Lin et al., 2015; Xia et al., 2017; Berman et al., 2018). Our study however, did not identify any OTUs to that genus, only one genus of Carnobacteriaceae was identified, belonging to Desemiza.

The function of Enterococcaceae in the gut microbiome of organisms has been suggested as a detoxifying agent through metabolizing pesticides or degradation of secondary metabolites. This has been found in Spodoptera exigua Hübner, Spodoptera littoralis Boisduval (Lepidoptera: Noctuidae) (Shao et al., 2011), Hyles euphorbiae Linnaeus (Lepidoptera: Sphingidae) and Brithys crini Fabricius (Lepidoptera: Noctuidae) (Vilanova et al., 2016). Enterococcaceae has also been suggested to have a direct influence on the immune system through inducing the expression of antimi- 
crobial peptides. This immune response was demonstrated for the greater wax moth (Galleria mellonella, Linnaeus, Lepidoptera: Pyralidae) (Krams et al., 2017), S. exigua (Hernández-Martínez et al., 2010) and even in rainbow trout (Oncorhynchus mykiss, Walbaum, Salmoniformes: Salmonidae) (Safari et al., 2016). The studies by Xia et al. $(2017,2018)$ and Raymond et al. (2009) do suggest that the diamondback moth microbiome has a detoxification and an immunity boosting role. However, in Xia et al. (2017) the detoxification was mainly attributed to Enterobacteriaceae which was the major family of bacteria found in diamondback moth in that study.

Our study found that the differences in microbiome were mainly driven by host (gut versus leaf) rather than by diet (plant species) or environment (field versus lab reared). The major differences were generated by the family Enterococcaceae and specifically the genus Enterococcus. Studies have narrowed down the function of Enterococcus spp. to potentially aid in insect immunity and pesticide resistance (Xia et al., 2017, 2018; Raymond et al., 2009). Disentangling the effect of this genus in the biology of the diamondback moth could be a potential route for improved biological control of this pest in the future. 


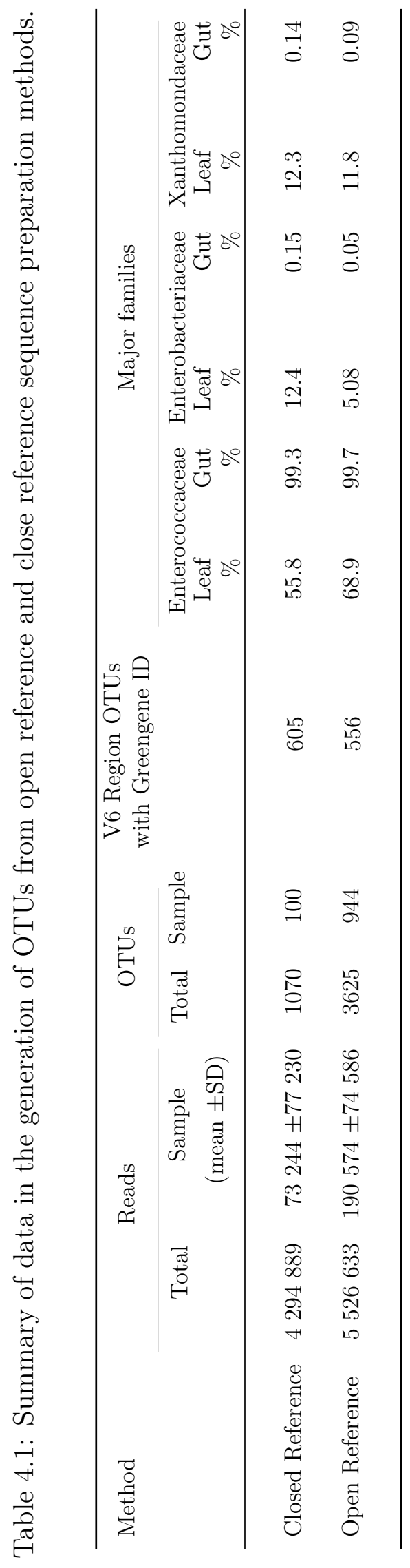


Table 4.2: Summary of alpha-diversity between leaf and gut samples on different plant types.

\begin{tabular}{llrrrr}
\hline Plant & Sample Type & $N$ & Total OTUs & Total Reads & $\begin{array}{c}\text { Median Shannon-Wiener } \\
\text { Index } \pm \text { IQR }\end{array}$ \\
\hline \multirow{3}{*}{ Cabbage } & Gut & 10 & 285 & 1153508 & $0.70 \pm 0.10$ \\
& Leaf & 9 & 448 & 584385 & $1.74 \pm 0.91$ \\
Canola & Gut & 10 & 292 & 1159220 & $0.69 \pm 0.08$ \\
& Leaf & 9 & 383 & 305425 & $1.87 \pm 0.57$ \\
Canola & Gut & 6 & 436 & 747730 & $0.76 \pm 0.16$ \\
Field & Leaf & 8 & 642 & 325823 & $2.89 \pm 0.65$ \\
& Control Leaf & 5 & 343 & 18798 & $2.49 \pm 0.80$ \\
& & & & & \\
\hline
\end{tabular}


Table 4.3: The eight core OTUs found in all samples and across both open and closed V6 only datasets with rarefied relative abundance normalized using a Hellinger transformation (abundance ranges from 0 to 1 ).

\begin{tabular}{|c|c|c|c|c|c|}
\hline \multirow[t]{3}{*}{ Taxonomy } & \multirow[t]{3}{*}{ Greengene ID } & \multicolumn{4}{|c|}{ Relative abundance (mean $\pm \mathrm{SD}$ ) } \\
\hline & & \multicolumn{2}{|c|}{ Open reference } & \multicolumn{2}{|c|}{ Closed reference } \\
\hline & & Leaf & Gut & Leaf & Gut \\
\hline \multirow{2}{*}{ Enterococcus casseliflavus } & 759349 & $0.08 \pm 0.10$ & $0.46 \pm 0.04$ & $0.32 \pm 0.22$ & $0.67 \pm 0.012$ \\
\hline & 1033413 & $0.09 \pm 0.10$ & $0.49 \pm 0.03$ & $0.34 \pm 0.23$ & $0.73 \pm 0.01$ \\
\hline Salmonella enterica & 1951826 & $0.02 \pm 0.009$ & $0.01 \pm 0.009$ & $0.09 \pm 0.06$ & $0.02 \pm 0.01$ \\
\hline \multirow[t]{2}{*}{ Varivorax paradoxus } & 4456068 & $0.03 \pm 0.01$ & $0.01 \pm 0.005$ & $0.15 \pm 0.1$ & $0.02 \pm 0.01$ \\
\hline & 4391287 & $0.01 \pm 0.009$ & $0.007 \pm 0.003$ & $0.08 \pm 0.05$ & $0.01 \pm 0.006$ \\
\hline \multirow[t]{2}{*}{ Acidovorax spp. } & 7046 & $0.02 \pm 0.01$ & $0.01 \pm 0.005$ & $0.11 \pm 0.08$ & $0.15 \pm 0.009$ \\
\hline & 339185 & $0.02 \pm 0.01$ & $0.01 \pm 0.005$ & $0.13 \pm 0.08$ & $0.02 \pm 0.011$ \\
\hline Xanthomonadaceae & 34580 & $0.02 \pm 0.02$ & $0.02 \pm 0.007$ & $0.14 \pm 0.11$ & $0.02 \pm 0.01$ \\
\hline
\end{tabular}




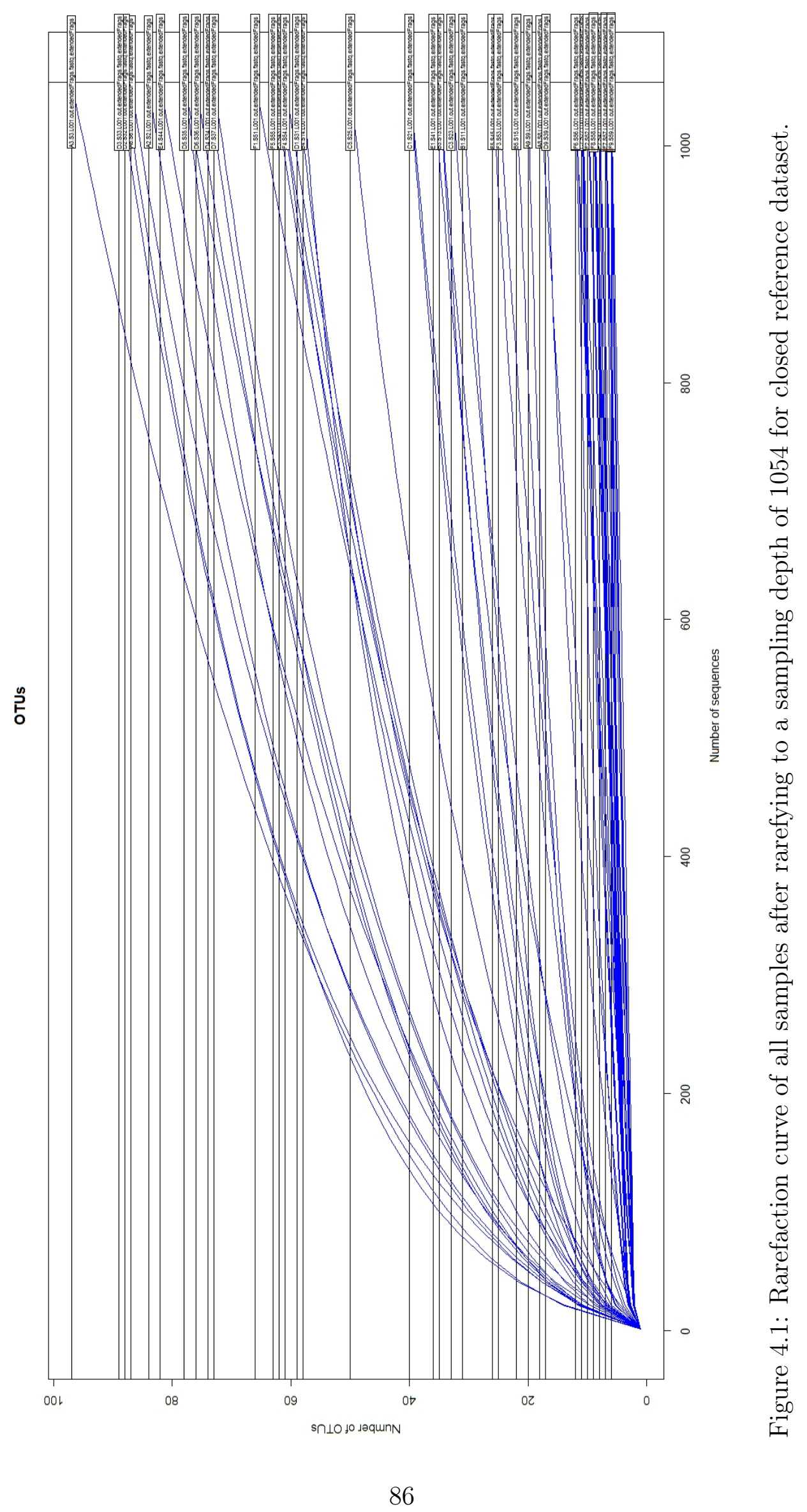



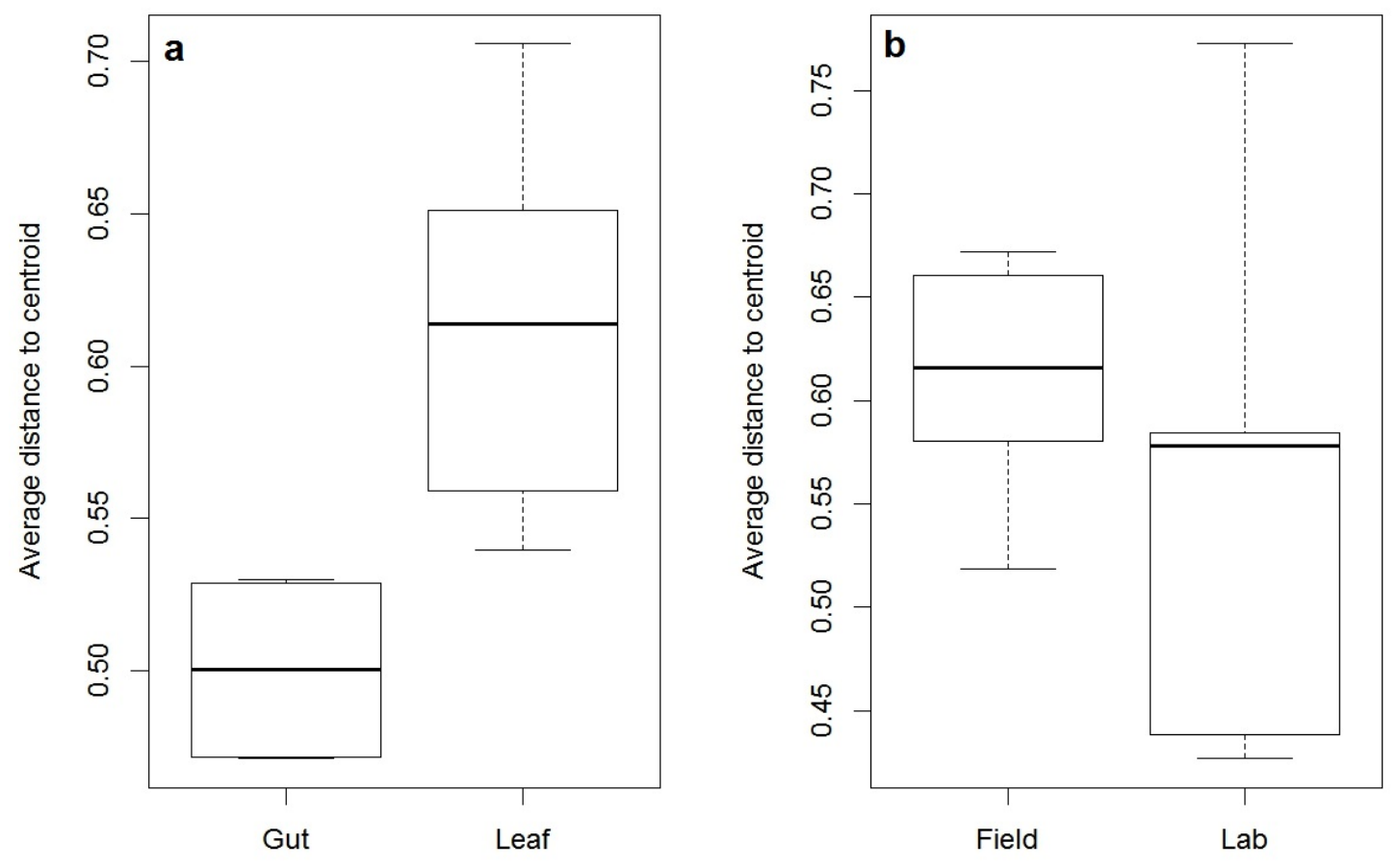

Figure 4.2: Variability in bacterial community using beta dispersion through BrayCurtis dissimilarity for a) host type; b) environment. 
Alpha-diversity pairwise comparison

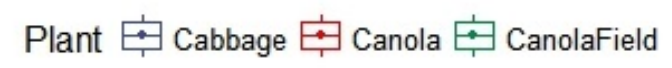

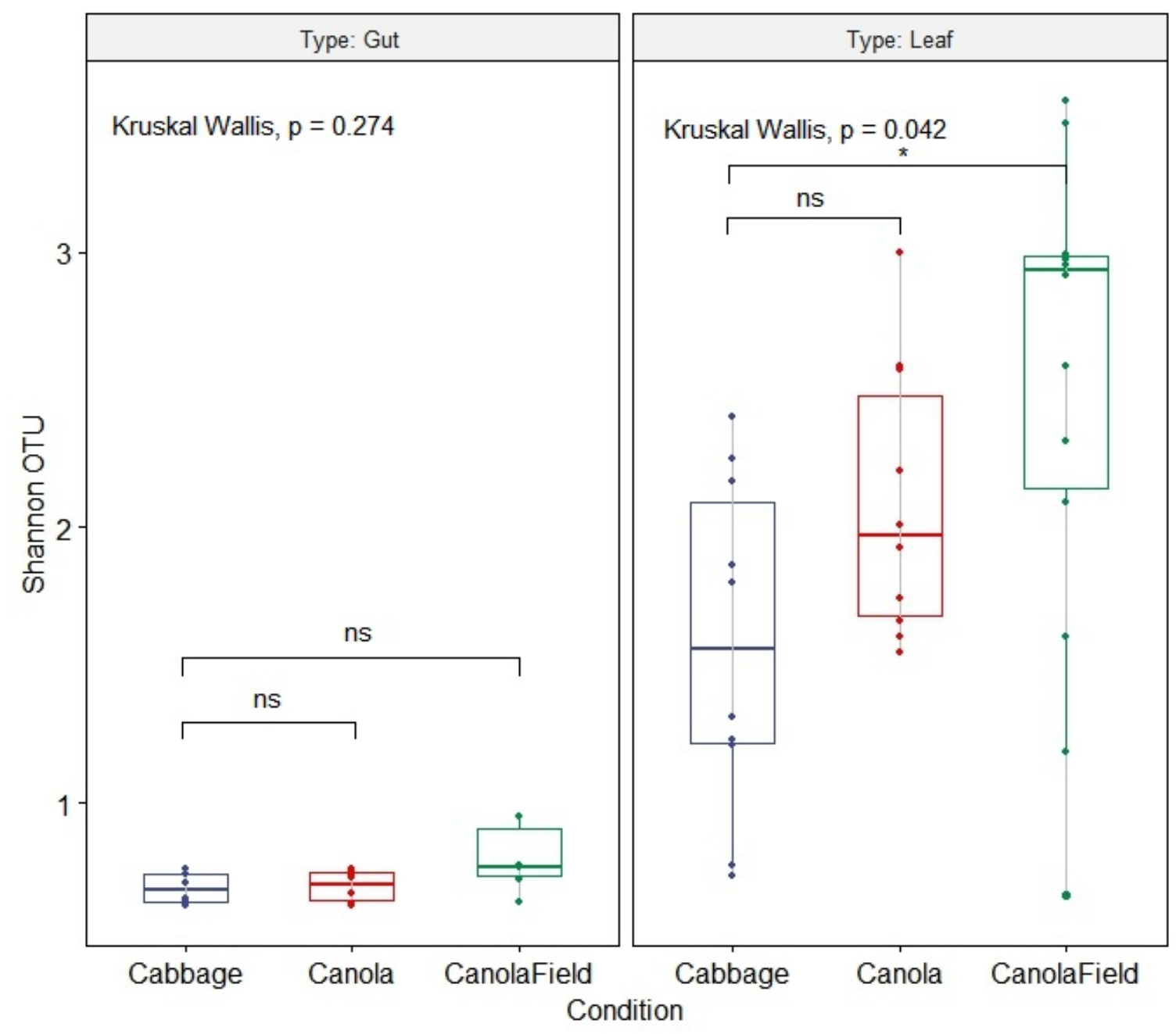

Figure 4.3: Plot comparing Shannon-Wiener index of OTUs in gut and leaves by plant type using the closed reference dataset. 


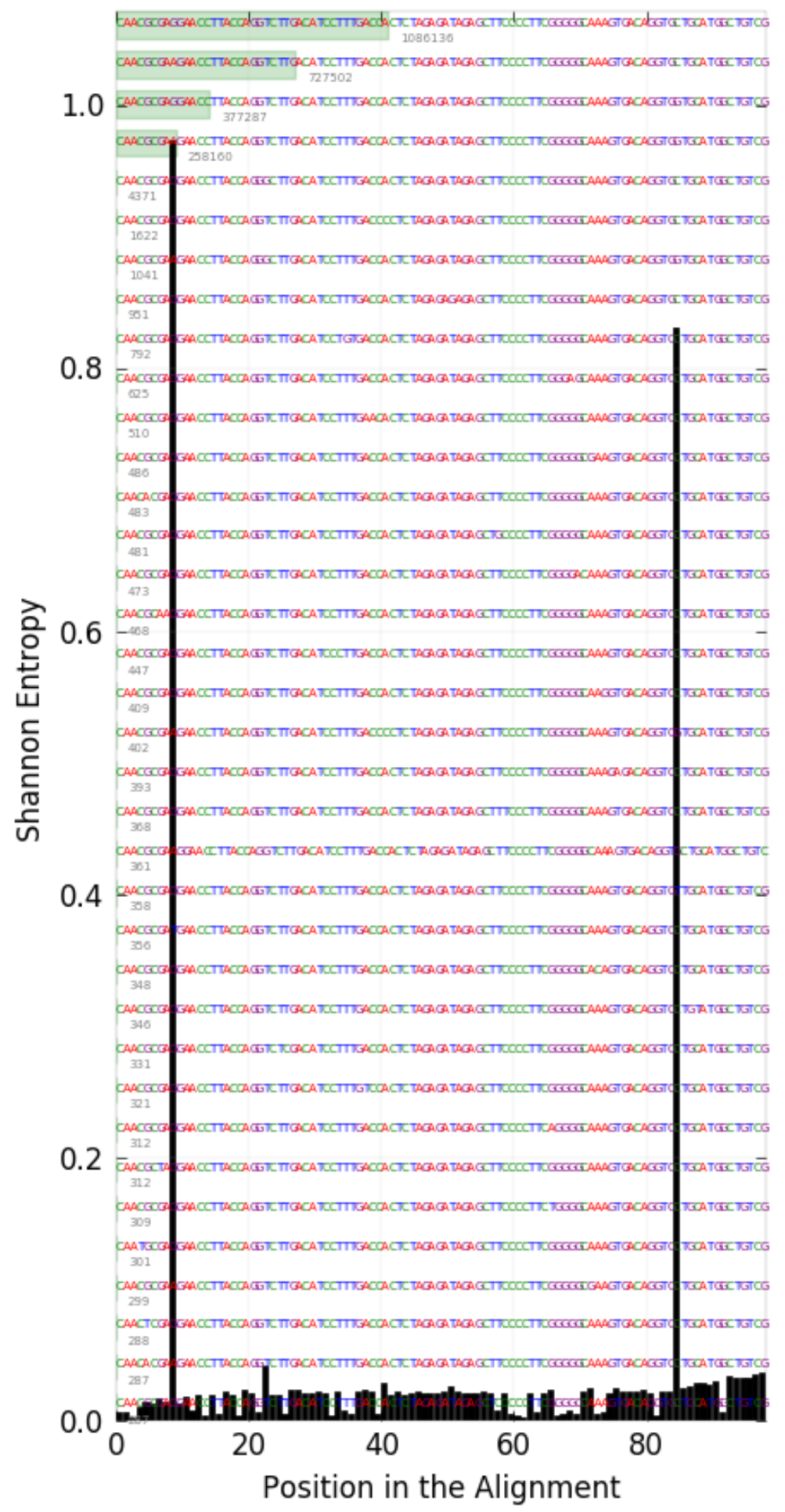

Figure 4.4: Shannon entropy analysis showing variable regions with high entropy in reads identified as Enterococcus. Highest variation was found in two regions at read positions 8 and 84. Data used was open reference dataset. 


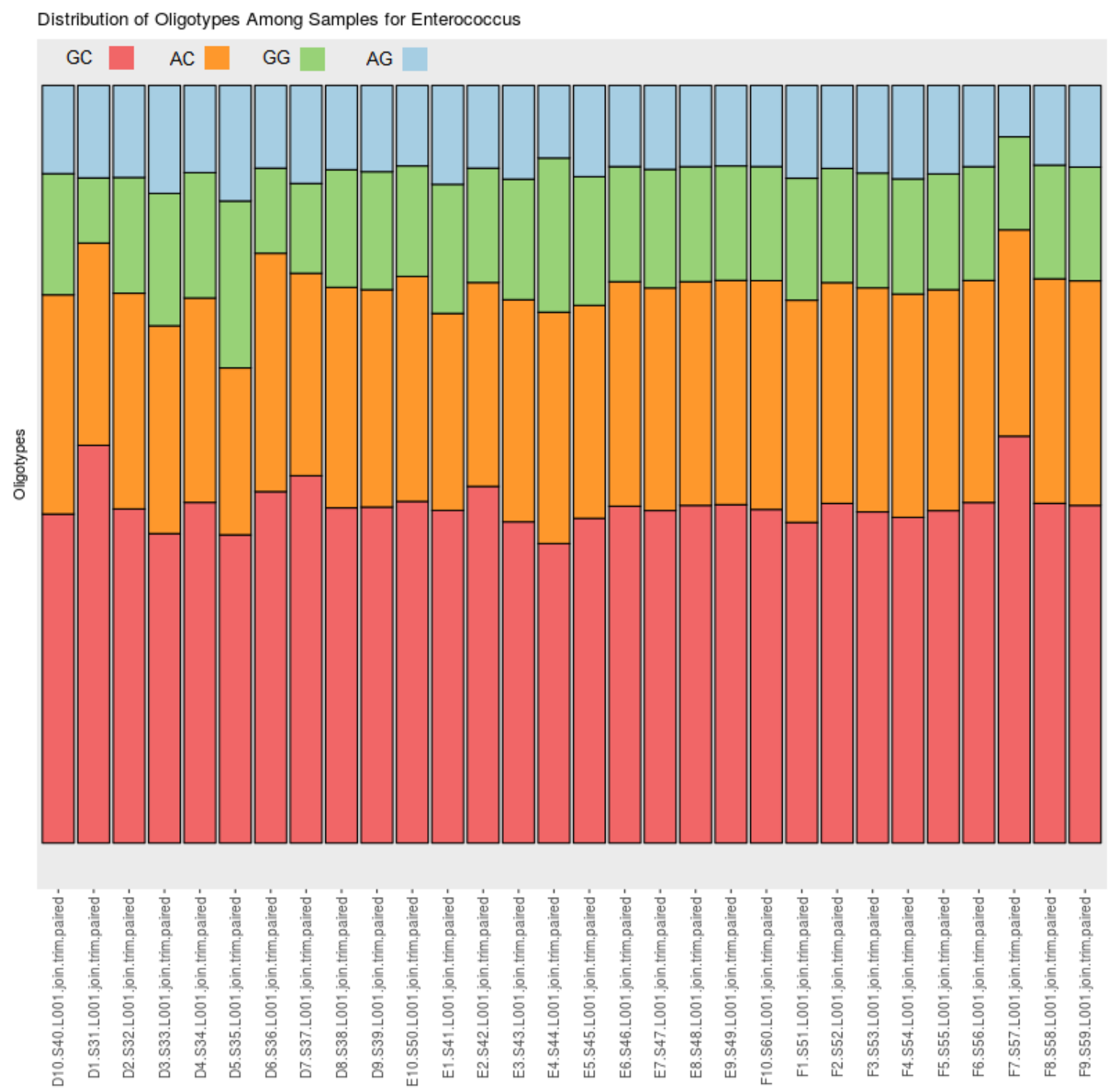

Figure 4.5: Output from Oligotyping analysis showing proportions of four different Enterococcus oligotypes in all samples. Data used for analysis was open reference $16 \mathrm{~S}$ V6 reads. 


\section{Chapter 5}

\section{General Conclusion}

As global temperatures increase, the range and population dynamics of pest species will likely shift (Olfert et al., 2016; Furlong and Zalucki, 2017). For the diamondback moth, understanding the capability of this species for cold temperature survival can help predict areas at risk of early infestation. In addition, revisiting the population dynamics of this species is important for pest management strategies moving into the future. New genomic tools can allow us to investigate the role of the insect microbiome in pest resistance, detoxification and immunity. Determining the effect of specific bacterial species on the biology of diamondback moth could lead to new strategies for biological control.

Summary of the literature determined diamondback moth was capable of surviving cold periods the longest at $0{ }^{\circ} \mathrm{C}$ in the adult stage. Chill-susceptible best describes the cold tolerance strategy for the diamondback moth. Overwintering likely occurs by outlasting periods of low temperature at any developmental stage. By outlining cold tolerance survival of the diamondback moth, it was determined that it is incapable of surviving Canadian winters. However, the latitude at which overwintering survival of the diamondback moth is possible was predicted to be much further North than previously mentioned in the literature. Winter temperatures in Ottawa during this study were too cold for diamondback moth to successfully overwinter.

The population dynamics of the diamondback moth remain much the same as in 
the studies conducted by Harcourt (1954, 1957, 1960b,a, 1963, 1986). In 2016 and 2017, there were 3-4 generations in the plot on the CEF. Generational mortality was over $99 \%$ in both years, with the major mortality factors being predation and abiotic and unknown factors. Diadegma insulare, Diadromus subtilicornis, Microplitis plutellae were the main parasitoids attacking diamondback moth in the past and present day in the Ottawa area (Harcourt, 1986, 1960a). Predation was a mortality factor looked at in this life table study that Harcourt had only made anecdotal observations on. The main species of predators were the carabid beetles: Harpalus pensylvanicus and Pterostichus melanarius. These beetles are confirmed predators of diamondback moth (Mauduit, 2012).

In examining the gut microbiome of diamondback moth larvae major differences in the bacterial community structure and composition were observed between the host the microbiome was found in (midgut or leaf). The diversity in the gut microbiome was consistent regardless of which plant the larvae fed on (cabbage, canola or field canola). With combined leaf and gut samples, the overall microbiome was different between the lab and the field. A large proportion of microbial abundance consisted of Enterococcus (Enterococcaceae). By examining more subtle variation beyond the OTU level, the community of Enterococcus did not differ between samples and was proportionally consistent among oligotypes of Enterococcus. This could potentially be contamination, however, considering that the abundance of Enterococcus was over 90 $\%$ of the gut microbiome of diamondback moth larvae, it appears to be highly unlikely. To date, studies have not found evidence of horizontal or vertical transmission of bacteria in diamondback moth, the microbiome is often assumed to be transient in this species. Diamondback moths have been shown to survive and develop in experimentally sterile conditions (e.g. Kaneko 1995; Raymond et al. 2009). Hammer et al. (2017) also determined that a symbiotic gut microbiome is not necessary for Lepidopteran development. Therefore, the microbiome of diamondback moth can be 
ecologically fluid depending on the treatment or conditions in nature. The studies by Lin et al. (2015) and Xia et al. $(2013,2017,2018)$ used specimens from Fuzhou (26.08 $\left.{ }^{\circ} \mathrm{N}, 119.28^{\circ} \mathrm{E}\right)$, Fujian, and Yangling region $\left(34.48^{\circ} \mathrm{N}, 108.13^{\circ} \mathrm{E}\right)$, Shaanxi, China, where the conditions are warmer and more humid compared to Ottawa, Canada. Differences in the major bacterial families between those studies and this study are likely attributed to geography and associated ecology of those regions.

\subsection{Limitations of research}

The major limitations in Chapter 3 were due choice of plant species used in the study. It has been shown that as plants mature their nutritional quality decreases by lower total nitrogen content and decreased palatability of the leaves (Awmack and Leather, 2002; Moreira et al., 2016). As cabbage matures and forms a bolt (or head) the younger tender leaves the early instars rely on, grow within the bolt and eventually become inaccessible. This may account for the smaller proportions of life stages found in the static life tables. However, after sampling, the plot was replanted with seedlings that could have acted as reservoirs of a young leaf resource for diamondback moth development in the plot. However, the author notes that due to the cool temperatures experienced in 2017, the lowest number of total individuals were recovered from the static life table despite the seedlings remaining in a small leafy state throughout the season (Dancau, personal observation). On the CEF, canola is planted in large plots and the presence of volunteer canola in adjacent and bordering plots may provide a superior food source for the larvae. This hypothesis is supported by an attempt to artificially infest both cabbage in the plot and neighbouring volunteer canola. Intentional introduction of diamondback moth eggs on plants in the experimental plot failed, whereas intentional infestation of volunteer canola was successful (Dancau, personal observation) (Section 4.3.1). In addition, parasitoid species composition in volunteer canola patches was strikingly different once the introduced diamondback 
moth individuals were recovered from the field (Dancau, personal observation). This suggests that the usual parasitoid complex associated with diamondback moth was present in the field in 2017, where canola provided a preferred environment for these parasitoids likely through a late season nectar resource and host availability. In this study cabbage was used as a host plant for the life table to reflect the methods used by Harcourt (1954). Experimental host plant choice and abiotic factors were the likely explanation for why the experiment did not detect these parasitoids in 2017. Future work on parasitoid community monitoring should consider a combination of host plants, including monitoring host plant quality.

The diamondback moth does not appear to overwinter in the Ottawa area. Therefore, population growth and transitional models can only be done on a monthly or generational scale and cannot be done on annual data. Due to pooling of the life table data into a single year the $R_{0}$ does not reflect growth rate over generation time. Additional life tables require more samples over multiple sites to obtain a better sense of the growth rate over the season. Based on field observation and life table data, it would appear infestations in the Ottawa area operated more like a population sink. Therefore, future studies should incorporate a source-sink population dynamics approach.

Using the values of $l_{x}$ calculated in each abridged life table, diamondback moth exhibits a type III survivorship curve. This type of curve indicates that the majority of the mortality experienced by this species occurs at the earliest life stages. Species of this type are typically characterized by the production of a large number of eggs. Since the static life tables showed the greatest abundance of late larval stages and pupal stages rather than the egg stage, the sampling was insufficient in describing the proper distribution of life stages in the field. Therefore, the net reproductive rate $\left(R_{0}\right)$ could not be calculated for the static life tables in this study.

Time limitations factored into Chapter 4. Despite having raw data from the V3 
region, the data preparation for the open reference pipeline encountered a fatal error. There was not enough time to resolve the error and to continue with the analysis. Hopefully, a full analysis can be completed in the future with the raw data generated in this study.

\subsection{Future directions}

Although Chapter 2 was a synthetic literature review, studies originating from China were difficult to obtain and through studies such as, Li et al. (2016) there is some exposure of that body of work to the English-speaking community. Through the review, another apparent knowledge gap involves little to no modern research on diamondback moth cold tolerance and overwintering in Europe. This is despite the presence of endemic species of Plutellidae that are fully capable of overwintering and diapause. As for Canada, more research needs to be done in the West, specifically in the province of British Columbia where there is potential for diamondback moth to survive most of the year in the temperate climate of the Fraser valley. Although British Columbia is not a prime growing region for Brassica sp., it could be a potential source of infestation into Alberta and Saskatchewan, although this will require testing.

For Chapter 3, the incorporation of high definition video monitoring may shed light on the behaviour of diamondback moth in the field as well as, the behaviour of predators. This will be most useful in describing the predator community since the use of pitfall trapping is not representative of the predator community nor is it direct evidence for predation on diamondback moth. Likewise, video monitoring can account for larvae that disappear or wander off the plant without interfering with the movement of predators and parasitoids. This can help disentangle the unknown mortality factor and aid in attributing predation mortality to specific species.

To help disentangle the abiotic mortality factor further in the life table, the reintroduction of the rain shelter treatment should be considered in future experiments. 
Although the shelters can aid in blocking rain specifically, the shelters can also act as sun shades and some protection from exposure. This can act as a treatment to simulate canopy cover or a sheltered site.

In Chapter 4 some methodological changes could greatly improve on the current study. Generally, full-length reads would greatly benefit the resolution and description of the microbiome since there was likely some primer bias for certain taxa in the current study. In addition, the incorporation of additional host plants, more specifically a treatment involving insects reared on cabbage in the field would have made the experimental design more rigorous. However, as explained in Section 5.1, intentional infestation of field cabbage late in the season was unsuccessful. This can be achieved with infesting plants earlier in the season. An additional treatment that was under consideration was a sterile treatment. Diamondback moth eggs hardened for 24 hours can successfully hatch after being submerged in $20 \%$ bleach solution for 10 seconds. However, sterile plant and insect rearing could not be achieved with the resources available and the treatment was ultimately abandoned. Another treatment that was considered involved wild cultivars of Brassica spp. and invasive plants in the Brassicaceae family but were deemed too difficult to grow in the greenhouse.

Although the diamondback moth has been a heavily studied species there are many areas that still require more research. Specifically, with climate change, the physiology of the diamondback moth must be scrutinized to determine its range in the future. Although, as shown in these studies, diamondback moth currently does not overwinter in Canada, this may not be indefinite as we continue into the future. For now, the population dynamics and natural enemies appear to be consistent and wellestablished across time. This could be an ideal system for the introduction of an exotic biological control agent such as, Diadromus collaris (Gravenhorst) (Hymenoptera: Ichneumonidae), a pre-pupal and pupal endoparasioid (Liu et al., 2001; Sarfraz et al., 
2005) that has been released in Australia (Goodwin, 1979), New Zealand, Barbados (Beck and Cameron, 1990), St. Helena (Kfir, 2005), Malaysia (Grzywacz et al., 2010), and Thailand (Rowell et al., 2005) for biological control of diamondback moth (Sarfraz et al., 2005). By providing current baseline data, new management strategies can be implemented in a modern day context. 


\section{References}

Abbott, W. (1925). A method of computing the effectiveness of an insecticide. Journal of Economic Entomology, 18(2):265-267.

Abram, P. K., Brodeur, J., Burte, V., and Boivin, G. (2016). Parasitoid-induced host egg abortion: an underappreciated component of biological control services provided by egg parasitoids. Biological Control, 98:52-60. doi: 10.1016/j.biocontrol.2016.04.002.

Amplicon, P. C. R., Clean-Up, P. C. R., and Index, P. C. R. (2013). 16s metagenomic sequencing library preparation. Available at: https://www.illumina.com/content/ dam/illumina-support/documents/documentation/chemistry_documentation/16s/ 16s-metagenomic-library-prep-guide-15044223-b.pdf.

Anderson, M. J. (2006). Distance-based tests for homogeneity of multivariate dispersions. Biometrics, 62(1):245-253. doi: 10.1111/j.1541-0420.2005.00440.x.

Anderson, M. J., Ellingsen, K. E., and McArdle, B. H. (2006). Multivariate dispersion as a measure of beta diversity. Ecology Letters, 9(6):683-693. doi: 10.1111/j.14610248.2006.00926.x.

Andrews, S. (2010). Fastqc: a quality control tool for high throughput sequence data. https://www. bioinformatics.babraham.ac.uk/projects/fastqc/.

Aronesty, E. (2011). ea-utils: Command-line tools for processing biological sequencing data. Durham, NC: Expression Analysis. https://github.com/ExpressionAnalysis/ ea-utils/blob/wiki/FastqJoin.md.

Atwal, A. (1955). Influence of temperature, photoperiod, and food on the speed of development, longevity, fecundity, and other qualities of the Diamondback moth Plutella maculipennis (Curtis) (Lepidoptera: Tineidae). Australian Journal of Zoology, 3(2):185221. doi: $10.1071 /$ ZO9550185.

Awmack, C. S. and Leather, S. R. (2002). Host plant quality and fecundity in herbivorous insects. Annual Review of Entomology, 47(1):817-844. doi: 10.1146/annurev.ento.47.091201.145300.

Bahar, H., Soroka, J. J., and Dosdall, L. M. (2012). Constant versus fluctuating temperatures in the interactions between Plutella xylostella (Lepidoptera: Plutellidae) and its larval parasitoid Diadegma insulare (Hymenoptera: Ichneumonidae). Environmental Entomology, 41(6):1653-1661. doi: 10.1603/EN12156.

Bahar, M., Soroka, J., Dosdall, L., and Olfert, O. (2013a). Occurrence of diamondback moth, Plutella xylostella (Lepidoptera: Plutellidae), and its larval parasitoids across 
Saskatchewan, Canada. Biocontrol Science and Technology, 23(6):724-729.

Bahar, M. H., Hegedus, D., Soroka, J., Coutu, C., Bekkaoui, D., and Dosdall, L. (2013b). Survival and hsp70 gene expression in Plutella xylostella and its larval parasitoid Diadegma insulare varied between slowly ramping and abrupt extreme temperature regimes. PloS One, 8(9):e73901. 10.1371/journal.pone.0073901.

Bale, J. (1996). Insect cold hardiness: a matter of life and death. European Journal of Entomology, 93:369-382.

Bale, J. and Hayward, S. (2010). Insect overwintering in a changing climate. Journal of Experimental Biology, 213(6):980-994.

Beck, N. and Cameron, P. (1990). Comparison of lepidopteran pest populations and their parasitoids in three vegetable brassicas. In Popay, A., editor, Proceedings of the Forty Third New Zealand Weed and Pest Control Conference, 14-16 August 1990, Dunedin, New Zealand, pages 21-25. New Zealand Weed and Pest Control Society Inc., Palmerston North, New Zealand.

Bellows, T., Van Driesche, R., and Elkinton, J. (1992). Life-table construction and analysis in the evaluation of natural enemies. Annual Review of Entomology, 37(1):587-612. doi: 10.1146/annurev.en.37.010192.003103.

Bellows, T. S. and Fisher, T. W. (1999). Handbook of biological control: principles and applications of biological control. Number 632.96 B4. Academic Press.

Berasategui, A., Salem, H., Paetz, C., Santoro, M., Gershenzon, J., Kaltenpoth, M., and Schmdit, A. (2017). Gut microbiota of the pine weevil degrades conifer diterpenes and increases insect fitness. Molecular Ecology, 26(15):4099-4110.

Berman, T. S., Laviad-Shitrit, S., Lalzar, M., Halpern, M., and Inbar, M. (2018). Cascading effects on bacterial communities: cattle grazing causes a shift in the microbiome of a herbivorous caterpillar. The International Society for Microbial Ecology Journal. Advance online publication. doi: 10.1038/s41396-018-0102-4.

Bolger, A. M., Lohse, M., and Usadel, B. (2014). Trimmomatic: a flexible trimmer for illumina sequence data. Bioinformatics, 30(15):2114-2120. http://www. usadellab.org/ cms/?page=trimmomatic.

Bousquet, Y., Bouchard, P., Davies, A. E., and Sikes, D. S. (2013). Checklist of beetles (Coleoptera) of Canada and Alaska. ZooKeys, 360:1-44.

Brandon, A. M., Gao, S.-H., Tian, R., Ning, D., Yang, S., Zhou, J., Wu, W.-M., and Criddle, C. S. (2018). Biodegradation of polyethylene and plastic mixtures in mealworms (larvae of Tenebrio molitor) and effects on the gut microbiome. Environmental science $\&$ Technology, 52(11):6526-6533.

Braun, L., Olfert, O., Soroka, J., Mason, P., and Dosdall, L. (2004). Diamondback moth 
biocontrol activities in canada. In Kirk, A. and Bordat, D., editors, Improving biocontrol of Plutella xylostella: Proceedings of the International Symposium, 21-24 October 2002, Montpellier, France, pages 144-146. French Agricultural Research Centre for International Development (CIRAD), Paris, France.

Bukovinszky, T., Poelman, E. H., Kamp, A., Hemerik, L., Prekatsakis, G., and Dicke, M. (2012). Plants under multiple herbivory: consequences for parasitoid search behaviour and foraging efficiency. Animal Behaviour, 83(2):501-509. doi: 10.1016/j.anbehav.2011.11.027.

Butts, R. and McEwen, F. (1981). Seasonal populations of the diamondback moth, Plutella xylostella (Lepidoptera: Plutellidae) in relation to day-degree accumulation. The Canadian Entomologist, 113(2):127-131. doi: 10.4039/Ent113127-2.

Butts, R. A. (1979). Some aspects of the biology and control of Plutella xylostella (L.)(Lepidoptera: Plutellidae) in southern Ontario. PhD thesis, University of Guelph.

Campos, W. G. (2008). Photoperiodism and seasonality in Neotropical population of Plutella xylostella L. (Lepidoptera: Yponomeutidae). Neotropical Entomology, 37(4):365-369. doi: 10.1590/S1519-566X2008000400003.

Canola Council of Canada (2016). The economic impact of canola on the canadian economy. www.canolacouncil.org/media/584356/lmc_canola_10-year_impact_study_-_ canada_final_dec_2016.pdf. [accessed 28 April 2017].

Caporaso, J. G., Kuczynski, J., Stombaugh, J., Bittinger, K., Bushman, F. D., Costello, E. K., Fierer, N., Pena, A. G., Goodrich, J. K., Gordon, J. I., Huttley, G., Kelley, S., Knights, D., Koenig, J., Ley, R., Lozupone, C., McDonald, D., Muegge, B., Pirrung, M., Reeder, J., Sevinsky, J., Turnbaugh, P., Walters, W., Widmann, J., Yatsunenko, T., Zaneveld, J., and Knight, R. (2010). Qiime allows analysis of high-throughput community sequencing data. Nature Methods, 7(5):335-336. http://qiime.org/index.html.

Capriol, M. A. and Tabashnik, B. E. (1992). Allozymes used to estimate gene flow among populations of diamondback moth (Lepidoptera: Plutellidae) in Hawaii. Environmental Entomology, 21(4):808-816. doi: 10.1093/ee/21.4.808.

Carey, J. R. (1993). Applied demography for biologists: with special emphasis on insects. Oxford University Press.

Carey, J. R. (2001). Insect biodemography. Annual Review of Entomology, 46(1):79-110.

Ceja-Navarro, J. A., Vega, F. E., Karaoz, U., Hao, Z., Jenkins, S., Lim, H. C., Kosina, P., Infante, F., Northen, T. R., and Brodie, E. L. (2015). Gut microbiota mediate caffeine detoxification in the primary insect pest of coffee. Nature communications, 6:7618.

Chakravorty, S., Helb, D., Burday, M., Connell, N., and Alland, D. (2007). A detailed analysis of $16 \mathrm{~S}$ ribosomal RNA gene segments for the diagnosis of pathogenic bacteria. Journal of Microbiological Methods, 69(2):330-339. 
Chang, W. X., Tabashnik, B. E., Artelt, B., Malvar, T., Ballester, V., Ferré, J., and Roderick, G. K. (1997). Mitochondrial DNA sequence variation among geographic strains of diamondback moth (Lepidoptera: Plutellidae). Annals of the Entomological Society of America, 90(5):590-595. doi: 10.1093/aesa/90.5.590.

Chapman, J. W., Reynolds, D. R., Smith, A. D., Riley, J. R., Pedgley, D. E., and Woiwod, I. P. (2002). High-altitude migration of the diamondback moth Plutella xylostella to the UK: a study using radar, aerial netting, and ground trapping. Ecological Entomology, 27(6):641-650. doi: 10.1046/j.1365-2311.2002.00472.x.

Chaturvedi, S., Rego, A., Lucas, L. K., and Gompert, Z. (2017). Sources of Variation in the Gut Microbial Community of Lycaeides melissa Caterpillars. Scientific Reports, 7(11335).

Chen, W., Simpson, J., and Levesque, A. C. (2016). Ram: R for amplicon-sequencing-based microbial-ecology. $\mathrm{R}$ package version 1.2.1.3.

Chen, X. and Zhang, Y. (2015). Identification of multiple small heat-shock protein genes in Plutella xylostella (L.) and their expression profiles in response to abiotic stresses. Cell Stress and Chaperones, 20(1):23-35. 10.1007/s12192-014-0522-7.

Cheng, D., Guo, Z., Riegler, M., Xi, Z., Liang, G., and Xu, Y. (2017). Gut symbiont enhances insecticide resistance in a significant pest, the oriental fruit fly Bactrocera dorsalis (Hendel). Microbiome, 5(13):1-12.

Choi, B. G., Hepat, R., and Kim, Y. (2014). RNA interference of a heat shock protein, Hsp70, loses its protection role in indirect chilling injury to the beet armyworm, Spodoptera exigua. Comparative Biochemistry and Physiology Part A: Molecular 85 Integrative Physiology, 168:90-95. doi: 10.1016/j.cbpa.2013.11.011.

Chown, S. and Sinclair, B. (2010). The macrophysiology of insect cold hardiness. In Denlinger, D. and Lee, R., editors, Low Temperature Biology of Insects, pages 191-222. Cambridge University Press, Cambridge, United Kingdom.

Christie, F. J., Cassis, G., and Hochuli, D. F. (2010). Urbanization affects the trophic structure of arboreal arthropod communities. Urban Ecosystems, 13(2):169-180. doi: 10.1016/j.biocon.2013.05.002.

Chu, Y. (1986). The migration of diamondback moth. In Talekar, N. and Griggs, T., editors, Diamondback moth management. Proceedings of the First International Workshop, 11-15 March 1985, Tainan, Taiwan, pages 77-81. Asian Vegetable Research and Development Center, Shanhua, Taiwan.

Colinet, H., Sinclair, B. J., Vernon, P., and Renault, D. (2015). Insects in fluctuating thermal environments. Annual Review of Entomology, 60(1):123-140. doi: 10.1146/annurev-ento010814-021017.

Coon, K. L., Vogel, K. J., Brown, M. R., and Strand, M. R. (2014). Mosquitoes rely on 
their gut microbiota for development. Molecular Ecology, 23(11):2727-2739.

Cortés, E. (2002). Incorporating uncertainty into demographic modeling: application to shark populations and their conservation. Conservation Biology, 16(4):1048-1062.

Coulson, S., Hodkinson, I., Webb, N., Mikkola, K., Harrison, J., and Pedgley, D. (2002). Aerial colonization of high Arctic islands by invertebrates: the diamondback moth Plutella xylostella (Lepidoptera: Yponomeutidae) as a potential indicator species. Diversity and Distributions, 8(6):327-334. doi: 10.1046/j.1472-4642.2002.00157.x.

Dale, A. G. and Frank, S. D. (2014). Urban warming trumps natural enemy regulation of herbivorous pests. Ecological Applications, 24(7):1596-1607. doi: 10.1890/13-1961.1.

Dancau, T., Mason, P. G., and Cappuccino, N. (2018). Elusively overwintering: a review of diamondback moth (lepidoptera: Plutellidae) cold tolerance and overwintering strategy. The Canadian Entomologist, 150(2):156-173. doi: 10.4039/tce.2018.2.

Denlinger, D. and Lee, R. (2010). Rapid cold-hardening: ecological significance and underpinning mechanisms. In Denlinger, D. and Lee, R., editors, Low Temperature Biology of Insects, pages 35-58. Cambridge University Press, Cambridge, United Kingdom.

Denlinger, D. L. (2002). Regulation of diapause. Annual Review of Entomology, 47(1):93122. doi: 10.1146/annurev.ento.47.091201.145137.

DeSantis, T. Z., Hugenholtz, P., Larsen, N., Rojas, M., Brodie, E. L., Keller, K., Huber, T., Dalevi, D., Hu, P., and Andersen, G. L. (2006). Greengenes, a chimera-checked 16s rrna gene database and workbench compatible with arb. Applied and Environmental Microbiology, 72(7):5069-5072. http://greengenes . secondgenome.com/.

Dosdall, L., Mason, P., Olfert, O., Kaminski, L., and Keddie, B. (2001). The origins of infestations of diamondback moth, Plutella xylostella (L.), in canola in western Canada. In Endersby, N. and Ridland, P., editors, The management of diamondback moth and other crucifer pests: Proceedings of the Fourth International Workshop, 26-29 November 2001, Melbourne, Australia, pages 95-100. The Regional Institute Ltd, Gosford, Australia.

Dosdall, L., Soroka, J., and Olfert, O. (2011). The diamondback moth in canola and mustard: current pest status and future prospects. Prairie Soils and Crops, 4:66-76. https: //prairiesoilsandcrops.ca/articles/volume-4-8-screen.pdf. [accessed 4 January 2018].

Dosdall, L., Weiss, R., Olfert, O., Mason, P., and Soroka, J. (2006). Diamondback moth, Plutella xylostella (L.), as a pest of canola in Canada: Its historical impact on the crop and predicted effects of climate change on its pest status. In Shelton, A., Collins, H., Youjun, Z., and Qingjun, W., editors, Proceedings of the Fifth International Workshop on the Management of Diamondback Moth and Other Crucifer Pests, 21-24 October 2006, Beijing, China, volume 24, pages 112-121. China Agricultural Science and Technology 
Press, Beijing, China.

Dosdall, L. M. (1994). Evidence for successful overwintering of diamondback moth, Plutella xylostella (L.)(Lepidoptera: Plutellidae), in Alberta. The Canadian Entomologist, 126(1):183-185. doi: 10.4039/Ent126183-1.

Dosdall, L. M. and Mason, P. G. (2010). Key pests and parasitoids of oilseed rape or canola in north america and the importance of parasitoids in integrated management. In I., W., editor, Biocontrol-based integrated management of oilseed rape pests, pages 167-213. Springer, Boston, Massachusetts, United States of America.

Edgar, R. C., Haas, B. J., Clemente, J. C., Quince, C., and Knight, R. (2011). Uchime improves sensitivity and speed of chimera detection. Bioinformatics, 27(16):2194-2200. https://drive5.com/usearch/manual/uchime_algo.html.

Endersby, N., McKechnie, S., Ridland, P., and Weeks, A. (2006). Microsatellites reveal a lack of structure in Australian populations of the diamondback moth, Plutella xylostella (L.). Molecular Ecology, 15(1):107-118. doi: 10.1111/j.1365-294X.2005.02789.x.

Eren, A. M., Maignien, L., Sul, W. J., Murphy, L. G., Grim, S. L., Morrison, H. G., and Sogin, M. L. (2013). Oligotyping: differentiating between closely related microbial taxa using 16s rrna gene data. Methods in Ecology and Evolution, 4(12):1111-1119. http: //merenlab.org/software/oligotyping/.

Fenoglio, M. S., Salvo, A., and Estallo, E. L. (2009). Effects of urbanisation on the parasitoid community of a leafminer. Acta Oecologica, 35(2):318-326. doi: 10.1016/j.actao.2008.12.001.

Fenoglio, M. S., Videla, M., Salvo, A., and Valladares, G. (2013). Beneficial insects in urban environments: Parasitism rates increase in large and less isolated plant patches via enhanced parasitoid species richness. Biological Conservation, 164:82-89. doi: 10.1016/j.biocon.2013.05.002.

Ferré, J., Real, M. D., Van Rie, J., Jansens, S., and Peferoen, M. (1991). Resistance to the Bacillus thuringiensis bioinsecticide in a field population of Plutella xylostella is due to a change in a midgut membrane receptor. Proceedings of the National Academy of Sciences, 88(12):5119-5123. doi: 10.1073/pnas.88.12.5119.

Frost, S. (1949). The diamondback moth in pennsylvania. Journal of Economic Entomology, 42(4):681-682.

Furlong, M. J., Shi, Z., Guo, S., Liu, Y., Liu, S., and Zalucki, M. (2004a). Quantitative evaluation of the biotic mortality factors affecting diamondback moth in south-east queensland, australia. In Endersby, N. and Ridland, P., editors, The management of diamondback moth and other crucifer pests: Proceedings of the 4 th international workshop, 26-29 November 2001, Melbourne, Australia, pages 185-193. The Regional Institute Ltd, 
Gosford, Australia.

Furlong, M. J., Shi, Z., Liu, S., and Zalucki, M. P. (2004b). Evaluation of the impact of natural enemies on Plutella xylostella L.(Lepidoptera: Yponomeutidae) populations on commercial Brassica farms. Agricultural and Forest Entomology, 6(4):311-322. doi: 10.1111/j.1461-9555.2004.00228.x.

Furlong, M. J., Wright, D. J., and Dosdall, L. M. (2013). Diamondback moth ecology and management: problems, progress, and prospects. Annual Review of Entomology, 58:517541. doi: 10.1146/annurev-ento-120811-153605.

Furlong, M. J. and Zalucki, M. P. (2017). Climate change and biological control: the consequences of increasing temperatures on host-parasitoid interactions. Current Opinion in Insect Science, 20:39-44. doi: 10.1016/j.cois.2017.03.006.

Gagné, S. A. and Fahrig, L. (2010). The trade-off between housing density and sprawl area: minimizing impacts to carabid beetles (Coleoptera: Carabidae). Ecology and Society, $15(4): 12$.

Ganley, J., Carr, G., Ioerger, T., Sacchettini, J., Clardy, J., and Derbyshire, E. (2018). Discovery of antimicrobial lipodepsipeptides produced by a Serratia sp. within mosquito microbiomes. ChemBioChem. Advance online publication. doi: 10.1002/cbic.201800124.

Gibb, H. and Hochuli, D. F. (2002). Habitat fragmentation in an urban environment: large and small fragments support different arthropod assemblages. Biological Conservation, 106(1):91-100. doi: 10.1016/S0006-3207(01)00232-4.

Golizadeh, A., Kamali, K., Fathipour, Y., and Abbasipour, H. (2007). Temperaturedependent development of diamondback moth, Plutella xylostella (Lepidoptera: Plutellidae) on two brassicaceous host plants. Insect Science, 14(4):309-316. doi: 10.1111/j.17447917.2007.00157.x.

Goodwin, S. (1979). Changes in Numbers in the Parasitoid Complex Associated With the Diamond-Back Moth, Plutella Xylostella (L.)(Lepidoptera), in Victoria. Australian Journal of Zoology, 27(6):981-989. doi: 10.1071/ZO9790981.

Goodwin, S. and Danthanarayana, W. (1984). Flight activity of Plutella xylostella (L.)(Lepidoptera: Yponomeutidae). Austral Entomology, 23(3):235-240.

Gressel, J. (2018). Microbiome facilitated pest resistance: potential problems and uses. Pest Management Science, 74(3):511-515.

Grzywacz, D., Rossbach, A., Rauf, A., Russell, D., Srinivasan, R., and Shelton, A. (2010). Current control methods for diamondback moth and other Brassica insect pests and the prospects for improved management with Lepidopteran-resistant Bt vegetable Brassicas in Asia and Africa. Crop Protection, 29(1):68-79. doi: 10.1016/j.cropro.2009.08.009.

$\mathrm{Gu}$, H. (2009). Cold tolerance and overwintering of the diamondback moth (Lepidoptera: 
Plutellidae) in Southeastern Australia. Environmental Entomology, 38(3):524-529. doi: 10.1603/022.038.0303.

Gutierrez, A. P. and Ellis, C. (1996). Applied population ecology: a supply-demand approach. John Wiley \& Sons.

Hammer, T. J., Dickerson, J. C., and Fierer, N. (2015). Evidence-based recommendations on storing and handling specimens for analyses of insect microbiota. PeerJ, 3:e1190.

Hammer, T. J., Janzen, D. H., Hallwachs, W., Jaffe, S. P., and Fierer, N. (2017). Caterpillars lack a resident gut microbiome. Proceedings of the National Academy of Sciences, 114(36):9641-9646.

Hance, T., Van Baaren, J., Vernon, P., and Boivin, G. (2007). Impact of extreme temperatures on parasitoids in a climate change perspective. Annual Review of Entomology, 52:107-126. doi: 10.1146/annurev.ento.52.110405.091333.

Hansen, J., Ruedy, R., Sato, M., and Lo, K. (2010). Global surface temperature change. Reviews of Geophysics, 48(4):1-29. doi: 10.1029/2010RG000345.

Hanshew, A. S., Mason, C. J., Raffa, K. F., and Currie, C. R. (2013). Minimization of chloroplast contamination in $16 \mathrm{~s}$ rrna gene pyrosequencing of insect herbivore bacterial communities. Journal of Microbiological Methods, 95(2):149-155.

Harcourt, D. (1954). The Biology and Ecology of the Diamondback Moth, Plutella maculipennis (Curt.). PhD thesis, Cornell University.

Harcourt, D. (1957). Biology of the diamondback moth, Plutella maculipennis (Curt.)(Lepidoptera: Plutellidae), in eastern Ontario. II. Life-history, behaviour, and host relationships. The Canadian Entomologist, 89(12):554-564.

Harcourt, D. (1960a). Biology of the diamondback moth, Plutella maculipennis (Curt.)(Lepidoptera: Plutellidae), in eastern Ontario III. Natural enemies. The Canadian Entomologist, 92(6):419-428.

Harcourt, D. (1960b). Distribution of the immature stages of the diamondback moth, Plutella maculipennis (Curt.)(Lepidoptera: Plutellidae), on cabbage. The Canadian Entomologist, 92(7):517-521. doi: 10.4039/Ent92517-7.

Harcourt, D. (1963). Major mortality factors in the population dynamics of the diamondback moth, Plutella maculipennis (Curt.)(Lepidoptera: Plutellidae). In LeRoux, E. J., editor, Population dynamics of agricultural and forest pests, volume 32, pages 55-66. The Memoirs of the Entomological Society of Canada, Ottawa, Ontario, Canada.

Harcourt, D. (1986). Population dynamics of the diamondback moth in southern Ontario. In Talekar, N. S. and Griggs, T. D., editors, Diamondback Moth Management, pages 315. Proceedings of the First International Workshop, Tainan, Taiwan, 11-15 March 1985, Shanhua, Taiwan, Asian Vegetable Research and Development Center, Shanhua, Taiwan. 
Harcourt, D. and Cass, L. (1966). Photoperiodism and fecundity in Plutella maculipennis (Curt.). Nature, 210(5032):217-218. doi: 10.1038/210217a0.

Hardy, J. E. (1938). Plutella maculipennis, Curt., its natural and biological control in England. Bulletin of Entomological Research, 29(4):343-372. doi: $10.1017 /$ S0007485300026274.

Hawkins, B. A., Cornell, H. V., and Hochberg, M. E. (1997). Predators, parasitoids, and pathogens as mortality agents in phytophagous insect populations. Ecology, 78(7):21452152 .

Hayakawa, H., Tsutsui, H., and Goto, C. (1988). A survey of overwintering of the diamondback moth, Plutella xylostella Linné, in the Tokachi district of Hokkaido. Annual Report of the Society of Plant Protection of North Japan, 39:227-228.

He, H., Wei, C., and Wheeler, D. E. (2014). The Gut Bacterial Communities Associated with Lab-Raised and Field-Collected Ants of Camponotus fragilis (Formicidae: Formicinae). Current Microbiology, 69(3):292-302.

Heppell, S. S. (1998). Application of life-history theory and population model analysis to turtle conservation. Copeia, 2:367-375.

Hernández-Martínez, P., Naseri, B., Navarro-Cerrillo, G., Escriche, B., Ferré, J., and Herrero, S. (2010). Increase in midgut microbiota load induces an apparent immune priming and increases tolerance to Bacillus thuringiensis. Environmental Microbiology, 12(10):2730-2737.

Hodkova, M. and Hodek, I. (2004). Photoperiod, diapause and cold-hardiness. European Journal of Entomology, 101(3):445-458. doi: 10.14411/eje.2004.064.

Honda, K. (1992). Hibernation and migration of diamondback moth in northern japan. In Talekar, N., editor, Diamondback moth and other crucifer pests: Proceedings of the second international workshop, 10-14 December 1990, Tainan, Taiwan., pages 43-50. Asian Vegetable Research and Development Center, Tainan, Taiwan.

Honda, K., Miyahara, Y., and Kegasawa, K. (1992). Seasonal abundance and the possibility of spring immigration of the diamondback moth, Plutella xylostella (Linnaeus)(Lepidoptera: Yponomeutidae), in Morioka City, northern Japan. Applied Entomology and Zoology, 27(4):517-525. doi: 10.1303/aez.27.517.

Hopkinson, R. and Soroka, J. (2010). Air trajectory model applied to an in-depth diagnosis of potential diamondback moth infestations on the Canadian Prairies. Agricultural and Forest Meteorology, 150(1):1-11. doi: 10.1016/j.agrformet.2009.07.015.

Hosseini, R., Keller, M., Schmidt, O., and Baker, G. (2006). Predators associated with crop pests of Brassica spp. In Shelton, A., Collins, H., Youjun, Z., and Qingjun, W., editors, Proceedings of the Fifth International Workshop on the Management of Diamondback 
Moth and Other Crucifer Pests, 21-24 October 2006, Beijing, China, volume 24, page 27. China Agricultural Science and Technology Press, Beijing, China.

Idris, A. and Grafius, E. (1996). Evidence of pre-imaginal overwintering of diamondback moth, Plutella xylostella (Lepidoptera). Great Lakes Entomologist, 29(1):25-30.

Indiragandhi, P., Anandham, R., Madhaiyan, M., Poonguzhali, S., Kim, G., Saravanan, V., and Sa, T. (2007). Cultivable bacteria associated with larval gut of prothiofos-resistant, prothiofos-susceptible and field-caught populations of diamondback moth, Plutella xylostella and their potential for, antagonism towards entomopathogenic fungi and host insect nutrition. Journal of Applied Microbiology, 103(6):2664-2675.

Jaddoe, V. W., van Duijn, C. M., van der Heijden, A. J., Mackenbach, J. P., Moll, H. A., Steegers, E. A., Tiemeier, H., Uitterlinden, A. G., Verhulst, F. C., and Hofman, A. (2010). The Generation R Study: design and cohort update 2010. European Journal of Epidemiology, 25(11):823-841.

Jungreis, A. (1978). Insect dormancy. In Clutter, M., editor, Dormancy and developmental arrest: experimental analysis in plants and animals., pages 47-102. Academic Press, New York, New York, United States of America.

Juric, I., Salzburger, W., and Balmer, O. (2017). Spread and global population structure of the diamondback moth Plutella xylostella (Lepidoptera: Plutellidae) and its larval parasitoids Diadegma semiclausum and Diadegma fenestrale (Hymenoptera: Ichneumonidae) based on mtDNA. Bulletin of Entomological Research, 107(2):155-164. doi: $10.1017 /$ S0007485316000766.

Kaneko, J. (1995). Supercooling point of the diamondback moth, Plutella xylostella (L.): seasonal variations in field collecting individuals and differences by stage in rearing ones. Annual Report of the Society of Plant Protection of North Japan, 46:147-152.

Kanervo, V. (1936). The diamond back moth (Plutella maculipennis Curt.) as a pest of cruciferous plants in Finland. Valtion Maatalouskoetoiminnan Julkaisuja, 86:1-86.

Kfir, R. (2005). The impact of parasitoids on Plutella xylostella populations in South Africa and the successful biological control of the pest on the Island of St. Helena. In Hoddle, M., editor, Second International Symposium on Biological Control of Arthropods, 12-16 September 2005, Davos, Switzerland, pages 132-141, Washington DC, United States of America. United States Department of Agriculture, Forest Service.

Kikuchi, Y., Hayatsu, M., Hosokawa, T., Nagayama, A., Tago, K., and Fukatsu, T. (2012). Symbiont-mediated insecticide resistance. Proceedings of the National Academy of Sciences, 109(22):8618-8622.

Kim, E., Choi, B., Park, Y., Cha, O., Jung, C., Lee, D., Kim, K., and Kim, Y. (2014). Overwintering conditions of the diamondback moth and genetic variation of 
overwintering populations. Korean Journal of Applied Entomology, 53(4):355-365. doi: 10.5656/KSAE.2014.09.0.035.

Kim, E., Park, A., Park, Y., Kim, J., and Kim, Y. (2015). Decrease in genetic variation of overwintering populations of the diamondback moth during seasonal occurrence. Korean Journal of Applied Entomology, 54(4):303-310. doi: 10.5656/KSAE.2015.08.0.028.

Kim, I., Bae, J., Choi, K., Jin, B., Lee, K., and Sohn, H. (2000). Haplotype diversity and gene flow of the diamondback moth, Plutella xylostella (L.)(Lepidoptera: Yponomeutidae), in Korea. Korean Journal of Applied Entomology, 39(1):43-52.

Kimura, T. and Fujimura, T. (1988). Overwintering of the diamondback moth, Plutella xylostella Linne, in Aomori Prefecture. 4. Longevity of eggs, larvae, pupae and adults under the snow. Annual Report of the Society of Plant Protection of North Japan, 39:229231.

Kimura, T., Fujimura, T., and Araya, E. (1987a). Overwintering of the diamondback moth, Plutella xylostella Linne, in Aomori prefecture. 1. Field research on survivors after winter. Annual Report of the Society of Plant Protection of North Japan, 38:135-137.

Kimura, T., Fujimura, T., and Araya, E. (1987b). Overwintering of the diamondback moth, Plutella xylostella Linne, in Aomori prefecture. 2. Overwintering of adults, larvae and pupae released in a field or in a glass house before winter. Annual Report of the Society of Plant Protection of North Japan, 38:138-140.

Kimura, T., Fujimura, T., and Araya, E. (1987c). Overwintering of the diamondback moth, Plutella xylostella Linne, in Aomori Prefecture. 3. Mortality of the second instar larvae. Annual Report of the Society of Plant Protection of North Japan, 38:141-142.

Kindt, R. and Coe, R. (2005). Tree diversity analysis: a manual and software for common statistical methods for ecological and biodiversity studies. World Agroforestry Centre.

King, A. M. and MacRae, T. H. (2015). Insect heat shock proteins during stress and diapause. Annual Review of Entomology, 60:59-75. doi: 10.1146/annurev-ento-011613162107.

Klindworth, A., Pruesse, E., Schweer, T., Peplies, J., Quast, C., Horn, M., and Glöckner, F. O. (2013). Evaluation of general 16s ribosomal rna gene pcr primers for classical and next-generation sequencing-based diversity studies. Nucleic Acids Research, 41(1):e1.

Koštál, V. (2006). Eco-physiological phases of insect diapause. Journal of Insect Physiology, 52(2):113-127. doi: 10.1016/j.jinsphys.2005.09.008.

Koštál, V., Renault, D., Mehrabianova, A., and Bastl, J. (2007). Insect cold tolerance and repair of chill-injury at fluctuating thermal regimes: role of ion homeostasis. Comparative Biochemistry and Physiology Part A: Molecular $\&$ Integrative Physiology, 147(1):231-238. doi: $10.1016 /$ j.cbpa.2006.12.033. 
Krams, I. A., Kecko, S., Jõers, P., Trakimas, G., Elferts, D., Krams, R., Luoto, S., Rantala, M. J., Inashkina, I., Gudrā, D., Fridmanis, D., Contreras-Garduño, J., Frantiṇa-leviṇa, L., and Krama, T. (2017). Microbiome symbionts and diet diversity incur costs on the immune system of insect larvae. Journal of Experimental Biology, 220(22):4204-4212.

Kregel, K. C. (2002). Invited review: heat shock proteins: modifying factors in physiological stress responses and acquired thermotolerance. Journal of Applied Physiology, 92(5):21772186. doi: 10.1152/japplphysiol.01267.2001.

Kulaserkera, K. (2014). Historical provincial estimates by crop, 1981-2014 (canola). www . omafra.gov.on.ca/english/stats/crops/estimate_hist_metric.htm\#Canola. [accessed 18 April 2017].

Landry, M., Comeau, A. M., Derome, N., Cusson, M., and Levesque, R. C. (2015). Composition of the spruce budworm (Choristoneura fumiferana) midgut microbiota as affected by rearing conditions. PloS One, 10(12):e0144077.

Larochelle, A. and Larivière, M.-C. (2003). Natural history of the ground-beetles (Coleoptera: Carabidae) of America north of Mexico. Pensoft.

Leather, S. R., Walters, K. F., and Bale, J. S. (1993). The Ecology of Insect Overwintering. Cambridge University Press, Cambridge, United Kingdom.

Lebeis, S. L. (2017). Plant microbiome identification and characterization. Current Protocols in Plant Biology, 2:135-146. doi: 10.1002/cppb.20048.

Lee, R. (2010). A primer on insect cold-tolerance. In Denlinger, D. and Lee, R., editors, Low Temperature Biology of Insects., pages 3-34. Cambridge University Press, Cambridge, United Kingdom.

Levene, H. (1960). Robust tests for equality of variance. In Olkin, I., Ghurye, S., Hoeffeling, W., Madow, W., and Mann, H., editors, Contributions to Probability and Statistics, pages 278-292. Stanford University Press, Stanford, California, United States of America.

Li, W. and Godzik, A. (2006). Cd-hit: a fast program for clustering and comparing large sets of protein or nucleotide sequences. Bioinformatics, 22(13):1658-1659. http://weizhongli-lab.org/cd-hit/.

Li, Z., Feng, X., Liu, S., You, M., and Furlong, M. J. (2016). Biology, ecology, and management of the diamondback moth in China. Annual Review of Entomology, 61:277-296. doi: 10.1146/annurev-ento-010715-023622.

Lin, X. L., Kang, Z. W., Pan, Q. J., and Liu, T. X. (2015). Evaluation of five antibiotics on larval gut bacterial diversity of Plutella xylostella (Lepidoptera: Plutellidae). Insect Science, 22(5):619-628.

Liu, S., Chen, F., and Zalucki, M. P. (2002). Development and survival of the diamondback moth (Lepidoptera: Plutellidae) at constant and alternating temperatures. Environmental 
Entomology, 31(2):221-231. doi: 10.1603/0046-225X-31.2.221.

Liu, S., Wang, X., Guo, S., He, J., and Shi, Z. (2000). Seasonal abundance of the parasitoid complex associated with the diamondback moth, Plutella xylostella (Lepidoptera: Plutellidae) in Hangzhou, China. Bulletin of Entomological Research, 90(3):221-231. doi: $10.1017 /$ S0007485300000341.

Liu, S., Wang, X., Shi, Z., and Gebremeskel, F. (2001). The biology of Diadromus collaris (Hymenoptera: Ichneumonidae), a pupal parasitoid of Plutella xylostella (Lepidoptera: Plutellidae), and its interactions with Oomyzus sokolowskii (Hymenoptera: Eulophidae). Bulletin of Entomological Research, 91(6):461-469. doi: 10.1079/BER2001129.

Lloyd, D. (1940). Host selection by hymenopterous parasites of the moth Plutella maculipennis Curtis. Proceedings of the Royal Society of London. Series B, Biological Sciences, 128(853):451-484. doi: 10.1098/rspb.1940.0021.

Macfadyen, S., McDonald, G., and Hill, M. P. (2018). From species distributions to climate change adaptation: Knowledge gaps in managing invertebrate pests in broad-acre grain crops. Agriculture, Ecosystems \&6 Environment, 253:208-219. doi: 10.1016/j.agee.2016.08.029.

Machekano, H., Mvumi, B. M., and Nyamukondiwa, C. (2017). Loss of co-evolved basal and plastic responses to temperature may underlie trophic level host-parasitoid interactions under global change. Biological Control, 118:44-54. doi: 10.1016/j.biocontrol.2017.12.005.

MacOdrum Library Aerial Photographs (1958). 1958 ottawa air photos. https://library . carleton.ca/find/gis/aerial-images\#0ttGat. [accessed 05 Jan 2018].

Magoč, T. and Salzberg, S. L. (2011). Flash: fast length adjustment of short reads to improve genome assemblies. Bioinformatics, 27(21):2957-2963. https://ccb.jhu.edu/ software/FLASH/.

Mao, Y., Liu, Y., Chen, D., Chen, F., Fang, X., Hong, G., Wang, L., Wang, J., and Chen, X. (2017). Jasmonate response decay and defense metabolite accumulation contributes to age-regulated dynamics of plant insect resistance. Nature Communications, 8(13925):113. doi: 10.1038/ncomms13925.

Marsh, H. O. (1917). Life history of Plutella maculipennis, the diamondback moth. Journal of Agricultural Research, 10(1):1-9.

Mauduit, A. (2012). First assessment of predation by the arthropod natural enemy complex on the insect pests of canola-cropping systems in southern alberta in canada: example of diamondback moth (Plutella xylostella). Master's thesis, University of Alberta, Edmonton, AB.

McCarthy, C. B., Cabrera, N. A., and Virla, E. G. (2015). Metatranscriptomic analysis of larval guts from field-collected and laboratory-reared Spodoptera frugiperda from the 
South American subtropical region. Genome Announcements, 3(4):e00777.

McIntyre, N. E. (2000). Ecology of urban arthropods: a review and a call to action. Annals of the Entomological Society of America, 93(4):825-835. doi: 10.1603/00138746(2000)093[0825:EOUAAR]2.0.CO;2.

McIntyre, N. E., Rango, J., Fagan, W. F., and Faeth, S. H. (2001). Ground arthropod community structure in a heterogeneous urban environment. Landscape and Urban Planning, 52(4):257-274. doi: 10.1016/S0169-2046(00)00122-5.

Meineke, E. K., Dunn, R. R., and Frank, S. D. (2014). Early pest development and loss of biological control are associated with urban warming. Biology Letters, 10(20140586):1-4. doi: 10.1016/S0006-3207(01)00232-4.

Mereghetti, V., Chouaia, B., and Montagna, M. (2017). New insights into the microbiota of moth pests. International Journal of Molecular Sciences, 18(11):2450.

Micchelli, C. A. (2014). Whole-mount immunostaining of the adult Drosophila gastrointestinal tract. Methods, 68(1):273-279.

Moreira, L., Teixeira, N., Santos, N., Valim, J., Maurício, R., Guedes, R., Oliveira, M., and Campos, W. (2016). Diamondback moth performance and preference for leaves of Brassica oleracea of different ages and strata. Journal of Applied Entomology, 140(8):627-635. doi: $10.1111 /$ jen.12294.

Morey, A. C., Venette, R. C., Nystrom Santacruz, E. C., Mosca, L. A., and Hutchison, W. (2016). Host-mediated shift in the cold tolerance of an invasive insect. Ecology and Evolution, 6(22):8267-8275. doi: 10.1002/ece3.2564.

Morrow, J. L., Frommer, M., Shearman, D., and Riegler, M. (2015). The microbiome of field-caught and laboratory-adapted australian tephritid fruit fly species with different host plant use and specialisation. Microbial Ecology, 70(2):498-508.

Musolin, D. L. (2007). Insects in a warmer world: ecological, physiological and life-history responses of true bugs (Heteroptera) to climate change. Global Change Biology, 13(8):15651585. doi: $10.1111 /$ j.1365-2486.2007.01395.x.

Nakamura, A. and Noda, T. (2002). Effects of host age and size on clutch size and sex ratio of Oomyzus sokolowskii (Hymenoptera: Eulophidae), a larval-pupal parasitoid of Plutella xylostella (Lepidoptera: Yponomeutidae). Applied Entomology and Zoology, 37(2):319322. doi: 10.1303/aez.2002.319.

Nedorezov, L. V., Löhr, B. L., and Sadykova, D. L. (2008). Assessing the importance of self-regulating mechanisms in diamondback moth population dynamics: Application of discrete mathematical models. Journal of Theoretical Biology, 254(3):587-593.

Nedvěd, O. (2000). Snow white and the seven dwarfs: a multivariate approach to classification of cold tolerance. Cryo letters, 21(6):339-348. 
Nelson, A. E. and Forbes, A. A. (2014). Urban land use decouples plant-herbivore-parasitoid interactions at multiple spatial scales. PloS One, 9(7):e102127. doi: 10.1371/journal.pone.0102127.

Nguyen, C., Bahar, M. H., Baker, G., and Andrew, N. R. (2014). Thermal tolerance limits of diamondback moth in ramping and plunging assays. PloS One, 9(1):e87535. doi: 10.1371/journal.pone.0087535.

Noronha, C. and Bahar, M. (2018). First records of three parasitic wasps of diamondback moth (Lepidoptera: Plutellidae) in Prince Edward Island. Journal of the Acadian Entomological Society, 14:4-7.

Ohtomo, R. and Chiba, T. (2001). Ecological notes on diapause and overwintering of the allium leafminer, Acrolepiopsis sapporensis (Matsumura)(Lepidoptera: Plutellidae) in northern Japan. Japanese Journal of Applied Entomology and Zoology, 45(3):123-128.

Oksanen, J., Blanchet, F. G., Friendly, M., Kindt, R., Legendre, P., McGlinn, D., Minchin, P. R., O’Hara, R. B., Simpson, G. L., Solymos, P., Stevens, M. H. H., Szoecs, E., and Wagner, H. (2018). vegan: Community Ecology Package. R package version 2.5-1.

Olfert, O., Haye, T., Weiss, R., Kriticos, D., and Kuhlmann, U. (2016). Modelling the potential impact of climate change on future spatial and temporal patterns of biological control agents: Peristenus digoneutis (Hymenoptera: Braconidae) as a case study. The Canadian Entomologist, 148(5):579-594. doi: 10.4039/tce.2016.4.

Paniagua Voirol, L. R., Frago, E., Kaltenpoth, M., Hilker, M., and Fatouros, N. E. (2018). Bacterial symbionts in lepidoptera: Their diversity, transmission and impact on the host. Frontiers in Microbiology, 9:556.

Park, Y. and Kim, Y. (2014). A specific glycerol kinase induces rapid cold hardening of the diamondback moth, Plutella xylostella. Journal of Insect Physiology, 67:56-63. doi: 10.1016/j.jinsphys.2014.06.010.

Parmesan, C. (2001). Detection of range shifts: general methodological issues and case studies of butterflies. In "Fingerprints" of Climate Change, pages 57-76. Springer, Boston, Massachusetts, United States of America.

Pizzolante, G., Cordero, C., Tredici, S. M., Vergara, D., Pontieri, P., Del Giudice, L., Capuzzo, A., Rubiolo, P., Kanchiswamy, C. N., Zebelo, S. A., Bicchi, C., Maffei, M. E., and Alifano, P. (2017). Cultivable gut bacteria provide a pathway for adaptation of Chrysolina herbacea to Mentha aquatica volatiles. BMC plant biology, 17(1):30.

Putnam, L. (1978). Diapause and cold hardiness in Microplitis plutellae, a parasite of the larvae of the diamondback moth. Canadian Journal of Plant Science, 58(3):915-916.

Quantum GIS Development Team (2017). Quantum GIS geographic information system. Open Source Geospatial Foundation Project. Version 2.17. https://www.qgis.org/en/ 
site/. [accessed 3 October 2017].

R Core Team (2017). R: A Language and Environment for Statistical Computing. R Foundation for Statistical Computing, Vienna, Austria.

Rahmstorf, S., Foster, G., and Cahill, N. (2017). Global temperature evolution: recent trends and some pitfalls. Environmental Research Letters, 12(054001):1-7. doi: 10.1088/17489326/aa6825.

Ramya, S. L., Venkatesan, T., Murthy, K. S., Jalali, S. K., and Varghese, A. (2016). Degradation of acephate by Enterobacter asburiae, Bacillus cereus and Pantoea agglomerans isolated from diamondback moth Plutella xylostella (L), a pest of cruciferous crops. Journal of Environmental Biology, 37(4):611-618.

Rani, A., Sharma, A., Rajagopal, R., Adak, T., and Bhatnagar, R. K. (2009). Bacterial diversity analysis of larvae and adult midgut microflora using culture-dependent and culture-independent methods in lab-reared and field-collected Anopheles stephensi-an Asian malarial vector. BMC Microbiology, 9(96):1-22.

Raymond, B., Johnston, P. R., Wright, D. J., Ellis, R. J., Crickmore, N., and Bonsall, M. B. (2009). A mid-gut microbiota is not required for the pathogenicity of Bacillus thuringiensis to diamondback moth larvae. Environmental Microbiology, 11(10):2556-2563.

Razumov, V. (1970). How the diamond-back moth overwinters. Zashchita Rastenii, 15(10):38-38.

Rempoulakis, P., Sela, S., Nemny-Lavy, E., Pinto, R., Birke, A., and Nestel, D. (2017). Microbial composition affects the performance of an artificial tephritid larval diet. Bulletin of Entomological Research, pages 1-8. doi: 10.1017/S0007485317000943.

Rinehart, J. P., Li, A., Yocum, G. D., Robich, R. M., Hayward, S. A., and Denlinger, D. L. (2007). Up-regulation of heat shock proteins is essential for cold survival during insect diapause. Proceedings of the National Academy of Sciences, 104(27):11130-11137. doi: 10.1073 /pnas.0703538104.

Rivard, I. (1964a). Carabid beetles (Coleoptera: Carabidae) from agricultural lands near Belleville, Ontario. The Canadian Entomologist, 96(3):517-520.

Rivard, I. (1964b). Observations on the breeding periods of some ground beetles (Coleoptera: Carabidae) in eastern Ontario. Canadian Journal of Zoology, 42(6):1081-1084.

Robinson, C. J., Schloss, P., Ramos, Y., Raffa, K., and Handelsman, J. (2010). Robustness of the bacterial community in the cabbage white butterfly larval midgut. Microbial Ecology, 59(2):199-211.

Roscoe, R. J. (1997). An update of mortality from all causes among white uranium miners from the Colorado Plateau Study Group. American Journal of Industrial Medicine, $31(2): 211-222$. 
Roux, O., Gevrey, M., Arvanitakis, L., Gers, C., Bordat, D., and Legal, L. (2007). ISSRPCR: Tool for discrimination and genetic structure analysis of Plutella xylostella populations native to different geographical areas. Molecular Phylogenetics and Evolution, 43(1):240-250. doi: 10.1016/j.ympev.2006.09.017.

Rowell, B., Bunsong, N., Satthaporn, K., Phithamma, S., and Doungsa-Ard, C. (2005). Hymenopteran parasitoids of Diamondback moth (Lepidoptera: Ypeunomutidae) in northern Thailand. Journal of Economic Entomology, 98(2):449-456. doi: 10.1603/0022-049398.2.449.

Ruder, A. M., Hein, M. J., Nilsen, N., Waters, M. A., Laber, P., Davis-King, K., Prince, M. M., and Whelan, E. (2006). Mortality among workers exposed to polychlorinated biphenyls $(\mathrm{PCBs})$ in an electrical capacitor manufacturing plant in Indiana: an update. Environmental Health Perspectives, 114(1):18-23.

Ruokolainen, L., Ikonen, S., Makkonen, H., and Hanski, I. (2016). Larval growth rate is associated with the composition of the gut microbiota in the glanville fritillary butterfly. Oecologia, 181(3):895-903.

Safari, R., Adel, M., Lazado, C. C., Caipang, C. M. A., and Dadar, M. (2016). Hostderived probiotics Enterococcus casseliflavus improves resistance against Streptococcus iniae infection in rainbow trout (Oncorhynchus mykiss) via immunomodulation. Fish \& Shellfish Immunology, 52:198-205.

Saito, O. (1994a). Hibernation of the diamondback moth, Plutella xylostella (L.)(Lepidoptera: yponomeutidae), in the field or in the greenhouse at Sapporo, Hokkaido, 1984-1986. Annual Report of the Society of Plant Protection of North Japan, 45:160-162.

Saito, O. (1994b). Tolerance of the diamondback moth, Plutella xylostella (L.)(Lepidoptera: Yponomeutidae), to low constant temperature. Annual Report of the Society of Plant Protection of North Japan, 45:158-159.

San Francisco State University (2017). California regional weather server. http://virga. sfsu.edu/. [accessed 24 May 2017].

Sarfraz, M., Keddie, A. B., and Dosdall, L. M. (2005). Biological control of the diamondback moth, Plutella xylostella: a review. Biocontrol Science and Technology, 15(8):763-789. doi: 10.1080/09583150500136956.

SAS Institue (2017). JMP, Version 13. SAS Institute, Cary, North Carolina, United States of America.

Saunders, D. (2009). Photoperiodism in insects: migration and diapause responses. In R.J. Nelson, D. D. and Somers, D., editors, Photoperiodism: the biological calendar, pages 218-257. Oxford University Press, New York, New York, United States of America.

Schuler, T. H., Martinez-Torres, D., Thompson, A. J., Denholm, I., Devonshire, A. L., Duce, 
I. R., and Williamson, M. S. (1998). Toxicological, electrophysiological, and molecular characterisation of knockdown resistance to pyrethroid insecticides in the diamondback moth, Plutella xylostella (L.). Pesticide Biochemistry and Physiology, 59(3):169-182. doi: 10.1006/pest.1998.2320.

Shao, Y., Spiteller, D., Tang, X., Ping, L., Colesie, C., Münchberg, U., Bartram, S., Schneider, B., Büdel, B., Popp, J., Heckel, D., and Boland, W. (2011). Crystallization of $\alpha$-and $\beta$-carotene in the foregut of Spodoptera larvae feeding on a toxic food plant. Insect Biochemistry and Molecular Biology, 41(4):273-281.

Shirai, Y. (1993). Factors influencing flight ability of male adults of the diamondback moth, Plutella xylostella, with special reference to temperature conditions during the larval stage. Applied Entomology and Zoology, 28(3):291-301. doi: 10.1303/aez.28.291.

Sinclair, B. J. (1999). Insect cold tolerance: How many kinds of frozen? European Journal of Entomology, 96:157-164.

Sinclair, B. J., Alvarado, L. E. C., and Ferguson, L. V. (2015). An invitation to measure insect cold tolerance: methods, approaches, and workflow. Journal of Thermal Biology, 53:180-197. doi: 10.1016/j.jtherbio.2015.11.003.

Sinclair, B. J. and Roberts, S. P. (2005). Acclimation, shock and hardening in the cold. Journal of Thermal Biology, 30(8):557-562. doi: 10.1016/j.jtherbio.2005.07.002.

Slinkard, A. and Knott, D. R. (1995). Harvest of gold: the history of field crop breeding in Canada. University Extension Press, University of Saskatchewan.

Smith, D. and Sears, M. (1982). Evidence for dispersal of diamondback moth, Plutella xylostella (Lepidoptera: Plutellidae), into southern Ontario. Proceedings of the Entomological Society of Ontario, 113:21-27.

Sonoda, S., Ashfaq, M., and Tsumuki, H. (2006). Cloning and nucleotide sequencing of three heat shock protein genes (hsp90, hsc70, and hsp19. 5) from the diamondback moth, Plutella xylostella (L.) and their expression in relation to developmental stage and temperature. Archives of Insect Biochemistry and Physiology, 62(2):80-90. doi: $10.1002 / \operatorname{arch} .20124$.

Sonoda, S. and Tsumuki, H. (2008). Gene expression of hsp70 of the diamondback moth, Plutella xylostella (Lepidoptera: Yponomeutidae), in response to heat shock and insecticides. Applied Entomology and Zoology, 43(2):241-247. doi: 10.1303/aez.2008.241.

Sørensen, J. G., Kristensen, T. N., and Loeschcke, V. (2003). The evolutionary and ecological role of heat shock proteins. Ecology Letters, 6(11):1025-1037. doi: 10.1046/j.14610248.2003.00528.x.

Statistics Canada (2017). Table 001-0017 - estimated areas, yield, production, average farm price and total farm value of principal field crops, in metric and imperial units, annual. 
http://www5.statcan.gc.ca/cansim/a47. [accessed 30 January 2018].

Staudacher, H., Kaltenpoth, M., Breeuwer, J. A., Menken, S. B., Heckel, D. G., and Groot, A. T. (2016). Variability of bacterial communities in the moth Heliothis virescens indicates transient association with the host. PloS One, 11(5):e0154514.

Storey, K. B. and Storey, J. M. (2012). Insect cold hardiness: metabolic, gene, and protein adaptation. Canadian Journal of Zoology, 90(4):456-475. doi: 10.1139/z2012-011.

Talekar, N. and Shelton, A. (1993). Biology, ecology, and management of the diamondback moth. Annual Review of Entomology, 38(1):275-301.

Umeya, K. and Yamada, H. (1973). Threshold temperature and thermal constants for development of the diamond-back moth, Plutella xylostella L., with reference to their local differences. Japanese Journal of Applied Entomology and Zoology, 17:19-24.

United States Department of Agriculture, Economic Research Service (ERS) (2017). Canola. https://www.ers.usda.gov/topics/crops/soybeans-oil-crops/canola/. [accessed 31 May 2017].

United States Department of Agriculture, Foreign Agricultural Service (FAS) (2017). Production, supply and distribution report oilseeds. https://apps.fas.usda.gov/ PSDOnline/CircularDownloader ashx?year=2017\&month=05\&commodity=0ilseeds. [accessed 31 May 2017].

United States Department of Agriculture, National Agricultural Statistics Service (NASS) (2017). Crop production. http://usda.mannlib.cornell.edu/usda/nass/CropProd/ 2010s/2017/CropProd-09-12-2017.pdf. [accessed 02 November 2017].

University of Toronto Map and Data Library (1954). 1954 air photos of southern ontario. https://mdl.library.utoronto.ca/collections/air-photos. [accessed 05 Jan 2018].

Upanisakorn, A., Jeerapong, L., Ketelaar, J., and Lim, G. (2011). Diversity and abundance of diamondback moth parasitoids in north Thailand. In Srinivasan, R., Shelton, A., and Collins, H., editors, Proceedings of the 6th International Workshop on Management of the Diamondback Moth and other Crucifer Insect Pests, 21-25 March 2011, Nakhon Pathom, Thailand, pages 97-102. Asian Vegetable Research and Development Center, Shanhua, Taiwan.

Van Der Horst, J., Buijs, M. J., Laine, M. L., Wismeijer, D., Loos, B. G., Crielaard, W., and Zaura, E. (2013). Sterile paper points as a bacterial DNA-contamination source in microbiome profiles of clinical samples. Journal of Dentistry, 41(12):1297-1301.

Van Driesche, R., Hoddle, M., and Center, T. (2008). Control of Pests and Weeds with Natural Enemies: An introduction to biological control. John Wiley Sons.

Vilanova, C., Baixeras, J., Latorre, A., and Porcar, M. (2016). The Generalist Inside the Specialist: Gut Bacterial Communities of Two Insect Species Feeding on Toxic Plants Are 
Dominated by Enterococcus sp. Frontiers in Microbiology, 7:1005.

Wang, H.-J., Shi, Z.-K., Shen, Q.-D., Xu, C.-D., Wang, B., Meng, Z.-J., Wang, S.-G., Tang, B., and Wang, S. (2017). Molecular cloning and induced expression of six small heat shock proteins mediating cold-hardiness in Harmonia axyridis (Coleoptera: Coccinellidae). Frontiers in Physiology, 8:1-15. doi: 10.3389/fphys.2017.00060.

Ward, N. L. and Masters, G. J. (2007). Linking climate change and species invasion: an illustration using insect herbivores. Global Change Biology, 13(8):1605-1615. doi: 10.1111/j.1365-2486.2007.01399.x.

Wei, S.-J., Shi, B.-C., Gong, Y.-J., Jin, G.-H., Chen, X.-X., and Meng, X.-F. (2013). Genetic structure and demographic history reveal migration of the diamondback moth Plutella xylostella (Lepidoptera: Plutellidae) from the southern to northern regions of China. PloS One, 8(4):e59654. doi: 10.1371/journal.pone.0059654.

Western Committee on Crop Pests (1995). Minutes of the 34th Annual Meeting, 20-21 October 1995. Victoria, British Columbia, Canada. https://www.westernforum. org/Documents/WCCP/WCCP\%20Minutes/WCCP\%2001d\%20Minutes\%201962\%20to\%201999/ MInutes\%201995\%200CR.pdf. [accessed 08 January 2018].

Wisdom, M. J., Mills, L. S., and Doak, D. F. (2000). Life stage simulation analysis: estimating vital-rate effects on population growth for conservation. Ecology, 81(3):628-641.

Wong, A. C.-N., Luo, Y., Jing, X., Franzenburg, S., Bost, A., and Douglas, A. E. (2015). The host as the driver of the microbiota in the gut and external environment of Drosophila melanogaster. Applied and Environmental Microbiology, 81(18):6232-6240.

Wu, L. H., Hoffmann, A. A., and Thomson, L. J. (2016). Potential impact of climate change on parasitism efficiency of egg parasitoids: A meta-analysis of Trichogramma under variable climate conditions. Agriculture, Ecosystems 83 Environment, 231:143-155. doi: 10.1016/j.agee.2016.06.028.

Xia, X., Gurr, G. M., Vasseur, L., Zheng, D., Zhong, H., Qin, B., Lin, J., Wang, Y., Song, F., Li, Y., Lin, H., and You, M. (2017). Metagenomic sequencing of diamondback moth gut microbiome unveils key holobiont adaptations for herbivory. Frontiers in Microbiology, $8(663): 1-12$.

Xia, X., Sun, B., Geoff, G., Vasseur, L., Xue, M., and You, M. (2018). Gut microbiota mediate insecticide resistance in the Diamondback moth, Plutella xylostella (L.). Frontiers in Microbiology, 9:25.

Xia, X., Zheng, D., Zhong, H., Qin, B., Gurr, G. M., Vasseur, L., Lin, H., Bai, J., He, W., and You, M. (2013). DNA sequencing reveals the midgut microbiota of diamondback moth, Plutella xylostella (L.) and a possible relationship with insecticide resistance. PloS One, 8(7):e68852. 
Xiang, H., Wei, G.-F., Jia, S., Huang, J., Miao, X.-X., Zhou, Z., Zhao, L.-P., and Huang, Y.-P. (2006). Microbial communities in the larval midgut of laboratory and field populations of cotton bollworm (Helicoverpa armigera). Canadian Journal of Microbiology, 52(11):1085-1092.

Yang, J., Tian, L., Xu, B., Xie, W., Wang, S., Zhang, Y., Wang, X., and Wu, Q. (2015). Insight into the migration routes of Plutella xylostella in China using mtCOI and ISSR markers. PloS One, 10(6):e0130905. doi: 10.1371/journal.pone.0130905.

Zalucki, M. P., Shabbir, A., Silva, R., Adamson, D., Shu-Sheng, L., and Furlong, M. J. (2012). Estimating the economic cost of one of the world's major insect pests, Plutella xylostella (Lepidoptera: Plutellidae): just how long is a piece of string? Journal of Economic Entomology, 105(4):1115-1129. doi: 10.1603/EC12107.

Zhang, J., Zhang, Y., Li, J., Liu, M., and Liu, Z. (2016). Midgut transcriptome of the cockroach Periplaneta americana and its microbiota: Digestion, detoxification and oxidative stress response. PloS One, 11(5):e0155254.

Zhang, L. J., Wang, K. F., Jing, Y. P., Zhuang, H. M., and Wu, G. (2015). Identification of heat shock protein genes hsp70s and hsc70 and their associated mRNA expression under heat stress in insecticide-resistant and susceptible diamondback moth, Plutella xylostella(Lepidoptera: Plutellidae). European Journal of Entomology, 112(2):215. doi: 10.14411/eje.2015.039. 


\section{Appendix}

Appendix A: Supplementary Figures

Figure A1: Reverse wind trajectories starting at 10 and 11 April 2017, 00 UTC at Ottawa, Ontario. Reverse trajectories were calculated starting at 500, 1500 and 2500 meters above ground level (AGL), the line segments represent two-hour motion of the air parcel. The lower portion of each back trajectory plot illustrates the vertical behaviour of the air parcel in metres above sea level. Output generated by Ross Weiss.
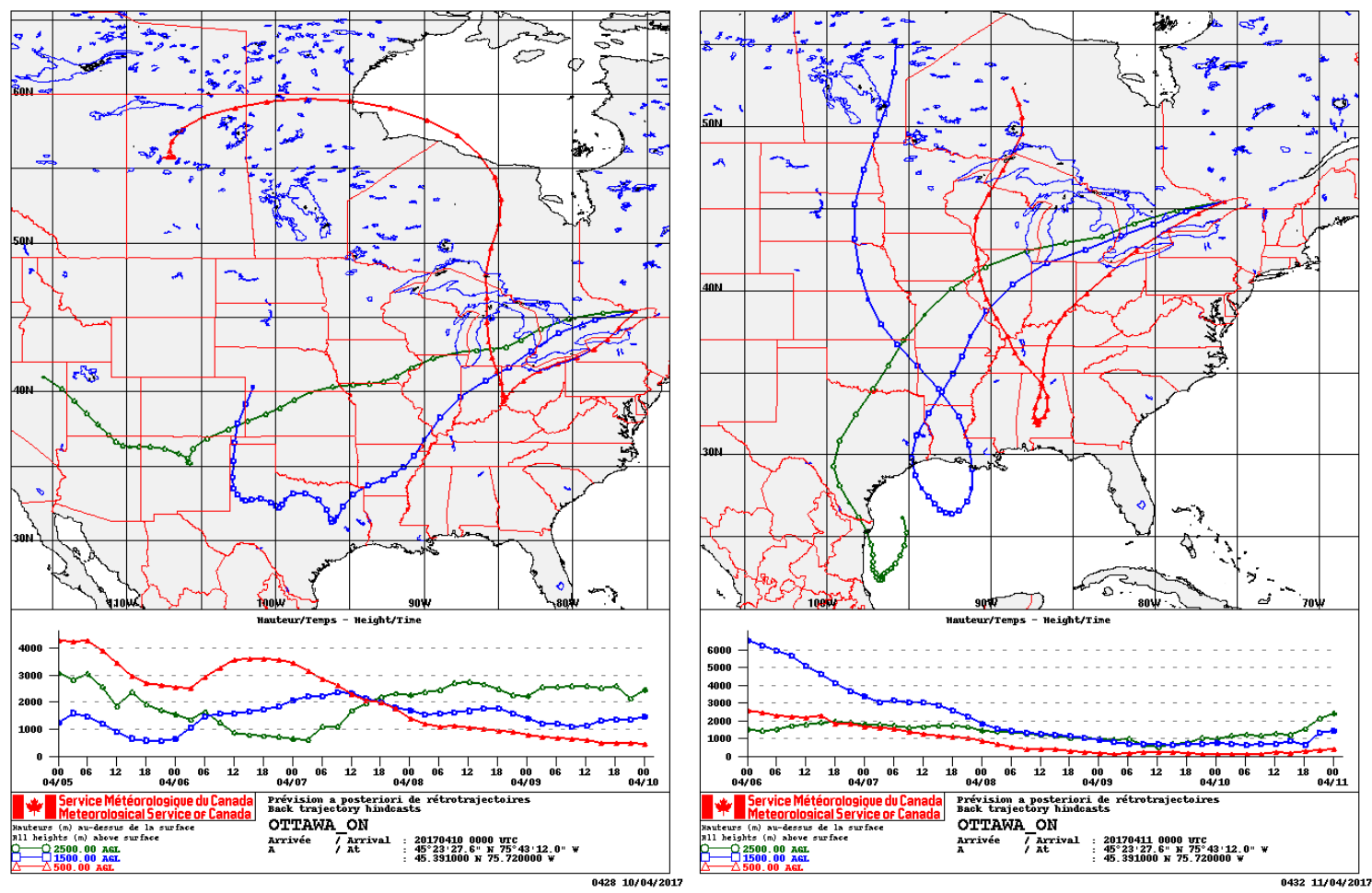
Figure A2: Drought conditions in Ottawa for the summer of 2016 and 2017. Output from The Canadian Drought Monitor program (Agriculture and Agri-Food Canada).
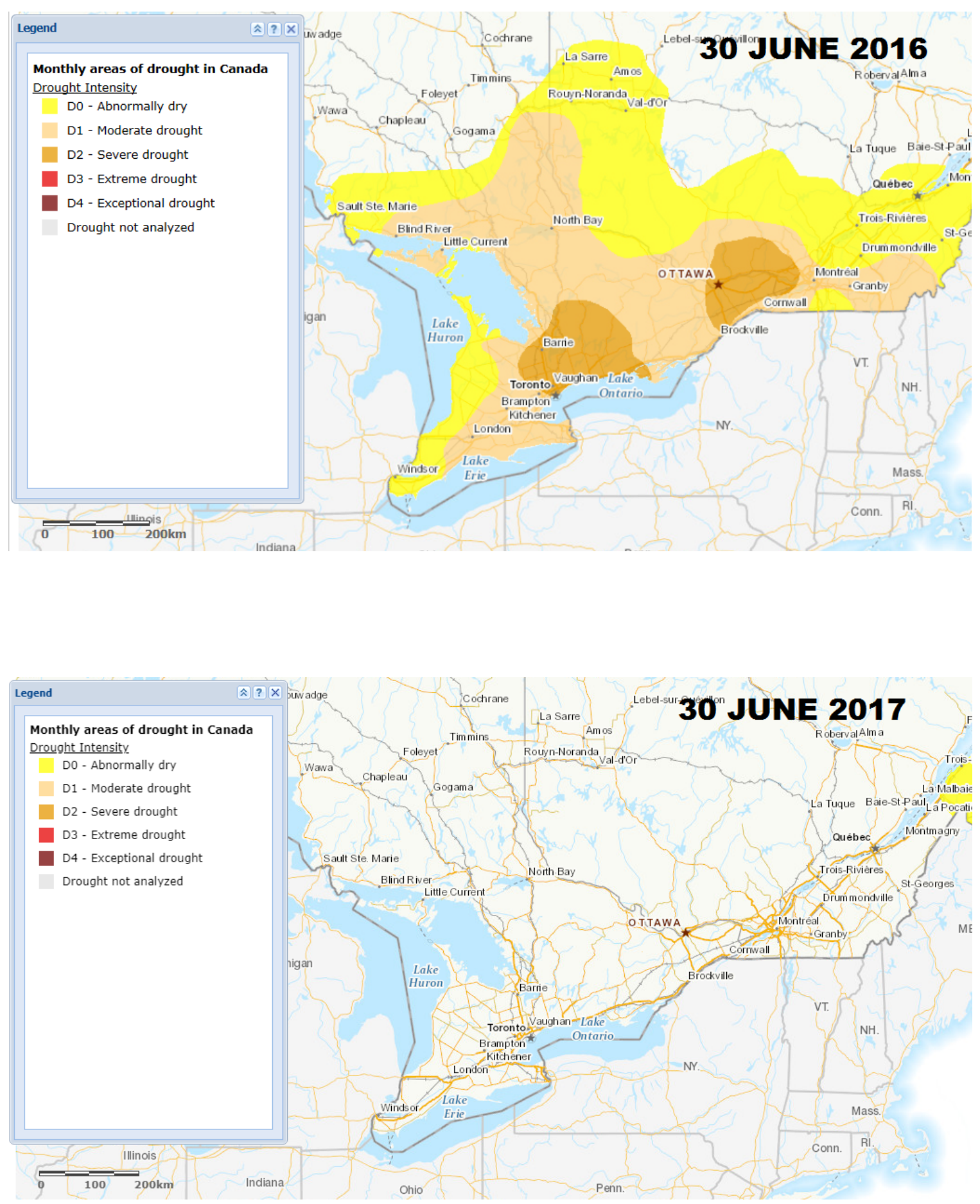
Figure A3: Output from bio-climatic model (DYMEX ${ }^{\circledR}$ ) presented in Dosdall et al. (2006) running 2016 and 2017 seasonal weather data from the National Climate Archive (ECCC) showing 4 (2016) and 3 (2017) generations of diamondback moth in the Ottawa area. Output generated by Ross Weiss.

\section{6}
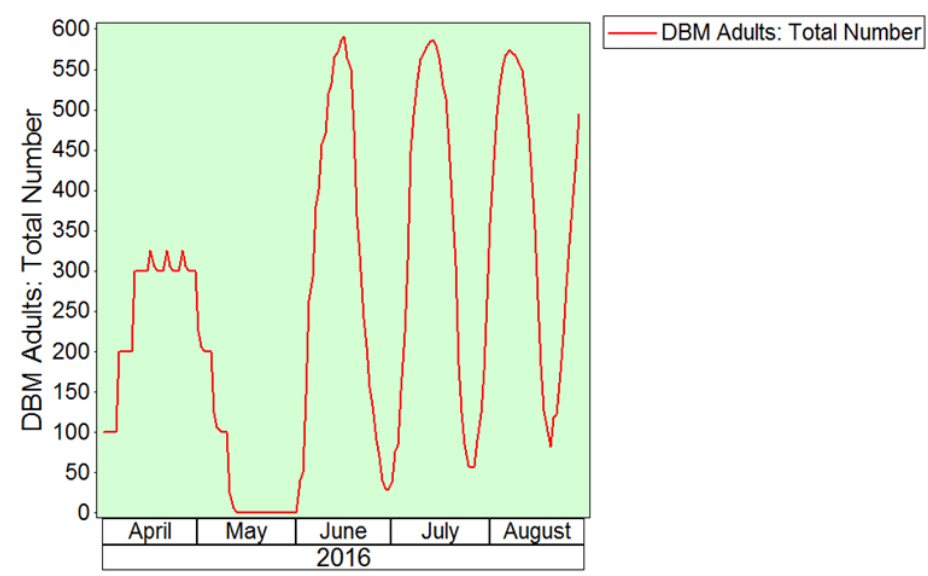

\section{7}
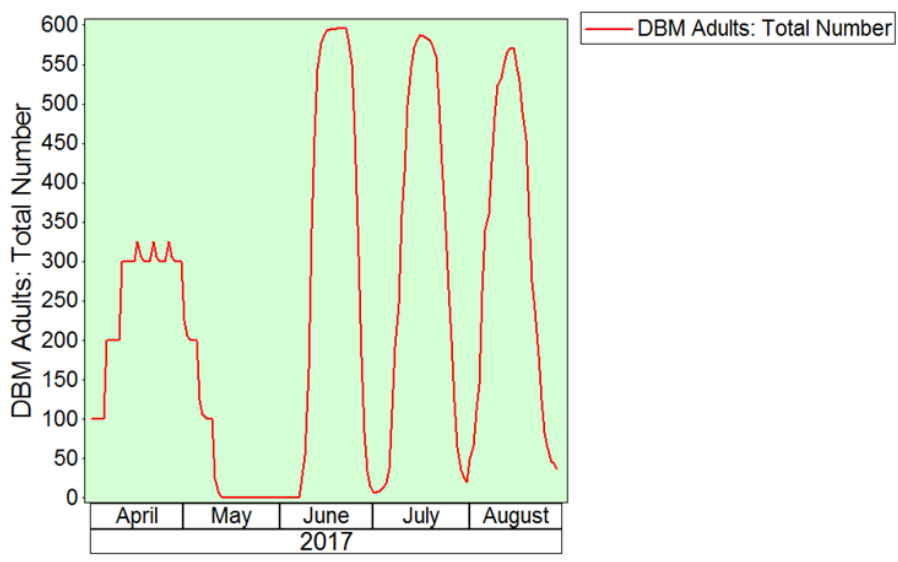


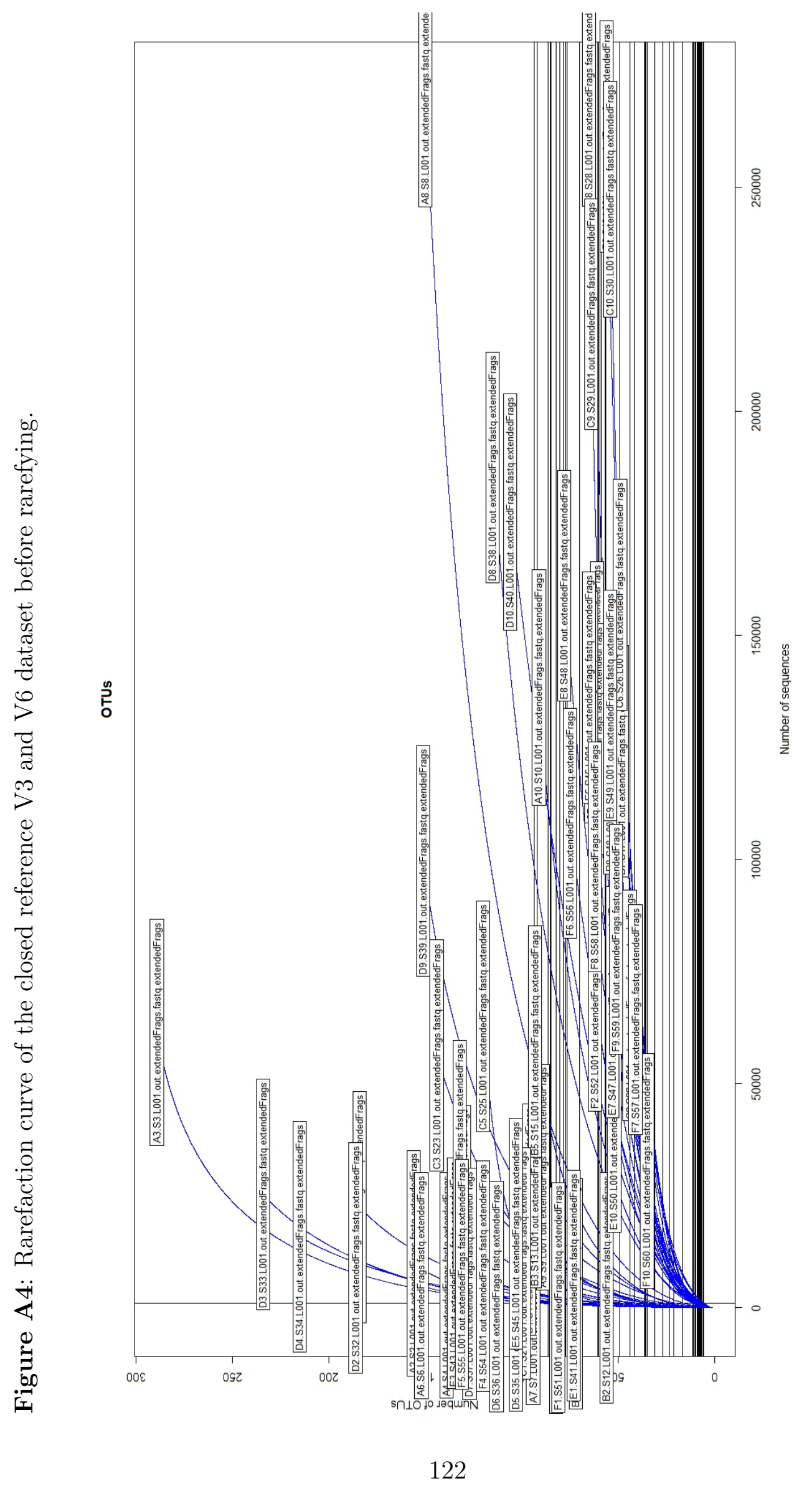




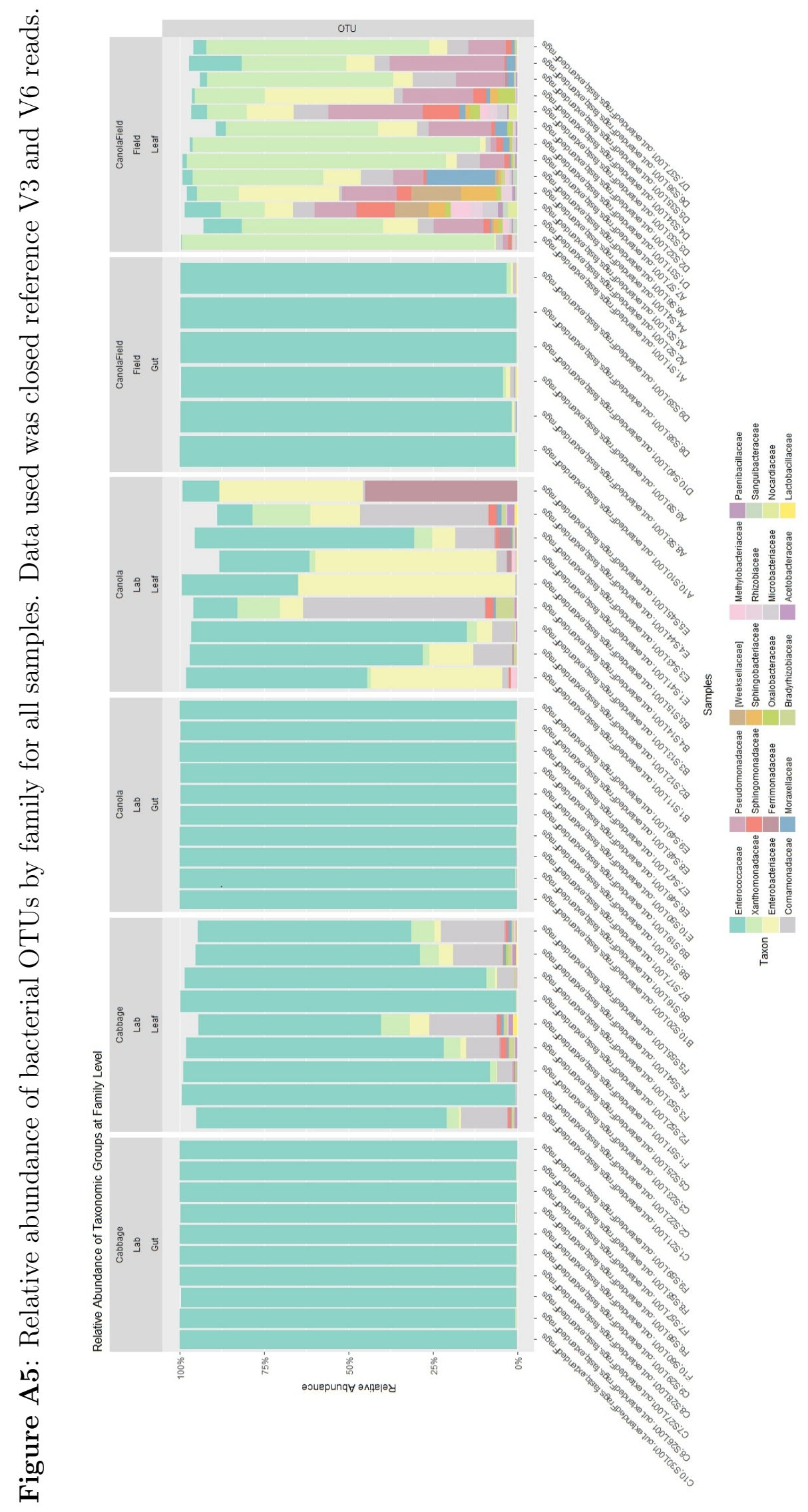


Appendix B: Parameters for pick_closed_reference_otus.py

pick_otus:enable_rev_strand_match True

pick_otus:similarity 0.97

assign_taxonomy:id_to_taxonomy_fp \$PWD/97_otu_taxonomy.fix.ascii.tax assign_taxonomy:assignment_method rdp

assign_taxonomy:rdp_max_memory 100000

assign_taxonomy:confidence 0.8 